NUREG/CR-6043

PNL-8614

Vol. 1

\title{
Aging Assessment of Essential HVAC Chillers Used in Nuclear Power Plants
}

Phase I

Manuscript Completed: July 1993

Date Published: September 1993

Prepared by

D. E. Blahnik, R. F. Klein

Pacific Northwest Laboratory

Richland, WA 99352

Prepared for

Division of Engineering

Office of Nuclear Regulatory Research

U.S. Nuclear Regulatory Commission

Washington, DC 20555-0001

NRC FIN B2911 


\begin{abstract}
The Pacific Northwest Laboratory conducted a Phase I aging assessment of chillers used in the essential safety air-conditioning systems of nuclear power plants. Centrifugal chillers in the 75- to 750-ton refrigeration capacity range are the predominant type used. The chillers used, and air-conditioning systems served, vary in design from plant to plant. It is crucial to keep chiller internals very clean and to prevent the leakage of water, air, and other contaminants into the refrigerant containment system. Periodic operation on a weekly or monthly basis is necessary to remove moisture and noncondensable gases that gradually build up inside the

The primary stressors and aging mechanisms that affect chillers include vibration, excessive temperatures and pressures, thermal cycling, chemical attack, and poor quality cooling water. Aging is accelerated by moisture, non-condensable gases (e.g., air), dirt, and other contamination within the refrigerant containment system; excessive start/stop cycling; and operation below the rated capacity. Aging is also accelerated by corrosion and fouling of the condenser and evaporator tubes. The principal cause of chiller failures is lack of adequate monitoring. Human errors and omission of scheduled maintenance also contribute to failures.
\end{abstract} chiller. This is especially desirable if a chiller is required to operate only as an emergency standby unit. 


\section{Contents}

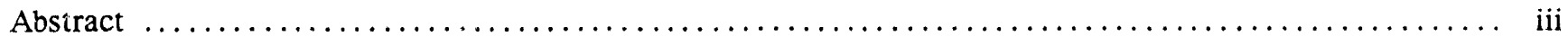

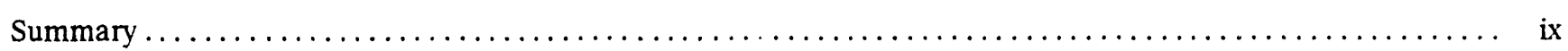

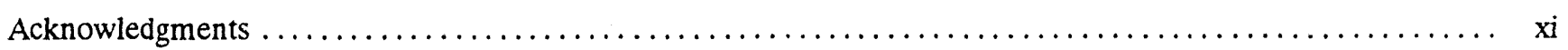

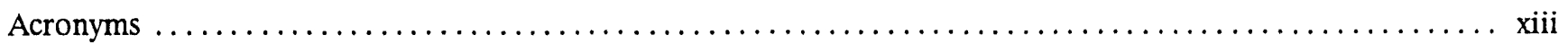

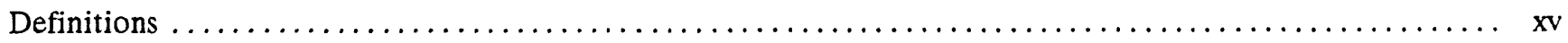

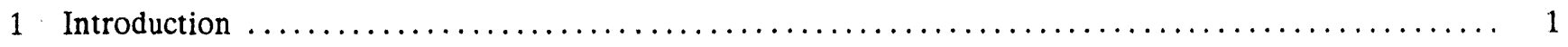

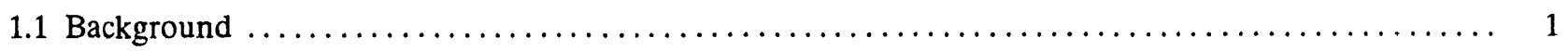

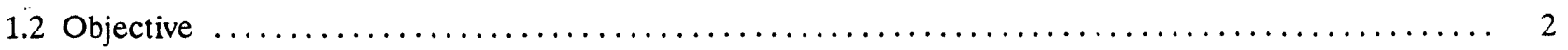

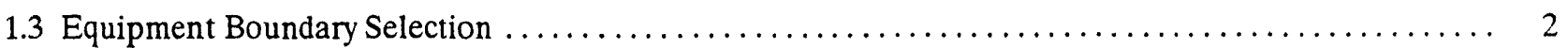

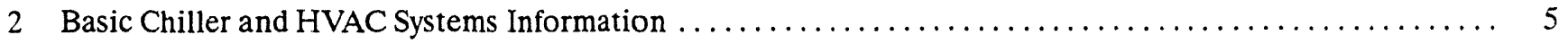

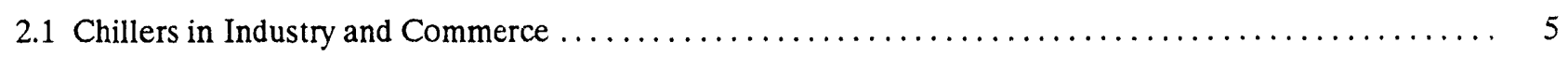

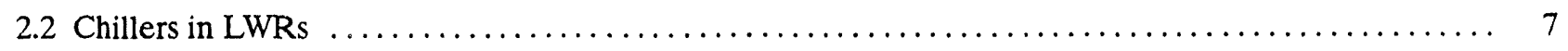

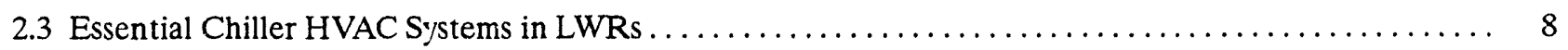

3 Regulatory, Code, and Standards Requirements for Essential Chillers $\ldots \ldots \ldots \ldots \ldots \ldots \ldots \ldots \ldots \ldots$. 11

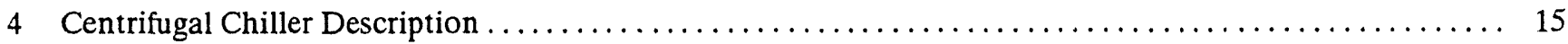

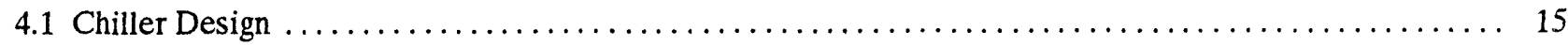

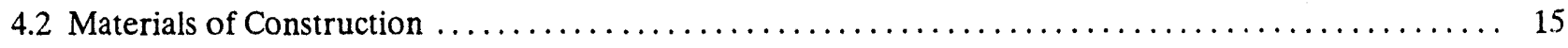

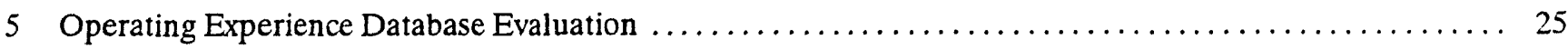

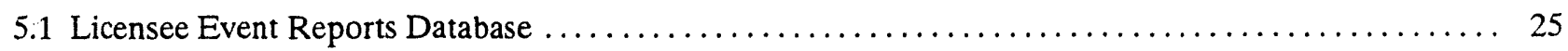

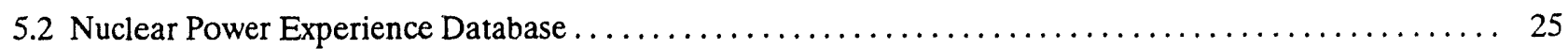

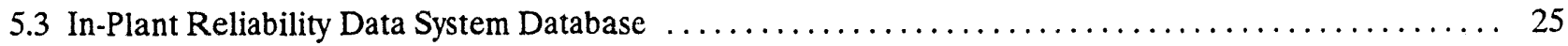

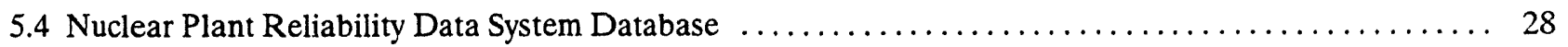


Contents

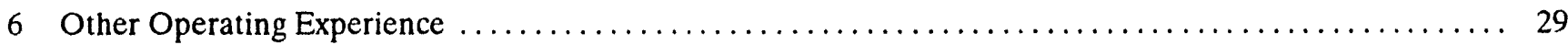

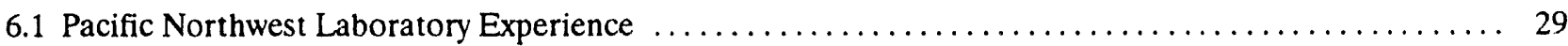

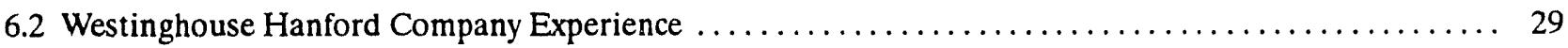

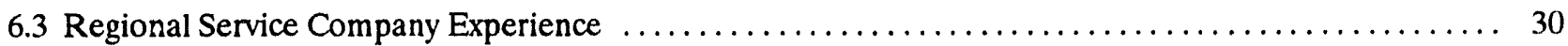

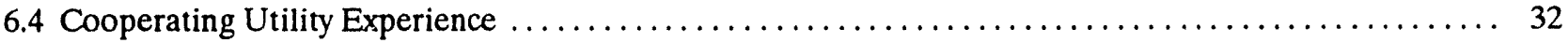

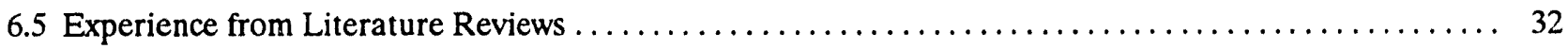

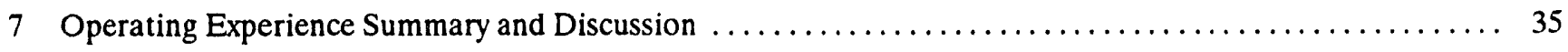

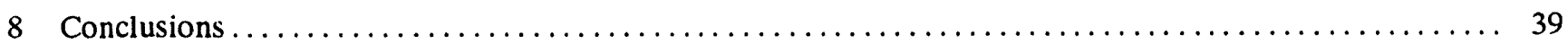

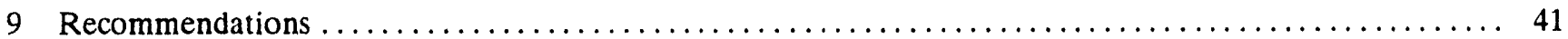

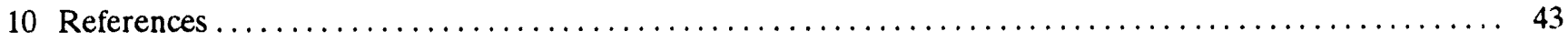

APPENDIX A: LWR Plant Chiller Systems Description (FSAR Data) $\ldots \ldots \ldots \ldots \ldots \ldots \ldots \ldots \ldots \ldots$ A.1

APPENDIX B: Hermetic Centrifugal Chiller Functional Description $\ldots \ldots \ldots \ldots \ldots \ldots \ldots \ldots \ldots \ldots \ldots$ B.1

APPENDIX C: LWR Plant LER Review Summary $\ldots \ldots \ldots \ldots \ldots \ldots \ldots \ldots \ldots \ldots \ldots \ldots \ldots \ldots \ldots \ldots \ldots \ldots \ldots \ldots \ldots$

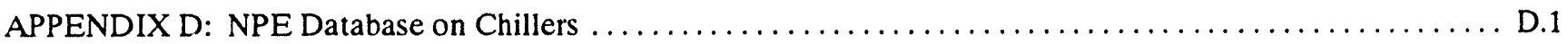

APPENDIX E: IPRDS Database Maintenance Report Summary for Nuclear

Power Plant A . . . . . . . . . . . . . .

APPENDIX F: Chiller Work Request Summary for Nuclear Power Plant B $\ldots \ldots \ldots \ldots \ldots \ldots \ldots \ldots \ldots$ F.1

APPENDIX G: ANS Paper Comparing Safety and Non-Safety Chillers $\ldots \ldots \ldots \ldots \ldots \ldots \ldots \ldots \ldots \ldots . .1$ 


\section{Figures}

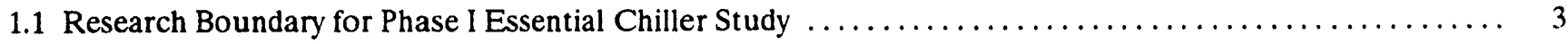

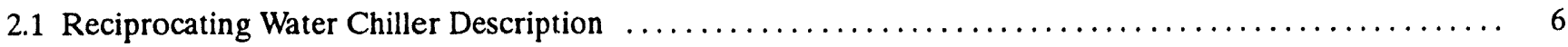

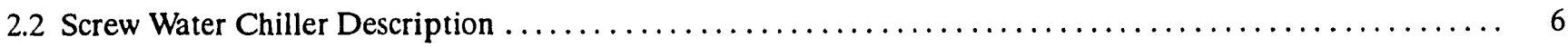

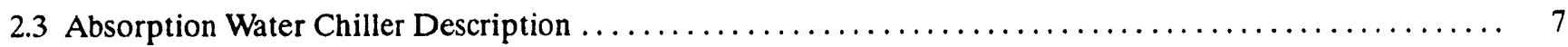

4.1 Recent Model of Liquid Hermetic Centrifugal Chiller Manufactured by the Carrier Corporation -

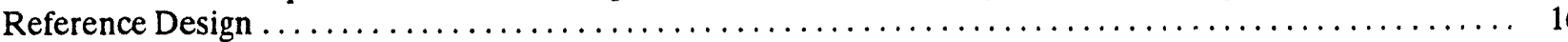

4.2 Recent Model of Liquid Hermetic Centrifugal Chiller Manufactured by the York

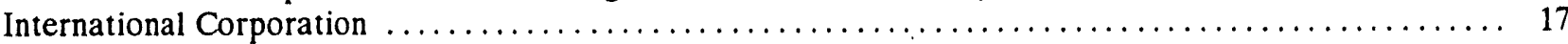

4.3 Recent Model of Liquid Hermetic Centrifugal Chiller Manufactured by The Trane Company ......... 18

4.4 Reference Centrifugal Chiller Cross-Sectional View Showing Refrigerant Flow Path .............. 19

4.5 Reference Centrifugal Chiller Compressor Cross-Section $\ldots \ldots \ldots \ldots \ldots \ldots \ldots \ldots \ldots \ldots \ldots \ldots \ldots \ldots$

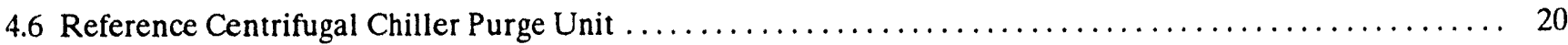

4.7 Reference Centrifugal Chiller Piping and Wiring Illustration $\ldots \ldots \ldots \ldots \ldots \ldots \ldots \ldots \ldots \ldots \ldots \ldots \ldots \ldots \ldots \ldots \ldots$

4.8 Reference Centrifugal Chiller Dimensions and Layout Requirements $\ldots \ldots \ldots \ldots \ldots \ldots \ldots \ldots \ldots \ldots 22$

4.9 Recent Model of Liquid Open Centrifugal Chiller Manufactured by the Carrier Corporation (for comparison with hermetic centrifugal chiller shown in Figure 4.8) $\ldots \ldots \ldots \ldots \ldots \ldots \ldots \ldots \ldots \ldots$

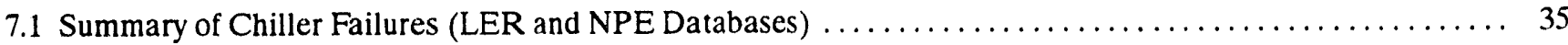

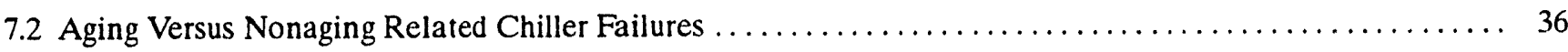


Contents

Tables

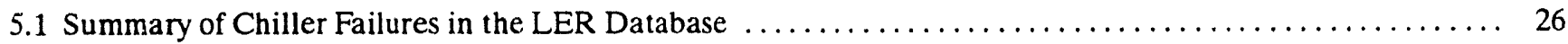

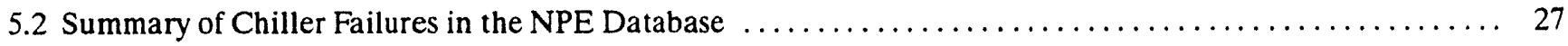

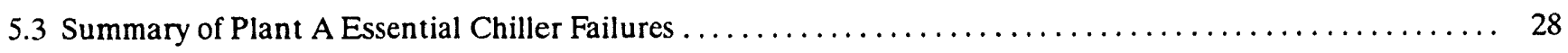




\section{Summary}

The Pacific Northwest Laboratory (PNL) ${ }^{1}$ conducted a Phase I aging assessment of chillers used in essential safety heating, ventilating, and air conditioning (HVAC) systems of nuclear power plants. Searches of traditional nuclear plant databases provided limited information on chillers. The information was heavily augmented by non-nuclear operating experience. More direct nuclear plant information will be incorporated in the Phase II portion of the aging study.

Centrifugal chillers in the 75- to 750-ton refrigeration capacity range are the predominant type used in essential nuclear plant HVAC systems. Other, less-used types include rotary, screw, and reciprocating chillers. The three primary manufacturers each have many models. The chillers used, and HVAC systems served, vary in design from plant to plant. It is difficult to select a generic design. This study focused on centrifugal packaged chillers.

Although centrifugal chillers are relatively complex equipment packages, they are usually designed for a lifetime of 40 years or more. They will exceed this lifetime if operations, maintenance, service water, and operating environment are properly managed and controlled. Units that are approaching 60 years of age are still operating in cold storage plants.

Major overhauls and maintenance that require entering the refrigerant containment region must be performed carefully by well-trained technicians. A small amount of contamination, or a damaged or misaligned part, can cause major damage during operation of the chiller. It is crucial to keep equipment internals very clean and to prevent the ingress of water, air, and other contaminants into the refrigerant containment system. Periodic operation for a few hours on a weekly or monthly basis is necessary to remove moisture and non-condensable gases that gradually build up inside the chiller, especially if a chiller is required to operate only as an emergency

\footnotetext{
${ }^{1}$ Operated for the U.S. Department of Energy by Battelle Memorial Institute under Contract DE-AC06-76RLO 1830.
}

standby unit. If multiple chillers are available, the operation should be alternated, and the operating hours should be balanced. The chiller should be operated as close to $100 \%$ capacity as practical to optimize operating parameters and minimize aging. Usually chillers are replaced due to lack of adequate monitoring and maintenance. Other causes for replacement of chillers include obsolescence due to 1) change of heat load (usually growth), 2) energy efficiency improvements, and, currently, 3) incompatibility with the new refrigerants required by new regulations. In many cases the chillers can be upgraded by installing adaptor equipment packages provided by the manufacturer.

Chillers used in both nuclear and non-nuclear applications will soon be affected, and in some cases become obsolete, due to environmental regulations that require changing to the use of alternative refrigerants. The impacts of the new refrigerants on the performance and life of chillers is not completely known. Currently the main concerns are potential efficiency loss, incompatible materials and design, and the aggressive nature of the new refrigerants. Chiller owners are encouraged to work with the chiller manufacturer to make satisfactory modifications.

The primary stressors and aging mechanisms that affect chillers are vibration, operation at excessive temperatures and pressures, thermal cycling, chemical attack, and poor quality condenser cooling water. Vibration is inherent in chillers due to high-speed rotation, boiling refrigerants, etc. Vibration is magnified further by misaligned or imbalanced components and/or operation below $25 \%$ of rated capacity. Aging is accelerated by moisture, non-condensable gases (e.g., air), dirt, and other contamination within the refrigerant containment system. Excessive start/stop cycling and under-loading of chillers can accelerate aging. Aging is also accelerated by corrosion and fouling of the condenser and evaporator tubes. The principal cause of premature chiller failures is lack of adequate monitoring. Human errors and omission of scheduled maintenance also contribute to failures. Failures due to design, operating procedures, and manufacturing discrepancies and 
defects usually occur during the start-up, shakedown, or first year of operation for a particular new chiller model. The time between recommended major overhauls ( 3 to 10 years) is usually established by the life of seals and gaskets.

The essential (safety-related) chillers are important to cool the control room and other safety-related equipment rooms.
The cooling is needed to prevent degradation and failure of safety-related equipment, to protect safety personnel, and to prevent or mitigate events and accidents. Control of temperature and humidity in these rooms is very important. Therefore, the essential chillers play an important role in nuclear plant safety and warrant a more in-depth Phase II study. 


\section{Acknowledgments}

The authors of this report acknowledge the support and technical guidance provided by Dr. J. J. Burns, Jr. of the Nuclear Regulatory Commission (NRC) during the course of this research under the Nuclear Plant Aging Research Program. Our thanks go to C. Michelson, member of the Advisory Committee on Reactor Safeguards at NRC, and other NRC staff that provided information important to the study; Oak Ridge National Laboratory for providing information from their SCSS, IPRDS, and NPE Databases; B. G. Berglin and J. D. Fulcher of Westinghouse Hanford Company and D. D. Hatley and H. D. Steele of Pacific Northwest Laboratory (PNL) who provided valuable insights by sharing their experience in the installation, start-up, operation, and maintenance of chillers; T. W. Camp of Landis \& Gyr Powers, Inc. for utilizing his 25 years of experience in "hands on" trouble-shooting and rebuilding chillers throughout the Pacific Northwest to help provide a preliminary assessment of chiller aging (he was also helpful in answering many of our questions on chillers); regional chiller manufacturing representatives who provided us with equipment catalogs; and staff at a cooperating nuclear plant who provided us with a tour of their plant's chiller HVAC facilities and helpful information on their plant's chiller HVAC operating and maintenance experience.

The authors also wish to thank the following PNL staff for their contributions to this report: Dr. R. P. Allen for project management support and technical guidance; Dr. A. B. Johnson, Jr. and Dr. I. S. Levy for their assistance in the Pre-Phase I prioritization of the essential chillers for further study; and the Hanford Technical Library staff who performed an extensive literature search on chillers. 


\section{Acronyms}

\begin{tabular}{|c|c|}
\hline ANS & American Nuclear Society \\
\hline ARI & Air-Conditioning and Refrigeration Institute \\
\hline ASHRAE & American Society of Heating, Refrigerating, and Air-Conditioning Engineers \\
\hline ASME & American Society of Mechanical Engineers \\
\hline $\mathrm{CCW}$ & component cooling water \\
\hline CFC & chlorofluorocarbon \\
\hline $\mathrm{ECW}$ & emergency cooling water \\
\hline ESF & engineered safety feature \\
\hline FFTF & Fast Flux Test Facility \\
\hline FSAR & final safety analysis report \\
\hline HCFC & hydrochlorofluorocarbon \\
\hline $\mathrm{HFC}$ & hydrofluorocarbon \\
\hline HVAC & heating, ventilating, and air conditioning \\
\hline $\mathrm{HX}$ & heat exchanger \\
\hline IEEE & Institute of Electrical and Electronics Engineers \\
\hline IPRDS & In-Plant Reliability Data System (database) \\
\hline LCO & limiting condition for operation \\
\hline LER & Licensee Event Report (database) \\
\hline LOCA & loss-of coolant accident \\
\hline LOP & loss of offsite power \\
\hline LWR & light-water reactor \\
\hline NDT & non-destructive testing \\
\hline NPAR & Nuclear Plant Aging Research \\
\hline
\end{tabular}


Acronyms

NPE

Nuclear Power Experience (database)

NPP

nuclear power plant

NPRDS

Nuclear Plant Reliability Data System (database)

NRC

U.S. Nuclear Regulatory Commission

NUDOCS/AD Nuclear Documentation System (database)

O\&M

operation and maintenance

PNL

Pacific Northwest Laboratory

PTS

Plant Technical Specification

RG

Regulatory Guide

RIDS

Regulatory Information Distribution System (database)

SAR

safety analysis report

SCSS

Sequence Coding and Search Systems (database)

SRP

Standard Review Plan

TIRGALEX

Technical Integration Review Group for Aging and Life Extension 


\section{Definitions}

age-related failure

chiller

essential chiller

failure

monitoring

non-age-related failure

partially age-related failure

safety-related items

ton, cooling rate

ton, storage failure that results from normal aging degradation caused by wear, corrosion, vibration, etc.

packaged refrigeration machine used to chill water that is pumped to the HVAC room cooler to cool room air - The absorbed heat is returned to the chiller, which transfers the heat to a plant cooling system.

a chiller used to cool rooms that contain safety-related equipment essential to plant safety

inability or interruption of ability of a system, structure, or component to function within acceptance criteria

includes both routine process parameter monitoring by operations and a preventative maintenance monitoring program; both aspects are very important to chiller reliability and performance

failure that occurs as a result of faulty design, manufacturing defect, misinstallation, human error, etc.

failure that is a combination of age- and non-age-related factors - Often the failure is accelerated when factors are combined (e.g., seal made of wrong material fails prematurally).

defined by 10 CFR 50, Appendix A, as "Those structures, systems, and components that provide reasonable assurance that the facility can be operated without undue risk to the health and safety of the public" - For details, see 10 CFR 50.49.

standard ton of refrigeration that is equivalent to an air conditioning capacity of $12,000 \mathrm{Btu} / \mathrm{hr}$

storage equivalent to the heat of fusion of $2000 \mathrm{lb}$ of ice $(2000 \mathrm{lb} \times 144 \mathrm{Btu} / \mathrm{lb}=$ 288,000 Btu to melt a ton of ice) 


\section{Introduction}

The essential chillers provide chilled water to cool the control room and other rooms containing safety-related equipment and personnel at nuclear power plants (NPPs). Essential chiller operability is mandated by Title 10, Part 50 of the Code of Federal Regulations and other regulations that govern habitability of the control room and operation of the safety-related rooms. The essential chilled water systems must be available at all times, have redundancy, and function during and after simultaneous or individual events, such as a safe shutdown earthquake, loss-of-coolant accident (LOCA), or loss of offsite power (LOP).

Because the ventilation systems these chillers serve are safety-related, the chillers are also safety-related. They must he designed, manufactured, and installed in accordance with Seismic Category I, American Society of Mechanical Engineers (ASME) Code, Section III, Class 3 requirements. The system must be powered from Seismic Category $1 \mathrm{E}$ buses.

With the above requirements in mind, work was initiated on a Nuclear Plant Aging Research (NPAR) Phase I aging study of NPP chillers. The discussion below outlines the background, objectives, and initial boundary selected for the study.

\subsection{Background}

Chillers were first formally identified as a candidate for an NPAR study in a Nuclear Regulatory Commission (NRC) prioritization study (Levy et al. 1988). In January 1991, work was initiated on a Pre-Phase I study to determine if a full Phase I study was justified. The Pre-Phase I study was completed and summarized in a letter report.

The study recommended that a full Phase I study proceed, and the NRC concurred. The recommendation was based upon the following reasons:

- The Technical Integration Review Group for Aging and Life Extension (TIRGALEX) component prioritization study recommended an aging assessment of chillers. Most U.S. NPPs are affected by this issue.

- NRC Generic Letter 89-13 stresses the importance and concern for chiller and room cooler heat exchanger (HX) performance in safety systems.

- NRC Generic Safety Issue No. 143, Availability of Chilled Water Systems and Room Cooling, is concerned with the availability of cooling services provided by chilled water, HVAC systems, and related auxiliaries to provide temperature control in rooms with safety-related equipment.

- Review of draft reports anc general literature indicated the importance of chillers in cooling safetyrelated roums. High temperatures and humidities in control rooms affect both personnel and equipment. High temperatures can cause operators to become uncomfortable and more susceptible to losing alertness and making errors in judgment. High control room temperatures also cause concern for premature degradation and failure of electrical and electronic components, which are often housed in cabinets with even higher than ambient room temperatures. The newer digital control systems are even more susceptible to high temperature failure than the older analog systems. Failure of control components and spurious alarms make the operators' job even more difficult and could become the principal cause of a major operating error. The situation is particularly difficult during a limiting condition for operation (LCO) caused by the failure of one of the chillers. Operators become much more tense due to a warmer environment and time limitations when the remaining chiller becomes inoperable.

- Preliminary review of Licensee Event Reports (LERs), Nuclear Power Experience (NPE), and In-Plant Reliability Data System (IPRDS) data indicated that chillers are subject to age-related degradation with failures resulting from the degradation. 
Introduction

Each year a few plants must reduce power or shut down because essential chillers are unavailable to $\mathrm{cool}$ the control room and other safety equipment rooms.

The full Phase I NPAR aging study was initiated in October 1991 and completed in September 1992, with the results summarized in this report.

\subsection{Objective}

The objective of the Phase I chiller study was to make an interim aging assessment of chillers. The following standard research elements were performed in accordance with the NPAR Program strategy (USNRC 1991):

- Review and analyze available information from chiller designs, specifications, operational parameters, and ongoing research.

- Evaluate chiller operating experience from readily available databases (e.g., IPRDS, NPE, and LERs).

- Utilize industry practices and the knowledge from experts on chillers.

- Characterize the aging mechanisms for chillers.

- Interact with key NRC staff involved with chillers.

\subsection{Equipment Boundary Selection}

A simplified diagram of the major components of a centrifrugal chiller and the interfacing systems is shown in Figure 1.1. The research boundary selected for the Phase I study is indicated by the dashed line. The major components of the chiller are typically a motor-driven centrifugal compressor, a condenser $\mathrm{HX}$, an expansion device, and the evaporator-cooler HX. The refrigerant used as heat transfer media is usually CFC-11 or CFC- 12 refrigerant. The chiller waste heat is removed by the plant service water system or an emergency cooling water (ECW) system (especially in an accident or LOP situation). The chilled water from the evaporator is used to cool rooms that house safetyrelated equipment and personnel. The rooms cooled by chillers are plant specific, but the control rooms were in nearly all of the plants reviewed. The chiller and its interfacing systems (the cooling water system, chilled water system, and electric motor control center) can have a large effect on the performance of each other. In reality, a chiller is much more complex than shown in Figure 1.1. A chiller has hundreds of components and is interrelated with many remote safety system-controlled components.

The typical auxiliary components of a chiller include

- compressor guide vane

- control panels and indicators

- wires and terminals

- purge-dehydrator unit $^{1}$

- piping and tubing

- seals and gaskets

- base, package support structure, and vibration dampeners

- lubrication oil system ${ }^{1}$

- sensors, controls, and alarms

- switchgear, starter, and relays

- flash economizer ${ }^{1}$

- relief valves

- transmission gearbox and couplings ${ }^{1}$.

${ }^{1}$ These components have numerous sub-components. 


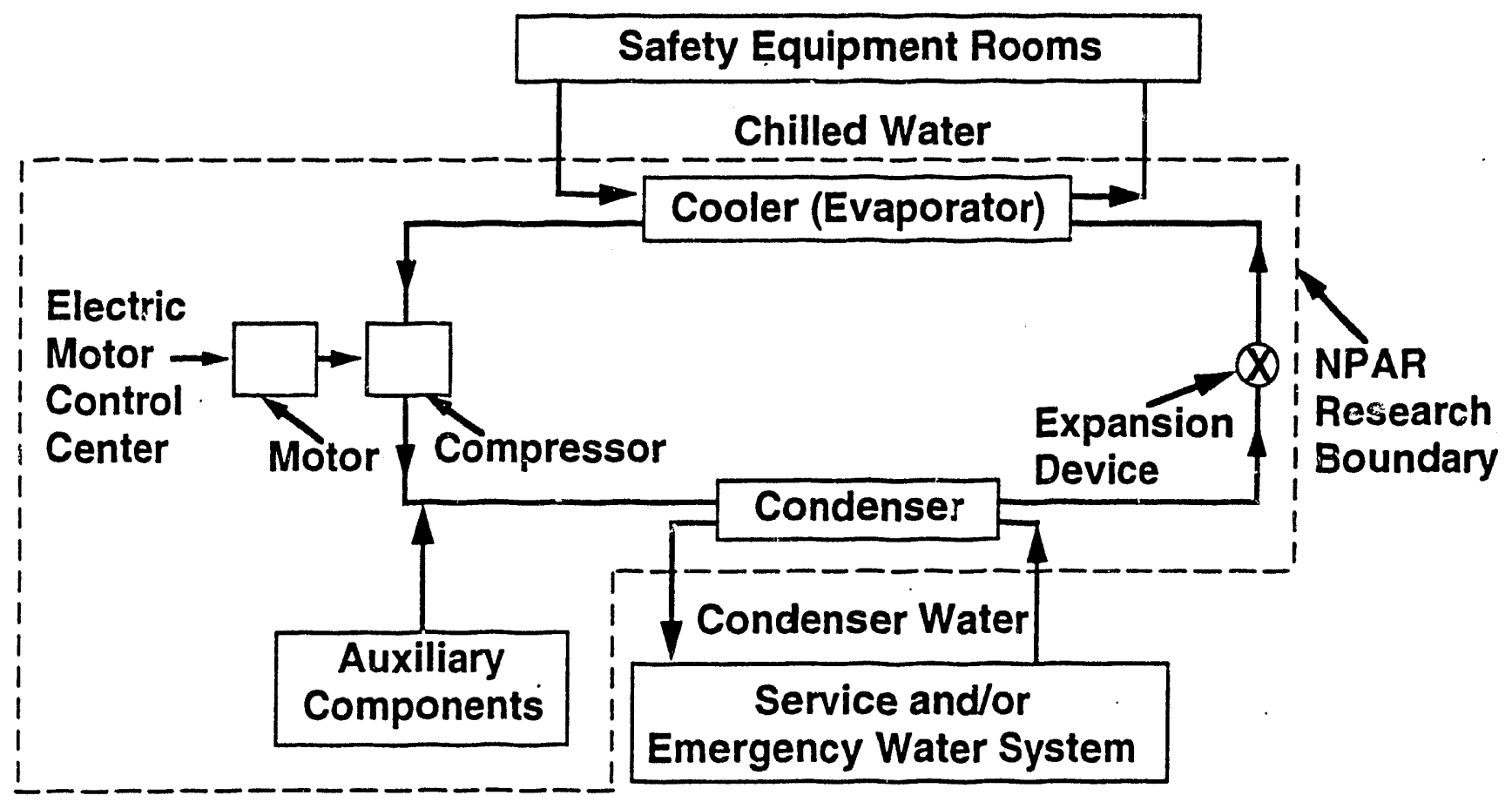

Figure 1.1 Research Boundary for Phase I Essential Chiller Study 


\section{Basic Chiller and HVAC Systems Information}

Chillers are used for numerous applications and are used extensively throughout developed portions of the world. Probably about 250,000 liquid cooling chillers are in use today. Approximately 80,000 are used in the U.S. alone. Most of the chillers are used in central HVAC applications where it is more economical and efficient to distribute chilled water to remote air hand.ling units than to use large space-consuming air ducts of a central air handler (Niess 1992). The temperature is better controlled by modulating chilled water flow through air-cooling coils than with a direct "on-off" expansion refrigerant distribution control.

\subsection{Chillers in Industry and Commerce}

Liquid chillers are used to cool water, glycol mixtures, or brines for central station air-conditioning systems, refrigeration, or process cooling. Nearly $90 \%$ of the chillers used in industry-provide water-based liquids for central station air-conditioning systems (Stebbins 1991).

The most common chiller systems utilize centrifugal, reciprocating, or screw compressors. Most of the chillers use freon or ammonia (usually not used in rooms or buildings occupied by personnel) in a closed refrigerant cycle. They use air, water or evaporative condensers, and flooded or direct-expansion evaporators. Hermetic or open drives, expansion devices, and controls complete the typical package. Other, less common systems used are the rotary and absorption cycle (water/steam) chillers.

This study focused on the centrifugal water chiller as a reference design. The centrifugal chiller is described in greater depth later in the report and is shown in Figure 4.1. Illustrations of alternative reciprocating, screw, and absorption water chiller designs are shown in Figures $2.1,2.2$, and 2.3 , respectively.

Centrifugal water chillers, the industry workhorses, provide a broad range of sizes between 75 and 5000 tons or more. The largest is believed to be 10,000 tons of refrigeration. The compressor is a variable-volume displacement machine using one or more rotating impellers compressing refrigerant vapor by centrifugal force. Since they are not constant volume machines, centrifugal chillers offer a wide range of capacities continuously modulated over a limited range of pressure ratios and can provide a wide range of chilled water temperatures.

Reciprocating water chillers are available in sizes up to 200 tons. The compressor is a fixed positive-displacement machine using crankshaft-powered pistons working in cylinders utilizing suction and discharge valves. The compressor maintains nearly constant flow rates over a wide range of pressure ratios and may be used when displacement volumes are small. They operate efficiently at high compression ratios and high concensing temperatures.

Screw water chillers are available in the size range between 50 and 750 tons. The compressor is a machine that provides positive disp!acement with a nearly constant flow of refrigerant using incremental capacity modulation. The refrigerant compression results from the meshing action of precision groove-machined lobes on the male and female rotors. The machine efficiency is increased by direct injection of oil into the compression region to seal the spaces between the two rotors and the rotor/casing annulus.

Absorption water chillers range in size between 100 and 1700 tons. These machines have a total of four heat exchangers: condenser, generator (concentrator), evaporator, and absorber. The chillers are usually powered by hot water or low-pressure steam. Water is the refrigerant, and lithium bromide, a salt that strongly attracts water, is the absorbent. Heat is transferred from the chilled water to the cooling water through evaporation and condensation of the refrigerant water.

Most of the chillers used in industrial and commercial HVAC applications are centrifugal chillers. About $80 \%$ use $\mathrm{CFC}-11$ refrigerant. The $\mathrm{CFC}-12$ refrigerant, also 
Basic Chiller and HVAC Systems Information

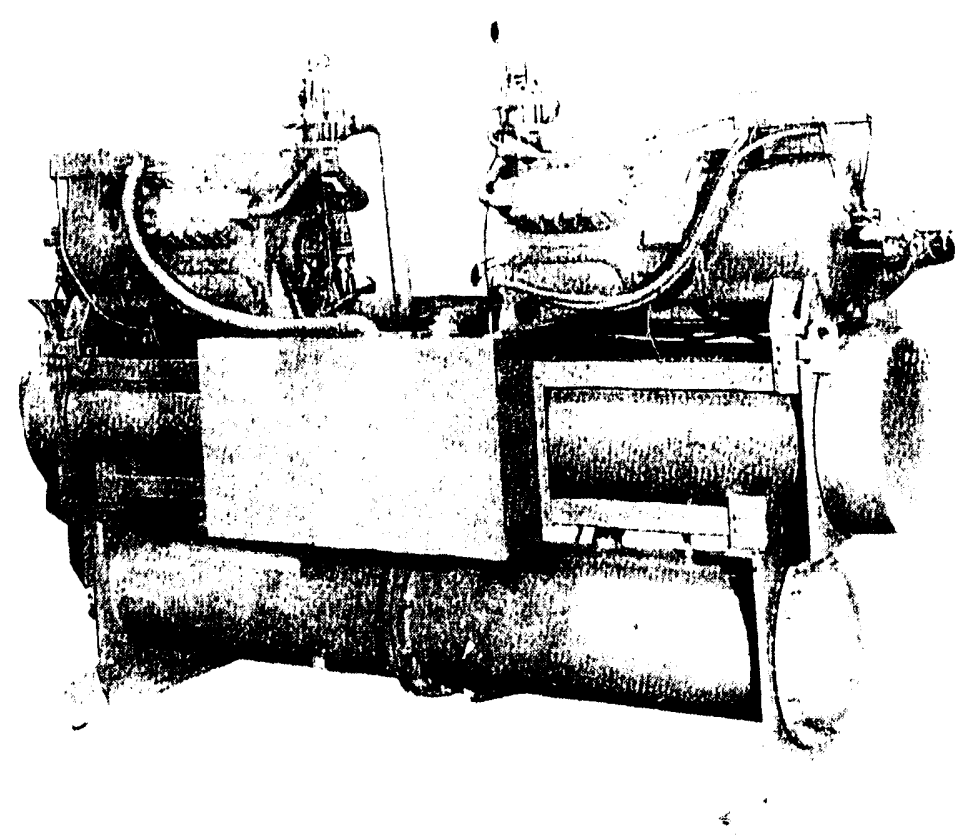

Figure 2.1 Reciprocating Water Chiller Description (Permission to use this copyrighted material is granted by the York International Corporation.)

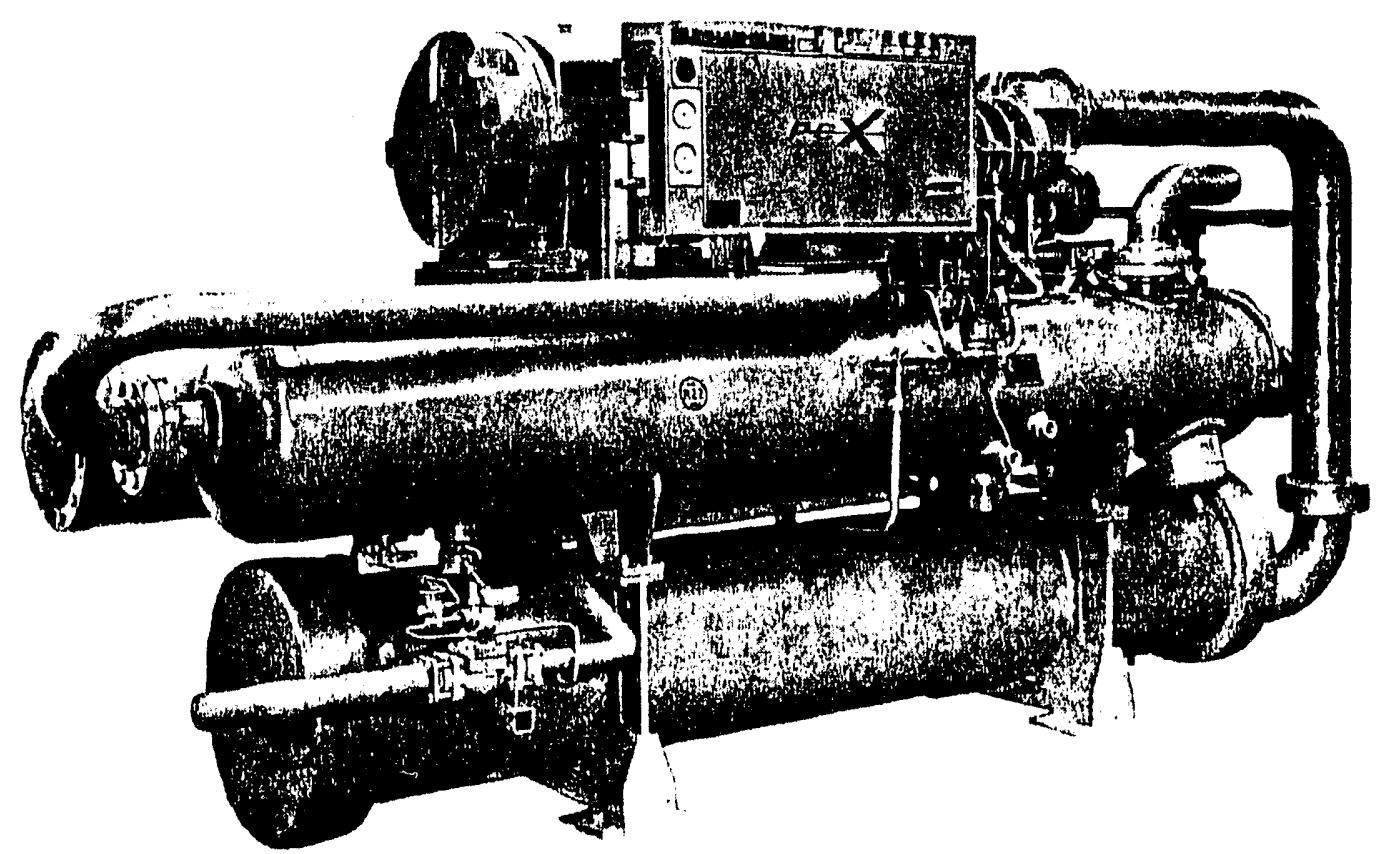

Figure 2.2 Screw Water Chiller Description (Permission to use this copyrighted material is granted by Dunham-Bush, Inc. The above graphic is from an obsolete Dunham-Bush, Inc. document.) 


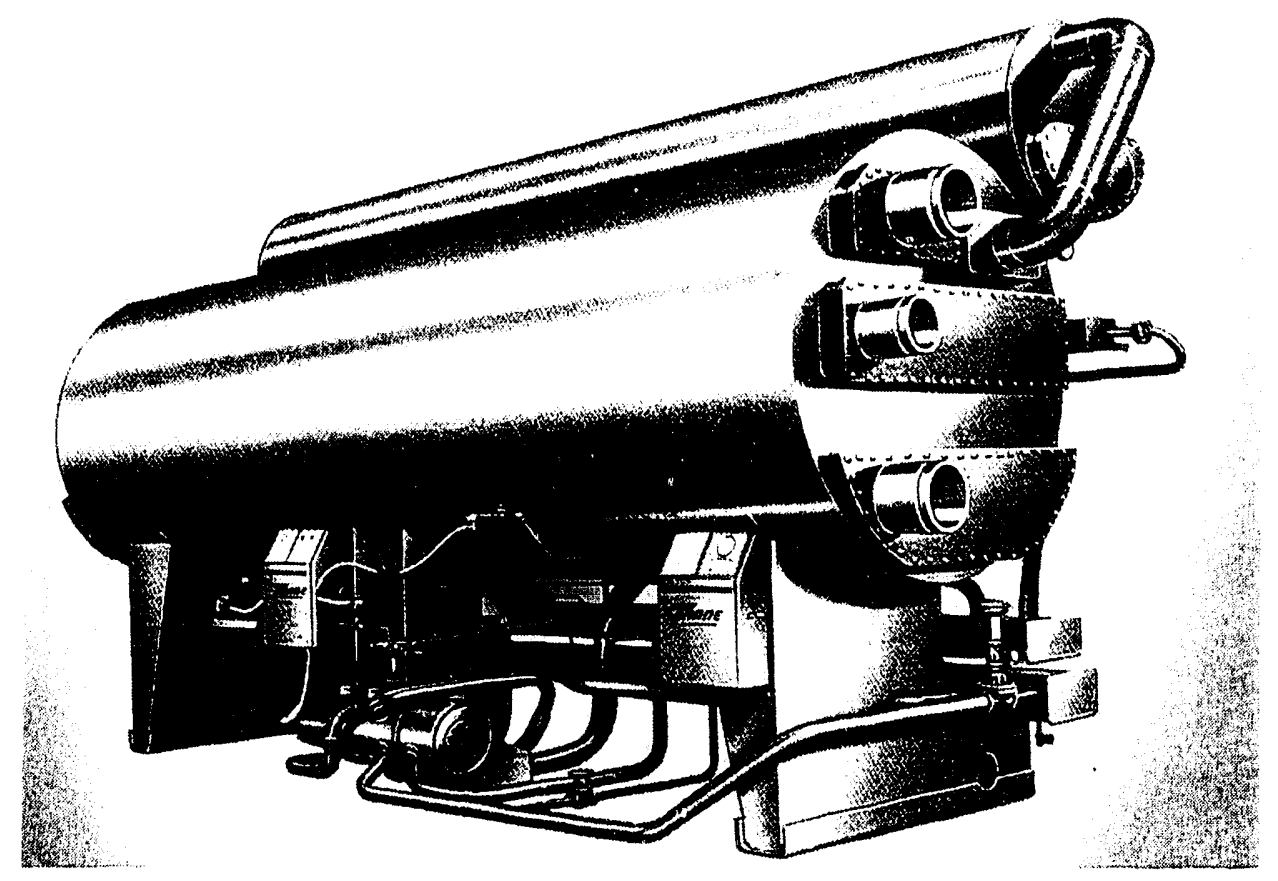

Figure 2.3 Absorption Water Chiller Description (Permission to use this copyrighted material is granted by The Trane Company.)

widely used in supermarket refrigeration and automobile air-conditioning, is used in about $15 \%$ of the centrifugal chillers. The balance of the centrifugal chillers use $\mathrm{R}-500, \mathrm{CFC}-114$, and $\mathrm{HCFC}-22$ refrigerant (Niess 1992). The CFC refrigerants (CFC-11, CFC-12, and CFC-114) will be phased out by the year 2000 , to meet current environmental control regulations established by the U.S. Congress Clean Air Act Amendments of 1990. The regulations were instituted to reduce degradation of the stratosphere ozone due to chlorine (Calm 1992). These regulations will also apply to the nuclear industry. Alternative refrigerants HCFC.-123 will likely replace $\mathrm{CFC}-11$, and $\mathrm{HFC}$-134a will likely replace CFC-12 (Clark 1991). The replacement for CFC-114 will likely be HCFC-124, for at least the short term.

\subsection{Chillers in LWRs}

General descriptions of chillers and the systems they serve in light-water reactor (LWR) NPPs are provided in Appendix $\mathrm{A}$ of this report. The descriptions are based upon information found in final safety analysis reports (FSARs) of U.S. NPPs. Chiller information was not found in many of the FSARs that were reviewed. A comprehensive survey of all the plants would be required to get exact, up-to-date descriptions. However, it is believed that this information is sufficient to be a representative sample of typical systems that are served by chillers in the United States.

Most of the plants listed in Appendix A had at least two essential chillers that serve safety systems in the control rooms and various equipment rooms. One chiller serves as a backup. The essential chillers were identified with an asterisk. The non-essential or non-safety chiller systems were also listed (without an asterisk), but this study focused on the essential chillers.

Centrifugal chillers were the predominant type of chiller used in LWRs. Most centrifugal chillers were hermetic drive (electric drive motor is sealed inside the refrigerant boundary). Some were open drive (sealed outside the refrigerant boundary and exposed to the chiller room environment). Other types of chillers used included screw, rotary, and reciprocating chillers. These 
latter types tended to be used in older and smaller plants. One plant used a hot water absorption chiller in a containment cooling system. The NPP chillers that were found all used liquid cooling.

The essential chillers were sized in the 50- to 750-ton refrigeration capacity range. Non-essential chillers were in the 200- to 1500 -ton range.

Based upon what was learned from the FSARs, it was decided to focus on centrifugal hermetic chillers during the Phase I aging study.

The review of the FSARs in Appendix A also provided the following information:

- In some cases essential chillers and their chilled water system are normally on standby for emergency situations (e.g., LOCA, LOP, etc.). During normal operations, non-essential (non-safety) chillers serve the control room and other safety-related rooms. In many cases the essential chillers are used for both normal operations and emergency situations to cool just safety-related rooms. Sometimes the essential chillers serve both safety and non-safety-related rooms and they reduce their capacity in an emergency to serve just the safety-related rooms.

- Essential chiller condenser cooling water is supplied by systems and arrangements such as the following:

- Service Water System (both normal and emergency)

- Service Water System during normal operation and Emergency Service Water System during emergencies

- Component Cooling Water System (both normal and emergency)

- Nuclear Closed Cooling System (normal) and Emergency Closed Cooling System (emergency)

- Emergency Nuclear Service Cooling Water System during emergencies

- Essentia! Cooling Water System during emergencies
- Plant Service Water System during normal operations and Shutdown Service Water System during emergencies.

- The South Texas Plants have two chillers serving each safety-related HVAC train (total of four). The Perry 1 Plant has three chillers serving two safetyrelated trains. The third chiller is used as a standby unit. All other plants surveyed have two chillers capable of serving each of the two trains.

Based upon the results of the above FSAR reviews, it was determined that generic plant designs do not exist. Even multiple plant units at a site may have substantial design differences. A study to determine which design options work the most reliably might be justified. Plants like River Bend (discussed later in this report) might be helped by such a study.

In addition to the chiller systems that serve HVAC applications (Appendix A), there are other chillers which serve safety systems in non-HVAC applications. Examples are chillers used to recover condensible offgas from the primary water system in every plant and to make and maintain ice for containment safety ice condensers in eight of the Westinghouse LWRs. The review and aging assessment of those chillers were beyond the scope of this study.

In addition to chiller cooling of essential safety-related rjoms, some plants have the option to use water directly from the Service Water System or other intermediate system in lieu of chiller-cooled water. In one plant, service water is cool enough the year around to keep the control room below $29^{\circ} \mathrm{C}\left(85^{\circ} \mathrm{F}\right)$.

\subsection{Essential Chiller HVAC Systems in LWRs}

The primary systems served by the essential chillers are listed in Appendix A. However, during an emergency the particular systems served varies from plant to plant. The control room was served by an essential HVAC system in all of the plants listed. However, the other rooms served by the essential HVAC system varied from plant to plant. 
Examples of the rooms and equipment served in various plants include the following:

- Containment Fan Coolers

- Electrical Equipment Room

- Battery Room

- Auxiliary Building Electrical Switchgear Room

- ESF Switchgear Room

- Electrical Penetration Room

- ESF Equipment Room

- ECW Pump Rooms

- Auxiliary Feedwater Pump Rooms

- Reactor Makeup Water and Boric Acid Transfer Pump Cubicles

- Relay Room

- Cable Spreading Room
- Computer Room ${ }^{1}$

- Control Room HVAC Equipment Room

- Relay Room

- Remote Shutdown Room

- CCW, Charging, Safety Injection, and Residual Heat Removal Pump Room fan/coil coolers

- Essential Equipment Rooms

- Standby Gas Treatment System Compartment and Area

- Spent Fuel Pool HX and Pump Rooms

- Auxiliary Building ESF Equipment, Switchgear, and Electrical Equipment Protection Room

- Safety-Related Panel Room

- Emergency Motor Control Center.

${ }_{1}^{1}$ some plants the Computer Room is not considered safety-related. 


\section{Regulatory, Code, and Standards Requirements for Essential Chillers}

The regulatory, code, and standards requirements for essential chillers are outlined below.

\section{Nuclear Regulatory Requirements}

The following nuclear codes and standards apply to essential chillers and the chilled water system they serve:

1. Title 10 of the Code of Federal Regulations, Part 50, Domestic Licensing of Production and Utilization Facilities, Appendix A, General Design Criteria for Nuclear Power Plants (10CFR50, Appendix A). The following General Design Criteria apply:

Criterion 2 - Design Bases for Protection Against Natural Phenomena

Criterion 4 - Environmental and Dynamic Effects Design Bases

Criterion 5 - Sharing of Structures, Systems and Components

Criterion 19 - Control Room

Criterion 44 - Cooling Water

Criterion 45 - Inspection of Cooling Water

Criterion 46 - Testing of Cooling Water.

2. Codes and Standards (10CFR50.55a)

3. Standard Review Plan (SRP) (NUREG-0800)

SRP 6.2.2 - Containment Heat Removal

SRP 6.4 - Control Room Habitability Systems

SRP 9.4.1 - Control Room Area Ventilation System
SRP 9.4.2 - Spent Fuel Pool Area Ventilation System (few plants)

SRP 9.4.3 - Auxiliary and Radwaste Building Ventilation Systems (some plants)

SRP 9.4.5 - Engineered Safety Feature Area Ventilation System (many plants).

4. A Review of Regulatory Requirements Governing Control Room Habitability (NUREG/CR-3786)

5. Nuclear Regulatory Commission Regulatory Guides (RG)

RG 1.26 - Quality Group Classifications and Standards for Water, Steam, and RadioactiveWaste-Containing Components of Nuclear Power Plants

RG 1.29 - Seismic Design Classification

RG 1.32 - Criteria for Safety-Related Electric Power Systems for Nuclear Power Plants

RG 1.40 - Design, Testing, and Maintenance Criteria for Normal Ventilation Exhaust System Air Filtration and Adsorption Units

RG 1.52 - Design, Testing, and Maintenance Criteria for Post Accident EngineeredSafety-Feature Cleanup System Air Filtration and Adsorption Units of LightWater-Cooled Nuclear Power Plants

RG 1.68 - Initial Test Programs for Water-Cooled Nuclear Power Plants

RG 1.78 - Assumptions for Evaluating the Habitability of a Nuclear Power Plant Control Room During a Postulated Hazardous Chemical Release 
RG 1.82 - Water Sources for Long-Term Recirculation Cooling Following a Loss-ofCoolant Accident

\section{RG 1.95 - Protection of Nuclear Power Plant Con- trol Room Operators Against an Acci- dental Chlorine Release.}

\section{Plant Technical Specifications}

The LCO and surveillance requirements are usually contained in the Plant Technical Specification (PTS). The technical specification applies to the two emergency HVAC trains that serve the control rooms, and it requires that at least one essential chiller be operable for 7 days. If the second chiller becomes inoperable, then there must be a Hot Shutdown within 12 hours and a Cold Shutdown within the next 24 hours.

The PTSs are plant specific, and the above description is an example only. Other sections of the PTS apply to ESF pump rooms and equipment rooms. The few PTSs reviewed for the main control room did not provide criteria about temperature or humidity limitations or surveillance requirements. Temperature requirements are generally contained in the surveillance portion of the PTS. The chillers are considered "attendant" equipment.

\section{Nuclear Safety Classification}

The essential chillers are classified as Nuclear Safety Class 3 equipment. The equipment component regions listed below are designed and fabricated in accordance with the ASME Boiler \& Pressure Code, Section III, Code Class 3. An ASME "N-Stamp" is required, as specified in Paragraph NA 6254.1 of the ASME Boiler \& Pressure Code, on the following item boundaries:

- evaporator water side

- evaporator refrigerant (shell side only)

- condenser water side

- condenser refrigerant (shell side only)
- oil cooler HX excluding oil piping and valves

- all external water piping and valves associated with the oil cooler.

\section{Seismic Requirements}

The essential chillers are classified as Category I Seismic Equipment, and they are designed to meet the applicable requirements. The chiller and all its accessories (including those remotely located from the chiller) are seismically qualified under the requirements of IEEE-344 by a combination of analysis and testing. The chillers are designed to withstand seismic loading in accordance with the Uniform Building Code (UBC) for the Earthquake Zone Level át the chiller's geographic location.

\section{Standards}

The equipment complies with all state inspection rules and laws. All nuclear vessels and components are designed, constructed, inspected, and tested in accordance with Section III of the ASME Boiler \& Pressure Vessel Code, and the associated safety relief valves must be registered with the National Board, and so stamped.

The chiller and its accessories, including the control panel and its related components, are qualified in accordance with IEEE-323, 334, and 344.

The materials, design, and construction of the chiller and its accessories comply with, but are not limited to, the following standards:

Anti-Friction Bearing Manufacturers Association (AFBMA)

American National Standards Institute (ANSI) Standards ANSI N18.2, N45.2.2, N5.12, B9.1, B16.5, B31.1, and B31.5

Air-Conditioning and Refrigeration Institute (ARI)

ARI 550 - Centrifugal Water-Chilling Packages

ARI 560 - Absorption Water-Chilling Packages

ARI 590 - Reciprocating Water-Chilling Packages. 
American Society of Heating, Refrigerating, and AirConditioning Engineers (ASHRAE)

ASHRAE 15 - Safety Codes

ASHRAE 30 - Methods of Testing Liquid Chilling Packages.

American Society of Mechanical Engineers (ASME)

Boiler \& Pressure Vessel Code

Section II - Materials Specifications

Section III - Nuclear Power Components

Section IX - Welding and Brazing Qualifications.

American Society for Testing and Materials (ASTM)

American Welding Society (AWS)

Institute of Electrical and Electronics Engineers (IEEE)

279 - Criteria for Protection System for Nuclear Power Generating Stations

308 - Criteria for Class IE Electric Systems for Nuclear Power Generating Stations

323 - Standard for Qualifying Class IE Electric Equipment for Nuclear Power Generating Stations
334 - Standard for Type Tests of Continuous Duty Class IE Motors for Nuclear Power Generating Stations

344 - Guide for Seismic Qualification of Class IE Electric Equipment for Nuclear Power Generating Stations

383 - Standard for Type Tests of Class IE Electric Cables, Field Splices, and Connections for Nuclear Power Generating Stations

384 - Independence of Class IE Equipment and Circuits

603 - IEEE Standard Criteria for Safety Systems for Nuclear Power Generating Stations.

National Electric Code (NEC)

MG-1 Standard Publication for Motors and Generators (NEMA)

National Fire Protection Association (NFPA) Standard 90-A

Occupational Safety and Health Administration (OSHA) Standards Health Act

Stcel Structures Painting Council (SSPC) Standards SP-1, 3, 5, 6, and 10

Underwriters Laboratory (UL) Incorporated Standard UL-723 


\section{Centrifugal Chiller Description}

About $90 \%$ of the chillers found in the NPPs listed in Appendix A were centrifugal chillers, and most of them were driven by hermetic electric motors. Therefore, this study has focused on the hermetic centrifugal chiller. A discussion of how a typical hermetic centrifugal chiller functions is provided in Appendix B. Alternative chiller types are discussed briefly in Section 2, and they will be reviewed in more detail in the Phase II study.

\subsection{Chiller Design}

A photograph of a recently marketed hermetic centrifugal chiller is shown in Figure 4.1. It is quite similar to older chillers that are still in service at NPPs. The newer chillers have advanced controls, and computer control is now available. Many improvements (e.g., solid state controls, more efficient moisture/air purge units, etc.) have been made in recent years; and the older chillers can be upgraded because manufacturers make many of the new features available in retrofit kits.

The reference chiller shown in Figure 4.1 is a Carrier Corporation model. For comparison purposes, a York International Corporation chiller is shown in Figure 4.2, and a chiller manufactured by The Trane Company is pictured in Figure 4.3. Most of the NPP centrifugal chiller market is divided among these three manufacturers.

A cross-sectional view with the refrigerant flow path of the reference chiller (Carrier Corporation) is illustrated in Figure 4.4. The compressor cross-section view is shown in Figure 4.5, and a view of a purge unit is shown in Figure 4.6. Typical piping and wiring are illustrated in Figure 4.7. Dimensions and layout requirements are given in Figure 4.8.

A liquid open centrifugal chiller is illustrated in Fig. ure 4.9. This figure shows the dimensional envelope changes compared to the liquid hermetic centrifugal chiller shown in Figure 4.8. The open centrifugal chiller has a motor that is sealed external to the refrigerant system boundary and is exposed to the chiller room environment.

\subsection{Materials of Construction}

Based upon information that was gathered from manufacturers' literature, the typical materials used in the construction of chillers are listed below.

- cooler (evaporator) - shell-and-tube

- shell - carbon steel plate

- waterboxes - carbon steel plate

- division plates - steel plate

- tubes - 1.91-2.54 cm (0.75 - 1.00 in.) diameter externally finned seamless copper or copper $90 /$ nickel 10 tubing

- tube sheets - carbon steel plate sometimes clad with copper/nickel alloy sheet

- tube support sheets - steel plate.

- condenser - shell-and-tube materials the same as for cooler (evaporator).

- compressor

- drive shaft - heat-treated alloy steel

- impeller - high-strength aluminum casting

- casing - close-g: ained cast iron

- labyrinth seals - non-ferrous metal

- bearings - aluminum alloy, bronze or babbitt

- pre-rotation vanes - manganese bronze

- shaft seal - carbon ring with elastomer O-ring. 


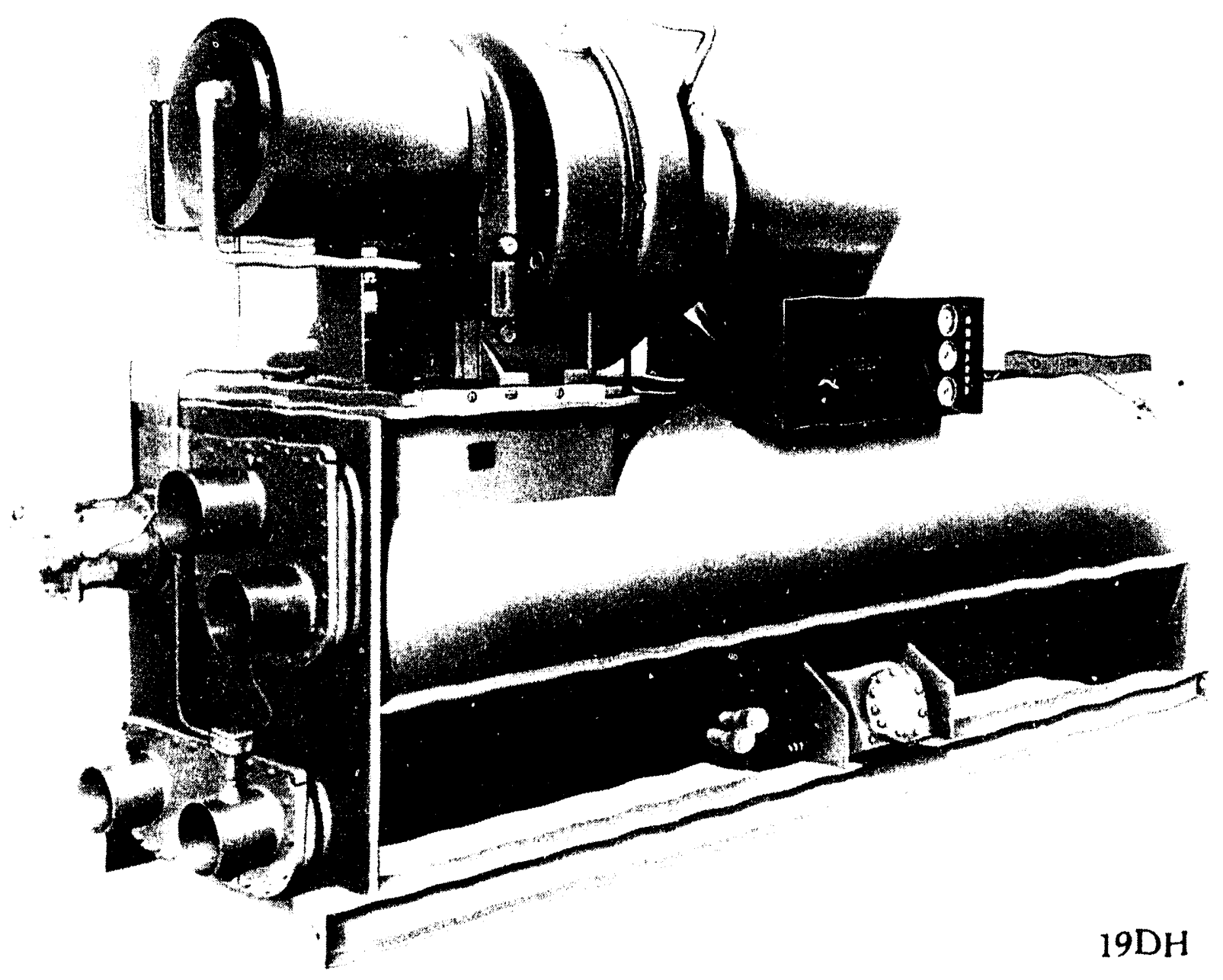

Figure 4.1 Recent Model of Liquid Hermetic Centrifugal Chiller Manufactured by the Carrier Corporation Reference Design (Permission to use this copyrighted material is granted by the Carrier Corporation.) 


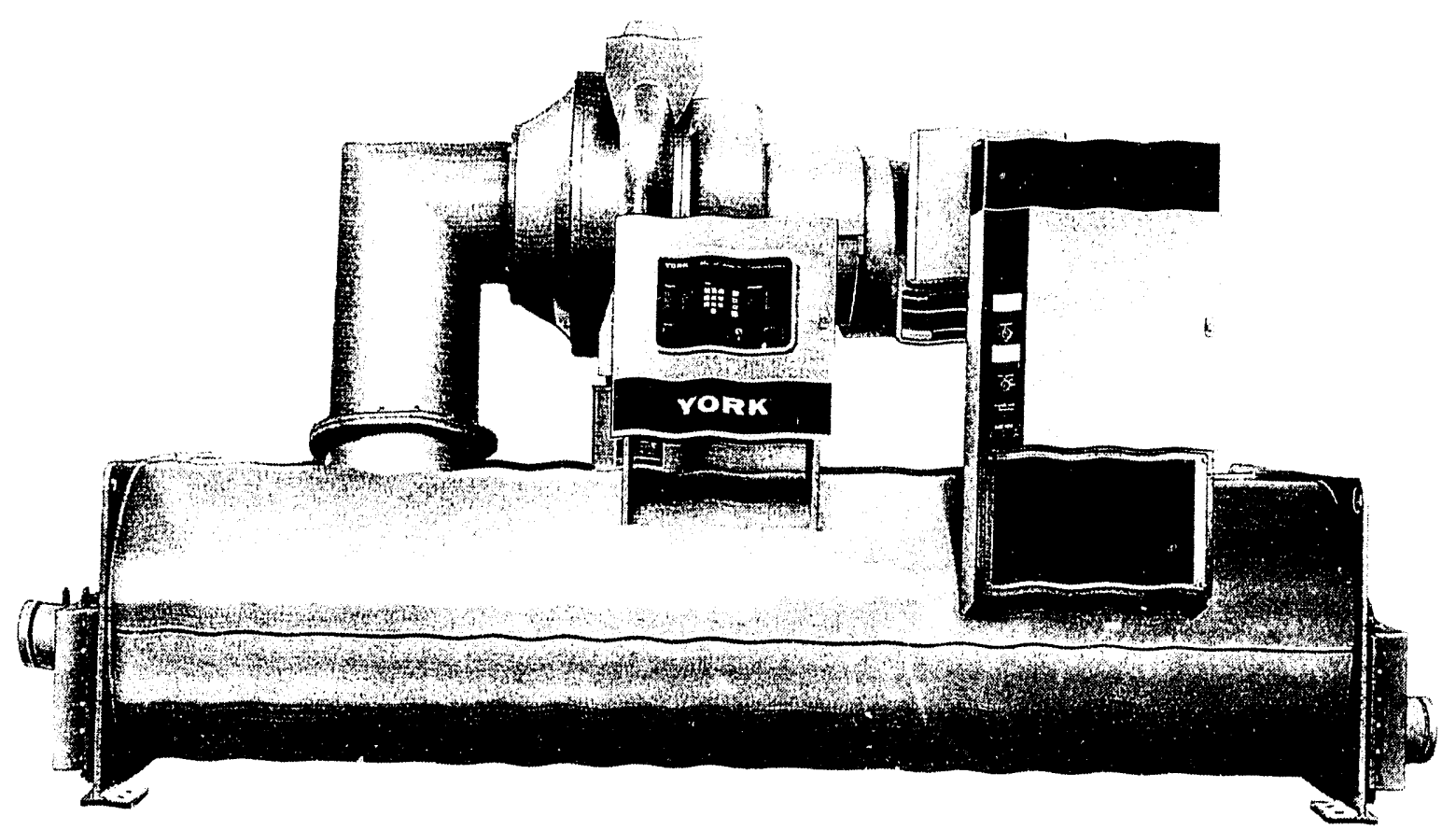

Figure 4.2 Recent Model of Liquid Hermetic Centrifugal Chiller Manufactured by the York International Corporation (Permission to use this copyrighted material is granted by the York International Corporation.)

- motor

components typical of squirrel cage induction-type motors with windings that are sealed hermetically with refrigerant resistant insulation.

- miscellaneous

- O-rings - fluorocarbon rubber, synthetic rubber, nitrile butadiene, chloroprene
- V-ring sets - molded teflon

- gauges - steel case, bronze or brass bourdon tube, monel or stainless steel movement, chrome-plated steel or brass face ring, and glass crystal

- oil cooler - steel shell, admiralty tubes, cast iron bonnets, and steel tube sheets and cross baffles

- isolation pads - molded neoprene. 
Centrifugal Chiller Description

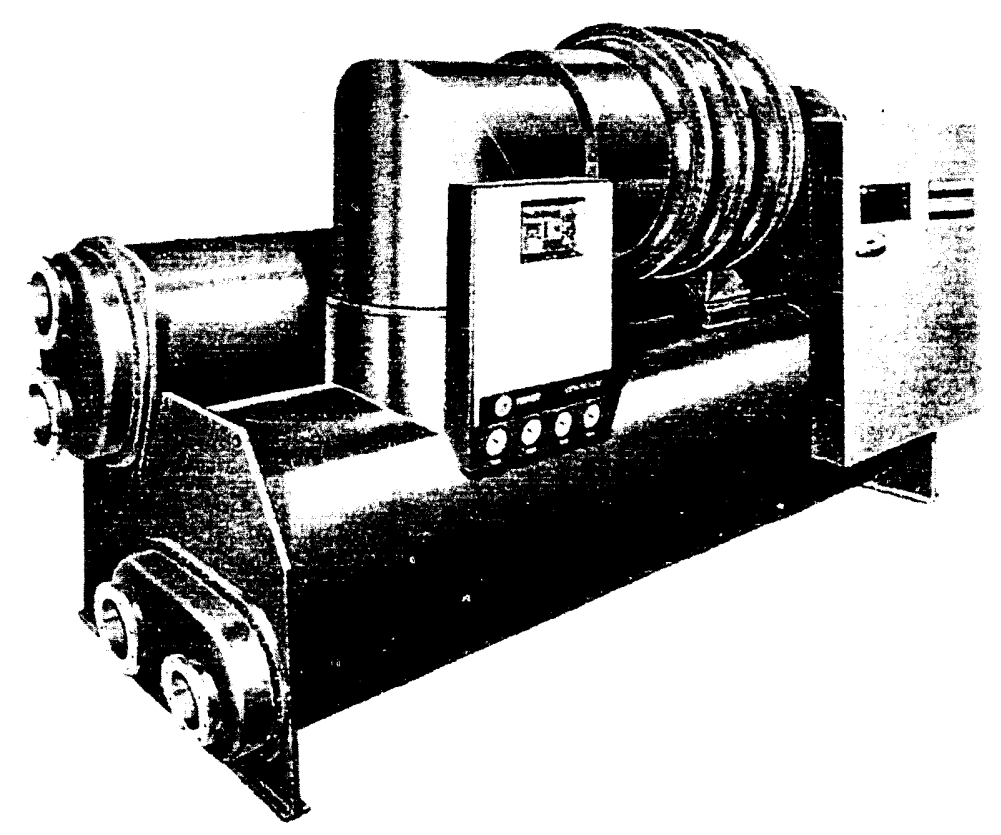

Figure 4.3 Recent Model of Liquid Hermetic Centrifugal Chiller Manufactured by The Trane Company (Permission to use this copyrighted material is granted by The Trane Company.) 


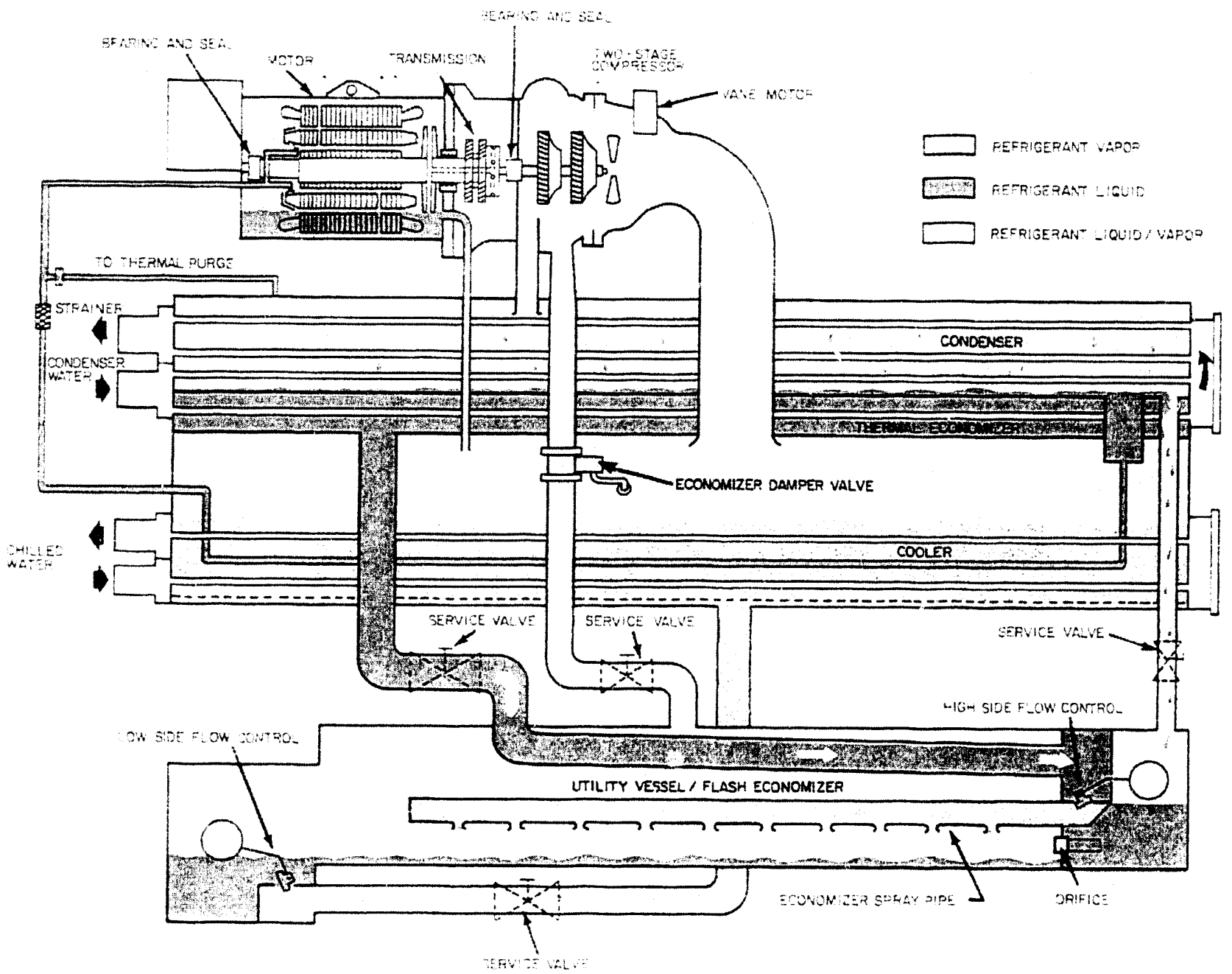

Figure 4.4 Reference Centrifugal Chiller Cross-Sectional View Showing Refrigerant Flow Path (Permission to use this copyrighted material is granted by the Carrier Corporation.) 


\section{Centrifugal Chiller Description}

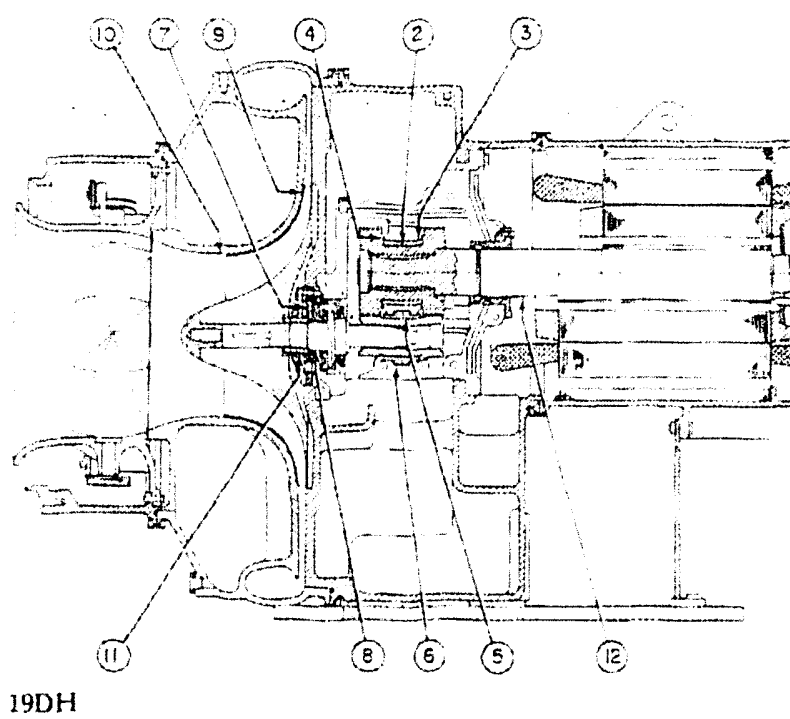

In-line impeller design

$\rightarrow$ In line impeller design, with diaphragm between stages, allows for more flexi. bility in compressor component selec tion, which results in first cost savings on other machine components. Also provides higher head capabilities, prevents uneven loading and allows for routine, easy maintenance.

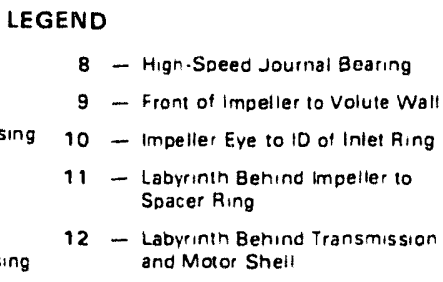

13 - End-Bell Bearing Labyrinth

Figure 4.5 Reference Centrifugal Chiller Compressor Cross-Section (Permission to use this copyrighted material is granted by the Carrier Corporation.)

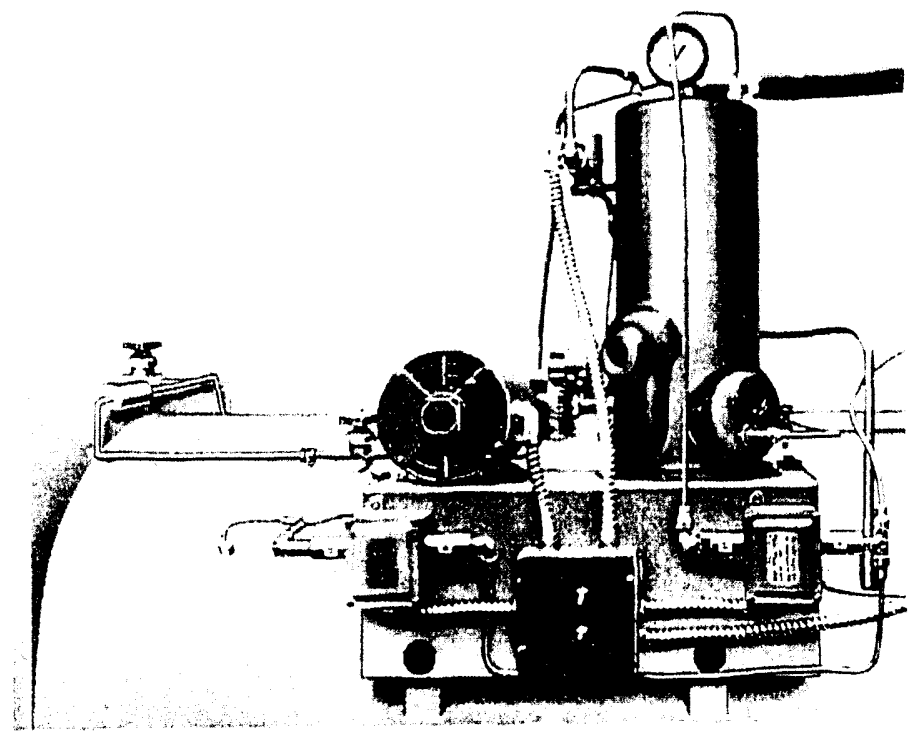

Figure 4.6 Reference Centrifugal Chiller Purge Unit (Permission to use this copyrighted material is granted by the Carrier Corporation.) 


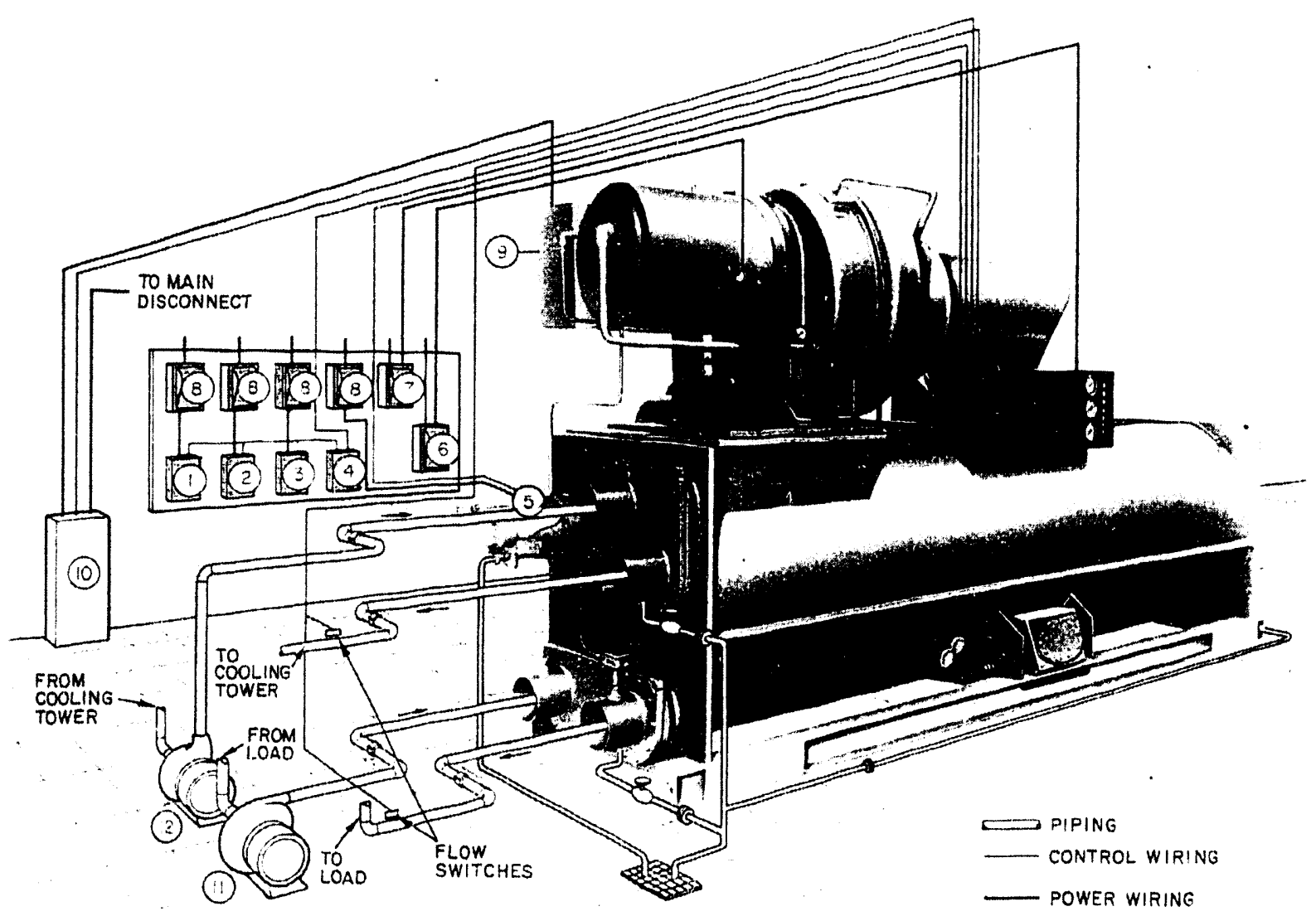

\section{LEGEND}

1 -... Cooling Tower Fan Starter

2 - Condenser Water Pump Starter

3 - Cooler Water Pump Starter

4 - Pilot Reiay

5 - Oil Pump Starter

6 - Fused Disconnect tor O1l Heater and Thermostat

7 - Fused Disconnect for Purge System

8 - Fused Disconnect

9 - Compressor Motor Terminal Box

10 - Compressor Motor Starter

11 - Cooler Water Pump

12 - Condenser Water Pump
NOTES

1 Wiring and piping shown are for general point-of-conmection only and are not intended to show details for a specific installation Certified field wiring and dimensional diagrams for specific 19 Series machines are available on request

2 All wiring must comply with applicable codes

3 Refer to Carrier System Design Manual for cetalls regarding piping techniques

4. A separate 115-volt fused power source for controls is required unless compressor motor control is furnished with a transformer

5 Pronde a separate fused 115 -volt power source for oll heater and thermostat

Figure 4.7 Reference Centrifugal Chiller Piping and Wiring Illustration (Permission to use this copyrighted material is granted by the Carrier Corporation.) 


\section{Centrifugal Chiller Description}
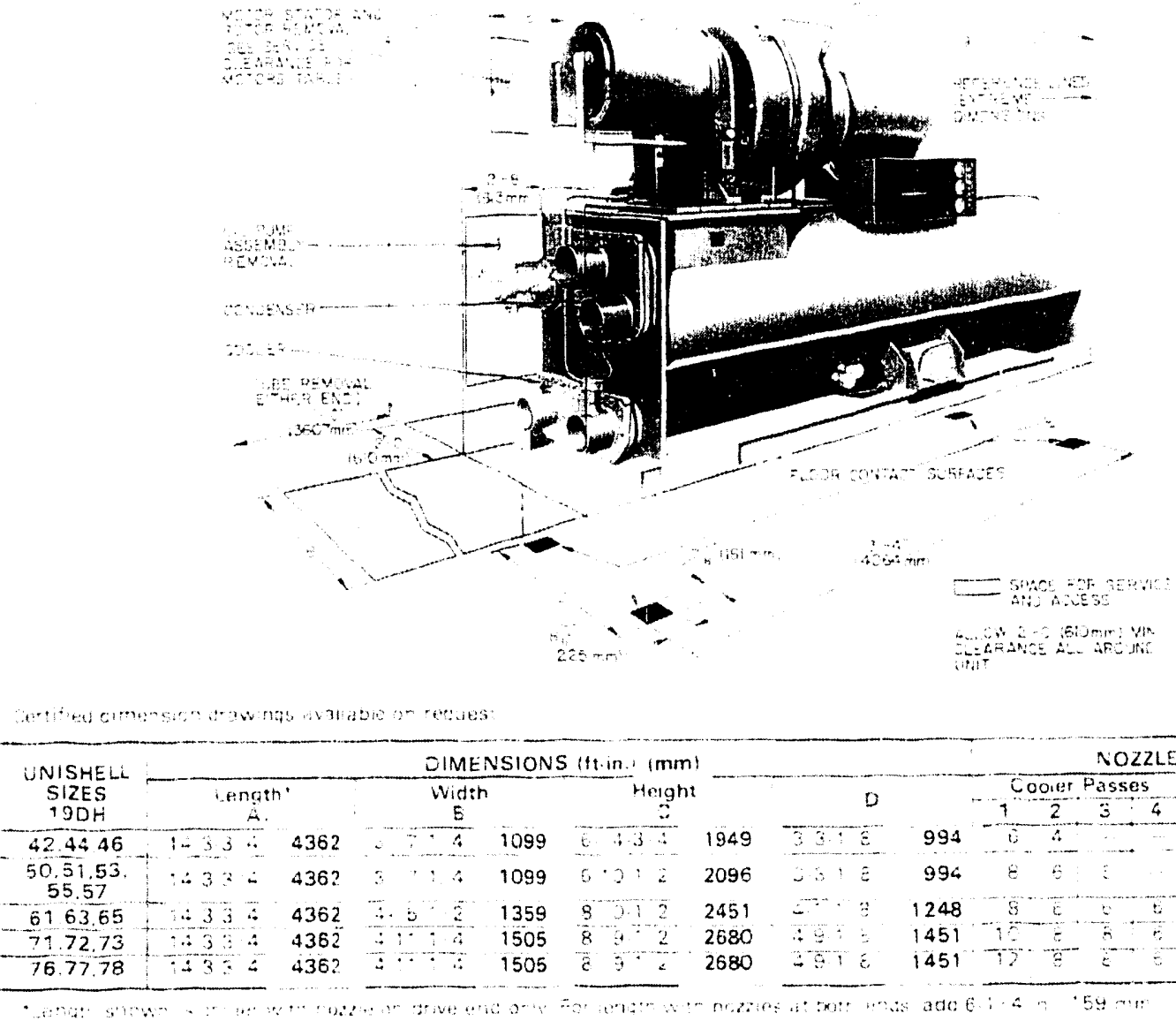

SERUICF CIEARA \CL FOR NOTORS (t1-in:
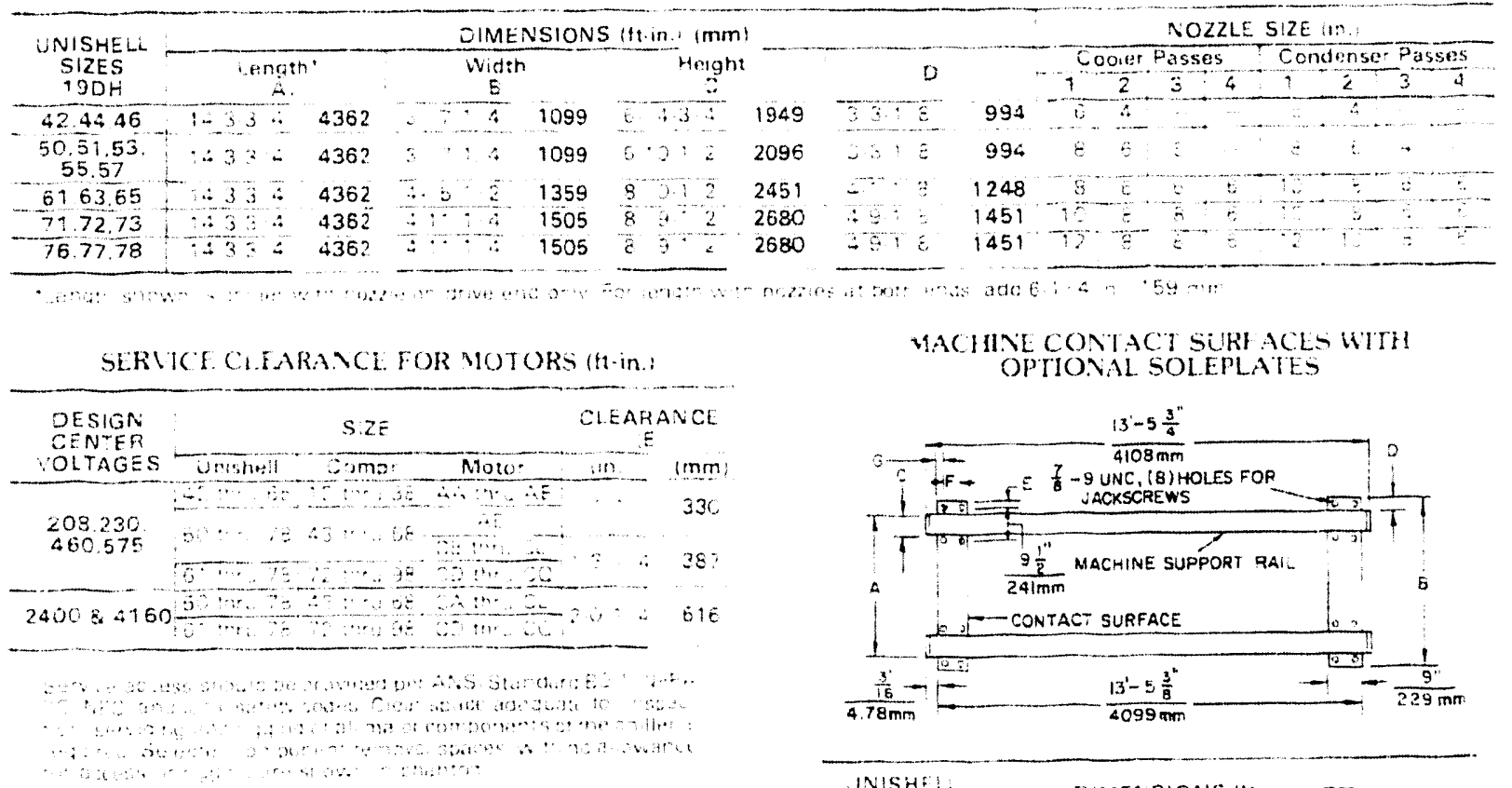

MACHINE CONTACT SURF ACLS WTHH OPTIONAL SOLEPLATES

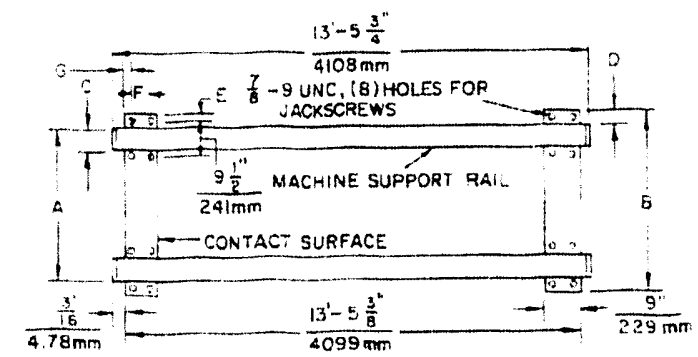

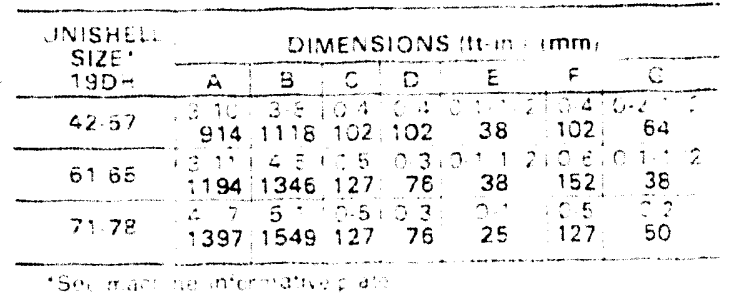

Figure 4.8 Reference Centrifugal Chiller Dimensions and Layout Requirements (Permission to use this copyrighted material is granted by the Carrier Corporation.) 


\section{Dimensions}

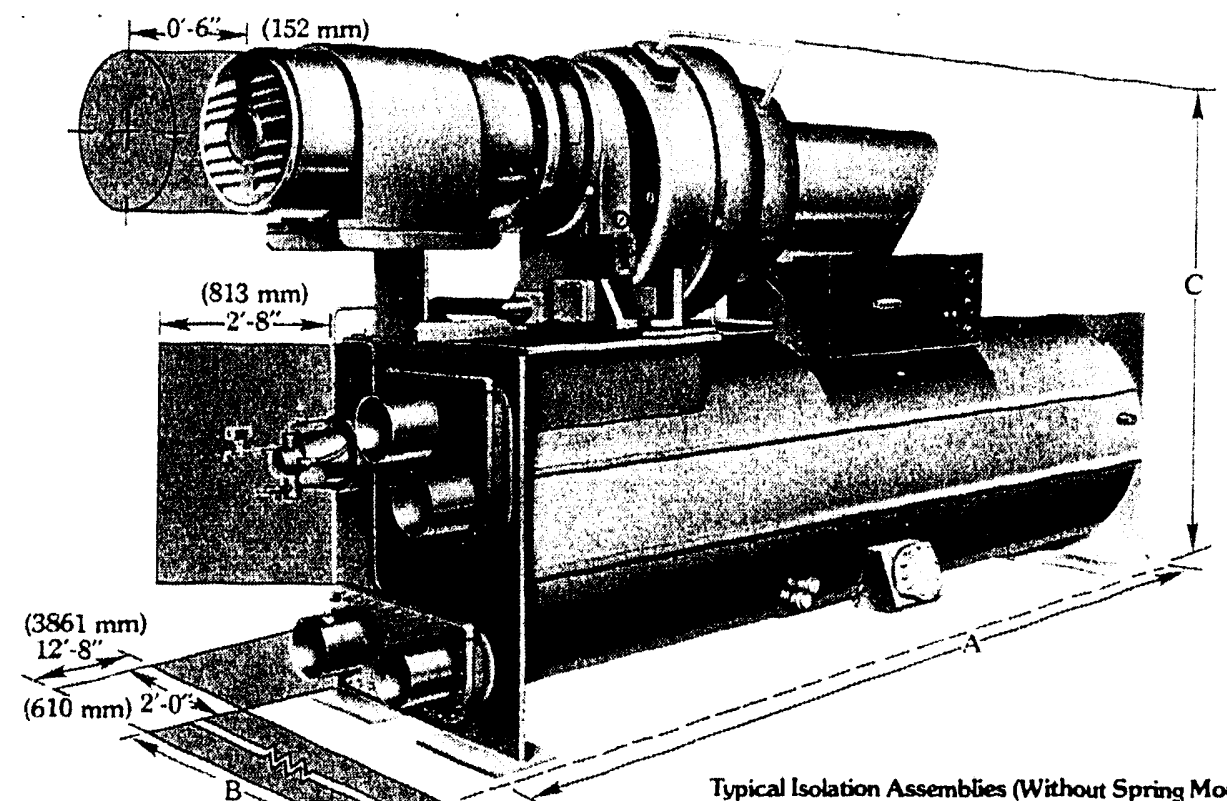

Space tor service and accoss.

Recommended clearance: Allow $2-\sigma(610 \mathrm{~mm})$ minimum vertical and hortzontal clearance.

Certifiod dimension drawing available on request.

NOTES:

Service access should be provided per ANSI Standard B9.1. NFPA 70 (NEC) and local salety codes. Clear space adequate for inspection. 2 Ciearance listed is verical helght that compressor must il itted to be removed. No allowance lor rigging is included.

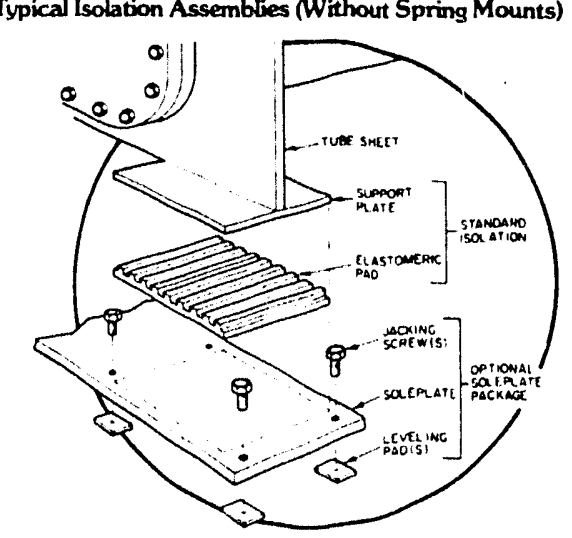

\begin{tabular}{|c|c|c|c|c|c|c|c|c|c|c|c|c|c|c|}
\hline \multirow{3}{*}{$\begin{array}{l}\text { UNISHELL } \\
\text { SAZES } \\
\text { ITOK }\end{array}$} & \multicolumn{6}{|c|}{ DIMENSIONS } & \multicolumn{8}{|c|}{ NOZZZE SIZE (In) } \\
\hline & \multicolumn{2}{|c|}{ Length'A } & \multicolumn{2}{|c|}{ Whath $B$} & \multicolumn{2}{|c|}{ Helght C } & \multicolumn{4}{|c|}{ Cooler Pauses } & \multicolumn{4}{|c|}{ Condenser Panaves } \\
\hline & $n+n$. & $\mathrm{mm}$ & $n+m$. & $\mathrm{mm}$ & $n-m$ & $\mathrm{~mm}$ & 1 & 2 & 3 & 4 & 1 & 2 & 3 & 4 \\
\hline $12,44,40$ & $14-5$ & 4394 & $3-8$ & 1118 & $6-5$ & 1956 & 6 & 4 & - & - & 8 & 6 & - & - \\
\hline $\begin{array}{c}50,51,53 \\
55,57\end{array}$ & $14-5$ & 4394 & $3-8$ & 1118 & $6-11$ & 2108 & $\theta$ & 6 & 6 & - & 8 & 6 & 4 & - \\
\hline $61,63,65$ & $14-11$ & 4546 & $4-6$ & 1372 & $8-1$ & 2464 & 8 & 6 & 6 & 6 & 10 & 8 & 6 & 6 \\
\hline $71,72,73$ & 14-11 & 4546 & 50 & 1524 & $8-10$ & 2692 & 10 & 8 & 8 & 6 & 10 & 8 & 6 & 6 \\
\hline$\pi, \pi, \pi$ & $14-11$ & 4546 & $5-0$ & 1524 & $0-10$ & 2692 & 12 & 8 & 8 & 6 & 12 & 10 & 8 & 6 \\
\hline
\end{tabular}

Figure 4.9 Recent Model of Liquid Open Centrifugal Chiller Manufactured by the Carrier Corporation (for comparison with hermetic centrifugal chiller shown in Figure 4.8) (Permission to use this copyrighted material is granted by the Carrier Corporation.) 


\section{Operating Experience Database Evaluation}

The results of evaluating chiller operating experience from databases traditionally reviewed in NPAR studies are provided in this section of the report. A small portion of the data in the tables included information on alternative types to centrifugal chillers. The chiller failures listed were significant enough to cause the chiller to break down or shut down.

\subsection{Licensee Event Reports Database}

A Summary of the Chiller Licensee Event Reports (LERs) is given in Appendix C. The summary covers 1981 through 1991. The LERs were compiled from the Sequence Coding and Search Systems (SCSS), the Nuclear Documentation System (NUDOCS/AD), and Regulatory Information Distribution System (RIDS) databases. Some of these items (11) are common to the Nuclear Power Experience (NPE) database items discussed later. The results of the evaluation of chillerrelated failures are summarized in Table 5.1.

The largest number of failures (16) were electrical control component failures. Mechanical and electrical control component failures (28) represented about $44 \%$ of the total failures. Electrical component-related failures (28) occurred about twice as often as those failures which were believed to be mechanical componentrelated (14). Of the listed failures there were at least 5 non-aging-related failures. Three were failures due to human error, and one each was due to a manufacturing defect and use of a seal made of the wrong material. The balance of the failures were due to a combination of age- and/or non-age-related degradation. Insufficient detail was available to determine the quantity of just the age-related failures. Accelerated degradation may have occurred due to a combination of design, manufacturing, operating, and maintenance errors coupled with aging. Many LERs that reported chiller trips were not included because the events were caused by condenser cooling water system failures (e.g., filter, strainer, pump, and valve failures; plugging, air injection, undersize, etc., of cooling water piping).
Of the listed failures that stopped the chiller, three occurred outside the chiller boundary in the cooling water supply system.

\subsection{Nuclear Power Experience Database}

Information from the Nuclear Power Experience (NPE) database search is provided in Appendix D of this report. The information covers 1978 through 1990 . The chiller failures are summarized in Table 5.2.

The largest number of failures (9) again occurred with electrical components. Mechanical and electrical control component failures (19) represented about $26 \%$ of the total failures. Electrical component-related failures (17) occurred about twice as often as those failures that were believed to be mechanical component related (9). The total number of failures listed in Table 5.2 was 73 , and all were partially or totally age-related.

There were at least 12 non-aging-related failures that were not listed in Table 5.2 because the event description was too general. Three were failures due to human error, four were due to inadequate procedures, four were due to inadequate cooling capacity (facility design), and one was due to inadequate refrigeration load (equipment and facility design).

\subsection{In-Plant Reliability Data System Database}

A list of the chiller failures reported in the In-Plant Reliability Data System (IPRDS) database is given in Appendix $E$ of this report. This information is from a single nuclear power plant called Plant $A$. The plant essential chillers are identified as Chillers $1 \mathrm{~A}$ and $1 \mathrm{~B}$. These data cover about the first 5.5 years of operation at the plant. 
Operating Experience Database Evaluation

Table 5.1. Summary of Chiller Failures in the LER Database

\begin{tabular}{lc}
\hline \multicolumn{1}{c}{ Failure Description } & Number of \\
\hline Water Leak & 1 \\
HX Tube Fouling & 1 \\
HX Tube Plugging & 1 \\
Inadequate Cooling Water & 4 \\
Service Water Component Failure & 1 \\
Lubrication Oil Leak & 3 \\
Refrigerant Leak & 5 \\
Refrigerant Plugging & 2 \\
Open Motor Bearing Failure & 1 \\
Mechanical Component Failure & 2 \\
Mechanical Control Component Failure & 7 \\
Electrical/Mechanical Control Component Failure & 5 \\
Electrical Control Component Failure & 16 \\
Electrical Component Failure & 7 \\
Motor Starter Failure & 1 \\
No Failure Cause Determined & 7 \\
Total Failures & $64^{1}$ \\
\hline
\end{tabular}

${ }^{1}$ Some of the LERs listed multiple failures.

The failure data for the essential chillers are summarized in Table 5.3.

The category showing the most failures for Plant A was for electrical control component failures (25). That was also the largest failure category for the LER data in Table 5.1. The next largest failure category was lubrication oil leaks (20), which with lubrication oil plugging (7) made up about $25 \%$ of the total failures. The balance between mechanical component-type failures and electrical component failures was about the same. Of the failures shown in Table 5.3, the non-age-related failures totaled four. Three were due to human error and one was due to manufacturing error. The rest of the failures were a combination of aging and non-aging failures with insufficient detail available for further analysis. The failure ratio of about 10 failures per chiller per year appears abnormally high. The number of service hours each chiller had is unknown. 
Table 5.2. Summary of Chiller Failures in the NPE Database

\begin{tabular}{|c|c|}
\hline Failure Description & $\begin{array}{l}\text { Number of } \\
\text { Occurrences }\end{array}$ \\
\hline Water Leak & 1 \\
\hline HX Tube Fouling & 1 \\
\hline HX Tube Plugging & 0 \\
\hline Inadequate Cooling Water & 4 \\
\hline Service Water Component Failure & 0 \\
\hline Inadequate Chilled Water Flow & 6 \\
\hline Lubrication Oil Leak & 1 \\
\hline Lubrication Oil Plugging & 1 \\
\hline Lubrication Oil Excessive to Evaporator & 2 \\
\hline Refrigerant Leak & 7 \\
\hline Refrigerant Plugging & 0 \\
\hline Open Motor Bearing Failure & 0 \\
\hline Loose Parts Damage & 4 \\
\hline Mechanical Component Failure & 5 \\
\hline Mechanical Control Component Failure & 4 \\
\hline Electrical/Mechanical Control Component Failure & 7 \\
\hline Electrical Control Component Failure & 8 \\
\hline Electrical Component Failure & 9 \\
\hline Spurious Electrical Parameter & 3 \\
\hline Thermostat out of Calibration & 2 \\
\hline Switch or Valve out of Adjustment & 4 \\
\hline Motor Starter Failure & 0 \\
\hline Low Environmental Temperature & 1 \\
\hline No Failure Cause Determined & $\underline{3}$ \\
\hline Total Failures & $73^{1}$ \\
\hline
\end{tabular}

${ }^{1}$ Some of the occurrences listed multiple failures. 
Operating Experience Database Evaluation

Table 5.3. Summary of Plant A Essential Chiller Failures

\begin{tabular}{lccc}
\hline & \multicolumn{2}{c}{ Number of Occurrences } \\
\cline { 2 - 4 } \multicolumn{1}{c}{ Failure Description } & Chiller 1A & Chiller 1B & Total \\
\hline Water Leak & 1 & 4 & 5 \\
HX Tube Leak & 0 & 1 & 1 \\
HX Tube Fouling & 4 & 0 & 4 \\
HX Tube Plugging & 2 & 2 & 4 \\
Service Water System Failure & 0 & 1 & 1 \\
Chilled Water System Failure & 1 & 0 & 1 \\
Lubrication Oil Leak & 12 & 8 & 20 \\
Lubrication Oil Plugging & 5 & 2 & 7 \\
Refrigerant Leak & 7 & 3 & 10 \\
Mechanical Component Failure & 1 & 2 & 3 \\
Mechanical Control Component Failure & 1 & 1 & 2 \\
Electrical/Mechanical Control Component Failure & 6 & 4 & 10 \\
Electrical Control Component Failure & 14 & 11 & 25 \\
Electrical Component Failure & 6 & 7 & 13 \\
No Failure Cause Determined & 1 & 2 & 3 \\
Total Failures & 61 & 48 & 109 \\
\hline
\end{tabular}

\subsection{Nuclear Plant Reliability Data System Database}

The Oak Ridge National Laboratory search for chiller events found no records in the Nuclear Plant Reliability Data System (NPRDS) database. 


\section{Other Operating Experience}

\subsection{Pacific Northwest Laboratory Experience}

A total of seven liquid hermetic centrifugal chillers are used to cool Pacific Northwest Laboratory (PNL)

HVAC facilities. Five of the chillers are cooled by river water from an evaporation pond and two are cooled by well water from cooling towers. The chillers range in size from 185- to 450-ton capacity. Some of the chillers serve laboratories where temperature control is critical.

To ensure the reliability of the chillers, PNL contracts with experienced service companies that perform major overhauls and condensor tube eddy current testing activities. A maintenance program was established about 12 years ago to improve maintenance practices and reduce equipment neglect. The service company selected was considered the best available. They have used the same service personnel, so the history of the chillers can be monitored, problems can be anticipated, and service life improved. The PNL maintenance staff has been trained to monitor the chillers daily and to make all the minor repairs. Only the service company does major repairs inside the refrigerant boundary. Major overhauls are performed on the schedule recommended by the manufacturers. Because of good routine maintenance practices and equipment monitoring, it appears that the time between overhauls can be increased. The condenser tubes are cleaned annually and eddy current tested periodically by specialty service companies. The condenser performance has improved and little degradation of tubing has been observed.

Only one major failure in one machine has caused unscheduled downtime. The failure occurred in a $1.3-\mathrm{cm}$ ( 0.5 -inch) stcel pipe that broke due to vibration fatigue. The root cause was a lack of adequate pipe support. During overhauls the main tasks are to inspect the components and replace or repair them if needed. The only major repair required for a PNL chiller was to rebuild the labyrinth seal and impeller tips where some unexpected wear occurred. The seals, gaskets, filters, etc., are routinely replaced during overhauls. The entire refrigerant system is scrupulously cleaned to ensure all dirt, moisture, etc., are removed before the system is resealed. Overhauls are recommended at either 3- or 10. year intervals by the major centrifugal chiller manufacturers. Some of the machines have been upgraded with more modern purging units to remove moisture, noncondensable gases, etc., from the refrigerant system.

The equipment temperatures, pressures, and other indicated operating parameters are monitored daily. Samples of the lubrication oil are routinely analyzed. Using the same well-trained maintenance and service company staff has been an asset in achieving an excellent perform. ance record for the chillers. Conscientious management and supervision of chiller maintenance have also contributed to the performance.

\subsection{Westinghouse Hanford Company Experience}

The 337 Building has two 250-ton liquid hermetic centrifugal chillers that are cooled by treated river water from a cooling tower. The condenser cooling water has not caused problems. The chilled water system, which uses an ethylene glycol/water mixture, has also been problem-free.

The main problems have been with electrical and mechanical control components damaged by vibration and overheating of components in the motor control center cabinet. Major maintenance has been difficult in the past because plant forces are used. Human errors have been made, which caused subsequent failures. Recently, increased staff training has reduced problems and failures.

The cooling tower capacity for the chillers is undersized. This is a continuing difficult situation for the management of chiller control. There are times when compressor surging is prevalent.

The Fast Flux Test Facility (FFTF) reactor has eight 400-ton chillers that serve a variety of service functions. The chillers are hermetic centrifugal type. Both the 
chilled water and cooling water systems are closed, and they use glycol/water. There has been virtually no corrosion of the HX tubes or tube fouling. The original water came from on-site wells.

There have been no major failures except one, which was due to human error when one of the chillers was new. A main bearing near failure was discovered during an overhaul. The time between overhauls was reduced from 17,000 operating hours to 8000 hours, and no major problems have occurred since then. The overhauls are performed by a regional service company, and they have done an excellent job. FFTF management is satisfied knowing full-time overhaul experts are taking care of their equipment, which results in more reliable operations. The FFTF maintenance personnel are well trained and have good procedures that they follow for routine and minor maintenance work.

Most component failures result from vibration. Many of the failures are considered a nuisance. Indicator lamp bulb and terminal and wire connector damage are examples of vibration-induced failures that do not necessarily cause a chiller to shut down. FFTF maintenance estimates that about a third of the failures are electrical and the balance are mechanical. Repeated vibration damage to items like timers, cam switches, and relays could be reduced if the control cabinets were updated to the state-of-the-art.

Most of the vibration occurs because the chillers are often operating at partial or low loads. Vibration problems become more severe when operating below $25 \%$ capacity. Even though the equipment is rated for $10 \%$ capacity, operation at this level becomes intolerable duc to changing conditions. Sur ging becomes prevalent at the lower capacities. Ideally, FFTF would like to run the chillers continuously at full capacity, because they run smoother and do not have as many component failures.

\subsection{Regional Service Company Experience}

An expert consultant, Tom Camp of Landis \& Gyr Inc., provided insights into failure and failure causes. He has spent about 25 years trouble-shooting, overhauling, and doing major repairs on centrifugal chillers while working for service companies. He has serviced nonnuclear-related commercial chillers throughout the Pacific Northwest. Since he began servicing the PNL chillers, they have improved and had outstanding reliability. He helped train PNL staff to care for the chillers.

Based upon his experience, he made the estimates and observations listed below.

The general causes for chillers to completely fail are as follows:

\begin{tabular}{|c|c|c|}
\hline Failure Cause & $\%$ Failures & Comments \\
\hline Design & 1 & $\begin{array}{l}\text { Poor use of design } \\
\text { performance history }\end{array}$ \\
\hline Manufacturing & 3 & $\begin{array}{l}\text { Poor replacement } \\
\text { parts, packaging, } \\
\text { drawings }\end{array}$ \\
\hline Installation & 11 & $\begin{array}{l}\text { Lack of coordination } \\
\text { and instruction }\end{array}$ \\
\hline $\begin{array}{l}\text { Component } \\
\text { Aging Failures }\end{array}$ & 5 & $\begin{array}{l}\text { Friction, heat, non- } \\
\text { serviceable } \\
\text { component }\end{array}$ \\
\hline $\begin{array}{l}\text { Lack of } \\
\text { Monitoring and } \\
\text { Maintenance }\end{array}$ & 60 & $\begin{array}{l}\text { Poor O\&M manage- } \\
\text { ment and apathy }\end{array}$ \\
\hline $\begin{array}{l}\text { Human Error } \\
(O \& M)\end{array}$ & 15 & $\begin{array}{l}\text { Carelessness and } \\
\text { uncleanliness }\end{array}$ \\
\hline Other & 5 & Misapplication \\
\hline
\end{tabular}

The greatest cause of failure is lack of monitoring and inadequate routine maintenance. Monitoring and maintenance steps that will significantly help reduce the number of failures are as follows:

- Control the water quality supplied to the condenser and evaporator.

- Routinely analyze lubrication oil to ensure correct chemistry. 
- Routinely analyze refrigerant to ensure correct chemistry/need based upon results of lubrication oil analysis.

- Perform eddy current, non-destructive testing (NDT) on the tubes to monitor corrosion, etc.

- Periodically examine tubes; clean if necessary on a schedule.

- Periodically perform vibration analysis using same equipment.

- Heat-scan the electrical components with infrared temperature-sensing instruments.

- Visually inspect and record gauge readings on a daily basis.

- Record daily readings on trending charts. Analyze the trend and take immediate corrective action if the trend becomes adverse.

- Perform all routine maintenance and service per manufacturer's instructions.

- Annually service and test components to determine/ ensure reliability. Field strip motor control and starter contacts, change oil and filters, service purge/ dehydrator unit, change drier, run operation and safety control tests, inspect $\mathrm{HX}$ tubes for fouling and corrosion, etc.

- Periodically (3 to 10 years) overhaul and inspect all wearing parts (using an interval based on the shortest life of the materials) within the chiller (typically the O-rings, gaskets, and carbon seals).

- In all cases, cleanliness and care are most important.

The components that most commonly fail, primarily due to age-related degradation, are

- pressure switches

- temperature switches

- relays
- flow switches

- gaskets and O-rings (external leaks).

The components which less commonly fail, primarily due to inadequate lubrication, chemical attack, maintenance, and age, are the following:

- bearings

- tubes

- guide vane

- oil relief valve

- oil pump

- seals

- expansion device

- float valves

- agitator

- minimum head control

- purge unit

- motor control center

- motor.

The following stressors and aging mechanisms are encountered by chillers:

- vibration (normal and excessive due to unbalance, misalignment, and low loads)

- excessive heat

- excessive pressure

- moisture

- dirt and contamination

- non-condensable gases (air, etc.) 
- corrosion

- tube freeze-up

- mineral contamination

- biological attack and growth

- flow erosion

- external environment (temperature, humidity, fumes, etc.), especially at damaged flanges, joints, and electrical control and wiring

- friction and wear

- thermal cycling

- misalignment

- start-up torque

- frequent starting/stopping.

\subsection{Cooperating Utility Experience}

Direct contact was made with one NPP to tour the plant and discuss chiller performance. A copy of the maintenance request data system was received for two nonessential chillers. The essential chillers are used only for emergency situations as back-up to service water. The only major problem incurred by the essential chillers was that one chiller had its tubes freeze up due to human error.

The plant is relatively new and only about 4 years of operating experience were available.

The summary of work requests for the non-essential chillers is presented in Appendix F of this report. Most of the activity was related to start-up and upgrade work. The following items were most notable:

- Thirteen tubes in the condenser and evaporator of Chiller 1A had to be replaced. The tube holes in the tube sheets had to be repaired. Crevice corrosion normally caused by excess moisture and subsequent vibration failure is suspected.

- Both units had the same manufacturing defect. The lubrication oil pump solenoid valves were installed backwards. The manufacturer determined that all 22 of the units for that model had the same problem. Both valves had to be replaced ultimately. Earlier oil jet pump problems were probably related to the valve being 180 degrees out of phase.

- A new mist eliminator had to be installed in Chiller $1 \mathrm{~A}$, which was probably related to excess moisture in the refrigerant.

\subsection{Experience from Literature Reviews}

Examples of age-related failures/causes that occur in chillers were compiled from a literature review. Surpr usingly, the discussion of aging and failures in the literature was sparse for such a large industry. There apparently is no database available for the HVAC or nuclear industries to document and compile failure/ cause data. The list of major types of failures/causes is outlined below.

\section{Major Age-Related Failures/Causes}

Excessive moisture in the refrigerant can cause many problems in the chiller (Traver 1976; ASHRAE 1990). When the amount of moisture exceeds the refrigerant saturation level (only a few ounces in 1000 pounds of refrigerant), the free water reacts with the refrigerant to form hydrochloric and hydrofluoric acid. The acid attacks crevices between the tubes and tube sheet. Combined with vibration of the tubes, especially from boiling refrigerant in the evaporator, the tubes widen the annulus and ultimately fail, allowing water entry to shut down the chiller and expose the entire system to water. Other degradation that occurs as a result of the acid attack includes the following:

- Acid contamination of the lubrication oil causes attack of the bearing surfaces. 
- The compressor inlet guide vane assembly can corrode and bind.

- Motor failure can result from insulation breakdown in hermetic units.

- The purge float valve can get stuck due to bearing and pivot corrosion.

- The condenser and economizer float valves can similarly fail.

- Shell scaling can cause clogging between tube fins, between tubes, and in the mist eliminators. Subsequently, the scale hardens to restrict heat transfer and flow of the refrigerant.

- Copper chloride deposits on upper tubes are caused by the wetting/unwetting process. These deposits reduce heat transfer and have hygroscopic properties that make removal of water difficult.

Tube fouling and corrosion can cause eventual chiller shutdown due to reduced heat transfer or tube failure (Banta 1974; Leitner 1980; Blake 1977; Alger 1977; Starner 1976).

Tube clogging can occur if the condenser water is not filtered, treated, and controlled at the cooling tower or source (Barber 1983).

Non-condensable gases, such as air, get in the machine and raise the condenser pressure. This, in turn, raises the compressor's load and requires more power (Barber 1983). In addition, air can accumulate at the top of the condenser and combine with the refrigerant to drastically reduce heat transfer (Webb 1986; ASHRAE 1989).

Vibration can ultimately cause seals, gaskets, pipe joints, nnd fittings to fail and allow leakage of the refrigerant. Moisture and air can also enter the previously sealed system by the same route (Esslinger 1988; ASHRAE 1991).

The complete American Nuclear Society (ANS) Transactions Summary (Christie and McDougald 1992) of a paper presented in June 1992, is included in Appen$\operatorname{dix} \mathrm{G}$ of this report. The plant reliability analysis indicated that safety-related chillers fail three times as often as non-safety-related chillers at the River Bend nuclear power plant. The authors felt that the difference in reliability is due to the more stringent control requirements imposed on the safety-related chillers. The information needs to be examined more closely.

NRC Notice $85-89$ was addressed primarily at the potentia! loss of solid-state instrumentation following failure of control room cooling. The incident resulted in numerous spurious alarms. Previously the same plant had experienced similar behavior and numerous component failures and degradation due to high temperatures in control cabinets. The licensee had previously reported that their chillers develop oil level problems when loaded at less than full capacity. The heat load calculated during plant design was too large compared to the actual heat load resulting in oversized chillers.

The question "When does the final chiller failure occur?" is not an easy one to answer because there are many variables to consider. An extensive survey of building owners and managers was conducted (Akalin 1978). The results indicate that centrifugal chillers usually have a life of 20 to 30 years with a mean value of 23 years. The ASHRAE Handbook estimates the service life of centrifugal chillers at 23 years, but practical use for 30 to 40 years has been realized when the equipment is properly maintained (Calm 1992). The PNL consultant indicated that the major components of a chiller will last well beyond 40 years if they are properly cared for and maintained. Chillers up to 60 years old are in continuous use today. Most chillers fail and are replaced due to a lack of maintenance and monitoring. Other causes for replacement of chillers include obsolescence due to

- change of heat load (usually growth)

- energy efficiency improvements

- incompatibility with new refrigerants (result of new regulations)

- efficiency loss

- design of components

- aggressive nature of new refrigerants. 
Centrifugal chillers have motors that are not designed to be turned on and off frequently. Rapid cycling will lead to motor and starter failure. The only safe way to limit demand for a centrifugal chiller is by modulating the compressor's pre-rotation vanes, which control the capacity of the chiller. When the modulation is done, it is critical that it be done gradualiy. If not, surging of the compressor can occur, resulting in serious damage (Gorzelnik 1977). Prolonged operation in a surging mode is likely to damage the entire chiller, as well as the compressor. Surging loads and unloads the motor about every 2 seconds so that the motor current varies markedly (Ball 1987). Surging deteriorates performance and heavily stresses the thrust bearings. Surging is most likely to occur at the lower end of the chiller capacity range. Chiller manufacturers claim that their units can unload down to $10 \%$ of design loading, but one must remember that low load operation is conditional upon having lower condenser temperatures (Harmon 1991). 


\section{Operating Experience Summary and Discussion}

Review of the databases and literature in Sections 5 and 6 indicated general information on chiller failures experienced during plant operations. Details were limited and difficult to analyze from strictly an aging standpoint. Also, not all of the chiller-related LERs, LCOs, and chiller failures have been found and included in the results of this study. For example, consider the numerous failures that occurred in the single Plant $\mathrm{A}$. Most of those failures caused an essential chiller to trip. But few, if any, of the Plant A failures are contained in the L.ER or NPE databases. Considerably more time than a Phase I study would be required to get comprehensive failure data for each plant and consequently all of the plants. More specific information from additional plants will be sought for detailed aging analyses in the Phase II portion of the study.

The information shown in Figure 7.1 summarizes the quantities and failure areas from the LER and NPE databases. Duplicate failures were removed for this summary. Only failures that caused the chiller to shut down were included. About $11 \%$ of the failures were partially caused by flow rate variations in the cooling and chilled water systems and partially by the chiller condition (e.g., chiller fouling, load and capacity limitations, entrance strainers, etc.). Condenser/evaporator failures were only about $3 \%$ because most of the age degradation occurs gradually, maintenance access is usually easier, and it is handled during scheduled downtime. The refrigerant/lubrication oil system-related failures accounted for about $15 \%$ of the failures. About $17 \%$ of the failures were mechanical and mechanical control related. Electrical/mechanical control components caused about $9 \%$ of the failures. Electrical and electrical control components made up about $30 \%$ of the failures. Misadjustment and miscalibration resulted in approximately $8 \%$ of the failures, and the $7 \%$ balance

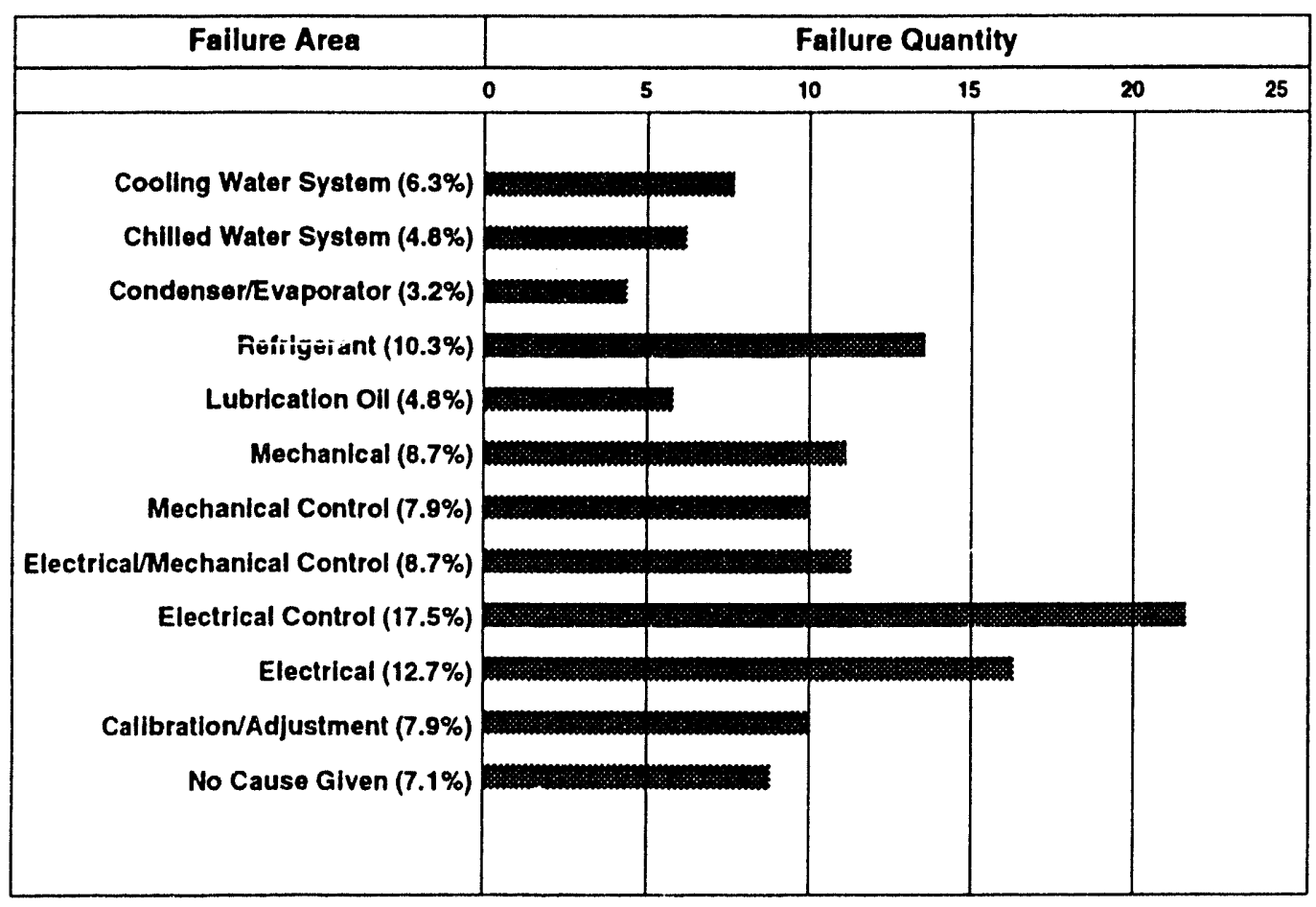

Figure 7.1 Summary of Chiller Failures (LER and NPE Databases) 
of failures was unknown. Nearly half of the failures were related to control components.

Using the same failure databases, an attempt was made to determine the degree to which failures were agerelated. The aging versus nonaging failures are illustrated in Figure 7.2 . About $81 \%$ of the failures were at least partially related to aging (time-related degradation). More detailed information would be needed to segregate the failures which were primarily or solely agerelated. About $12 \%$ of the failures were primarily due to design, manufacturing, installation, procedure, and human errors. The $7 \%$ balance of failures was unknown or unassignable.

All of the failures discussed above caused chiller trips and most of the failures caused LCO situations because one or both essential chillers were inoperable. Both chillers were inoperable 25 times and resulted in implementation of shutdown procedures. The LCOs were invoked for control rooms, ESF equipment rooms, and containment. At least five times the reactor power was reduced, and at least two plants had to be shut down. The exact number of LCOs, power reductions, and plant shutdowns that resulted from failed chillers is not known because of the limited information available to review. As demonstrated in Appendix F, some of the utilities are concerned about the LCO situation due to the unreliability and complexity of essential chiller systems.

The essential control room HVAC systems have increased complexity due to more interfacing systems than just the chillers. Numerous LCOs occur due to monitoring automatic actuation systems; e.g., radiation monitors, combustible gas detectors, chlorine detectors, loss of power, filter monitors, etc. There are many instances in which the control room HVAC system was erroneously switched to the emergency mode, and spurious detector faults were a major cause. Also, some control room LCOs are caused by failures in the chilled water system other than chillers (pumps, valves, piping, expansion tank, etc.).

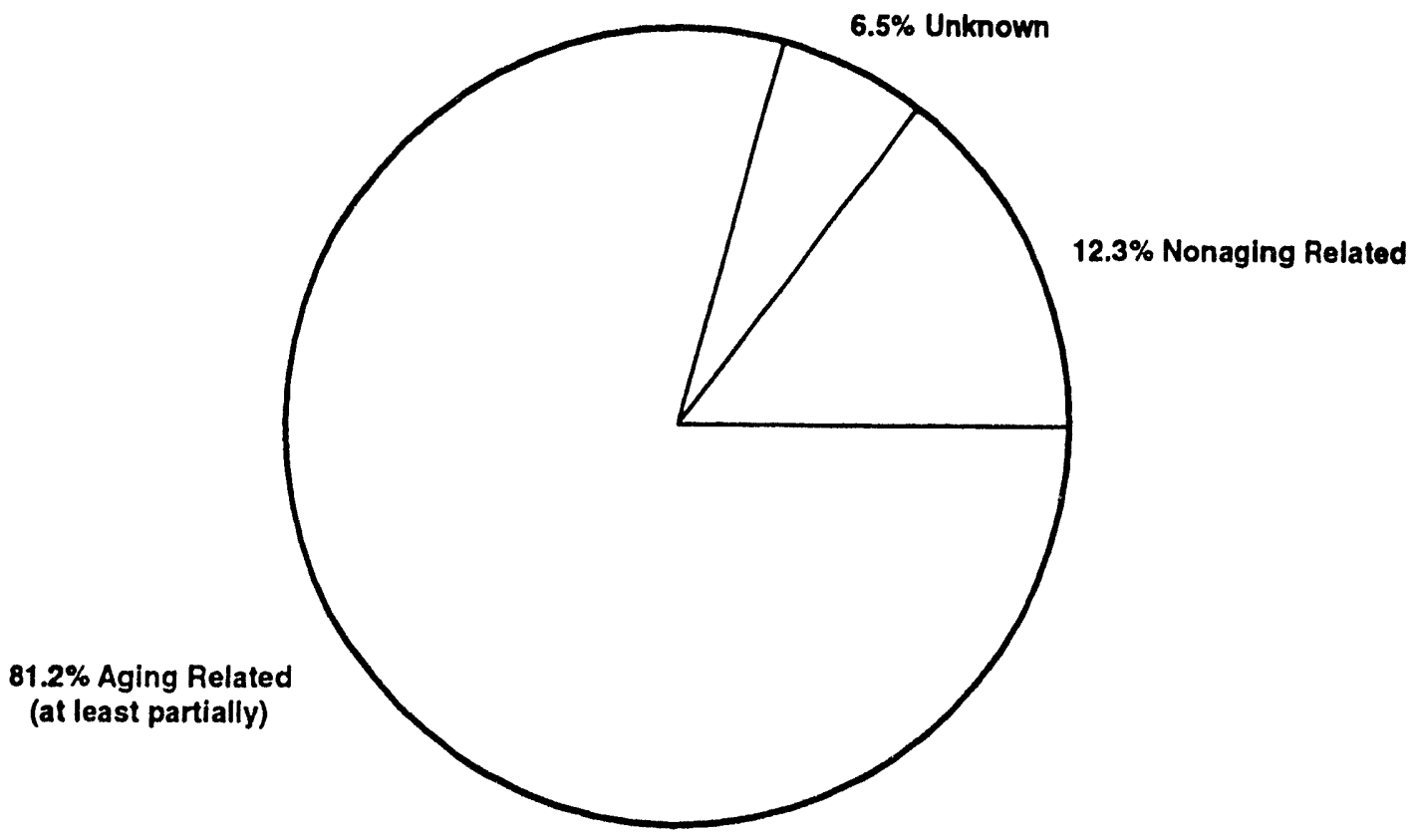

Figure 7.2 Aging Versus Nonaging Related Chiller Failures 
One step that might help to increase the LCO time limits associated with chiller failures would be to use a chill/ice storage system with a self-contained chiller that would provide 12 to 24 hours of extra buffer time before entering an LCO. The stored ice would provide a passive system for backup cooling. Numerous designs are available to provide such storage and additional backup chiller capability. The equipment could be located outside the control building. The back-up chiller could use air cooling rather than water cooling. The overall design, complexity, reliability, and practicality of such an additional system would have to be carefully reviewed for each plant. These systems have been employed primarily to reduce peak refrigeration power consumption in commercial buildings.

The review information indicated that preventing serious degradation of equipment in the control rooms and ESF rooms due to excessive ambient room temperatures is a concern. One plant had a maximum limit of $25^{\circ} \mathrm{C}$ $\left(77^{\circ} \mathrm{F}\right)$ for the control room temperature. Another plant had a limit up to $49^{\circ} \mathrm{C}\left(120^{\circ} \mathrm{F}\right)$. There is concern about high temperatures inside electronic cabinets, which can cause erroneous indications, alarms, etc., that can hinder control of the plant. Temperatures inside cabinets are much higher than the ambient room temperature. A cursory attempt to find data on the aging degradation of electronic components for various levels of temperatures, humidities, and vibration was not successful. Further research in this area is recommended, but will not be pursued through this program because that research is outside the scope of the chiller aging study.

The higher room ambient temperatures also cause discomfort for the personnel operating the reactor. In general, the comfort range is between $25 \%$ and $65 \%$ relative humidity and 22 to $26^{\circ} \mathrm{C}\left(72\right.$ to $\left.79^{\circ} \mathrm{F}\right)$ temperature. An operator's tracking skills, vigilance, and sustained attention become very sensitive with time when the temperature exceeds $30^{\circ} \mathrm{C}\left(86^{\circ} \mathrm{F}\right)$. Operators should not be exposed to temperatures above $35^{\circ} \mathrm{C}$ $\left(95^{\circ} \mathrm{F}\right)$ for a period of more than 1 hour. Very little other information was found about human factors tem. perature and humidity criteria for control room operators. It appears that more research should be performed to determine the effects of high temperatures upon personnel. Research in this area is also beyond the scope of the chiller study. 


\section{Conclusions}

It is apparent from this study that essential chillers, which are important to cool the control room and other safety-related equipment rooms, experience aging degradation. Chillers are integral equipment currently being addressed in regulatory issues of concern, which include Generic Safety Issue 143 and Generic Letter 89. 13. The cooling is needed to prevent degradation and failure of safety-related equipment, to protect safety personnel, and to prevent or mitigate events and accidents. Control of temperature and humidity in these rooms is very important.

The chillers used in the nuclear power plants are essentially the same as the ones used in other commercial and ind ustrial applications. The chillers are a relatively complex piece of equipment because of all the thermal and flow balances that need to be maintained. The essential safety-related chillers have more stringent standards and codes to meet. The basic equipment must meet seismic requirements which require some minor modifications to the components, structure, support base, and anchoring. The essential chillers have interfacing systems, often with complex interlocking controls. The analysis of chiller interfacing systems cannot be made generically because the systems vary from plantto-plant. Due to regulations, chillers need to be closely monitored and carefully operated and maintained. The essential chillers need to be afforded special care so they can be reliable and fulfill their safety role.

The review of operating experience indicated that chillers experience aging degradation and failures. The primary aging factors to be concerned about with chillers include vibration, excessive temperatures and pressures, thermal cycling, chemical attack, and poor quality cooling water. Aging is accelerated by moisture, noncondensable gases (e.g., air), and other contamination within the refrigerant containment system. Excessive start/stop cycling and under-loading of chillers can promote aging. Aging is also accelerated by corrosion and fouling of the condenser and evaporator tubes. The principal cause of chiller failures is lack of monitoring. It is important to record and trend on a daily basis the operating temperatures and pressure, and routinely analyze the lubricant oil and refrigerant chemistry.
Human errors and omission of scheduled maintenance also contribute to the failures. Failures due to design and manufacturing discrepancies usually occur during the original start-up, shakedown, or first year of operation for a particular new chiller model.

In the NPP data that was reviewed, the largest number of failures was related to electrical control component failures. Both electrical and mechanical control component failures represented almost half of the total failures. The lubrication oil system also had a relatively high failure rate. Most of the failures were at least partially age-related. Non-aging-related failures were a smaller number and were primarily the result of human error. Lack of monitoring is suspected to be the greatest contributor to both age- and non-age-related failures. The data available for evaluation was insufficient in detail to perform failure root cause analyses.

To minimize and eliminate most of the failures, the operators of chillers need to carefully follow stringent procedures and monitor equipment. Equipment performance must be recorded and trended on each shift or on a daily basis. The routine maintenance staff must be well-trained and careful. Major overhauls and maintenance that require entering the refrigerant containment region must be performed by careful, well-trained, and experienced technicians. It is preferable to use technicians who routinely overhaul chillers. A small amount of contamination or a damaged or misaligned part can cause major problems during operation of a chiller. It is crucial at all times to keep equipment internals very clean and prevent the leakage of water, air, and other contaminants into the sealed refrigerant containment system.

Periodic operation for a few hours on a weekly or monthly basis is necessary to remove moisture and noncondensable gases that gradually build up inside the chiller. A few hours of operation will help to provide the stable operation needed to evaluate the operating parameter performance, especially if the chiller is required to operate as an emergency standby unit. If multiple chillers are available, alternate operation of the chillers and balance the hours of use. Operate the 
Conclusions

chiller as close to $100 \%$ capacity as practical to minimize aging. Usually chillers are replaced due to lack of good monitoring and maintenance.

In-depth analysis of aging and non-aging failures will require close cooperation among the chiller industry, utilities, regulatory agencies, and researchers during the Phase II study. During the Phase I study it was difficult to obtain the detailed information that was needed to perform in-depth analyses of chiller aging. More detailed information will be sought during Phase II to address the root cause of failures; provide detailed information on current maintenance inspection, surveillance, and monitoring methods; and define current maintenance practices. 


\section{Recommendations}

The Phase I study determined that chillers play an important role in NPP safety. Chillers have been contributors to a number of serious safety events where plants had to reduce power or shut down. Some plant operators are concerned about a higher number of failures in the essential chillers than non-essential chillers. The operating experience reviewed so far indicates that chillers degrade and fail as a result of aging and other factors. It is recommended that a full-scale NPAR Phase II aging study be performed. Preliminary recommendations for improved operation, maintenance, and monitoring of chillers have been included in Sections 6.3 and 8 of this report. 


\section{References}

Akalin, M. T. 1978. "Maintenance Cost Survey." ASHRAE Joumal, October 1978, pp. 40-44.

Alger, J. 1977. "Treat Your Cooling Water to Cut Energy Consumption and Increase Production Output." Plastics Design \& Processing, April 1977, pp. 59-63.

ASHRAE. 1989. ASHRAE Fundamentals Handbook. American Society of Heating, Refrigerating, and Air Conditioning Engineers, Inc., Atlanta, Georgia.

ASHRAE. 1990. ASHRAE Refrigeration Handbook. American Society of Heating, Refrigerating, and Air Conditioning Engineers, Inc., Atlanta, Georgia.

ASHRAE. 1991. ASHRAE Applications Handbook. American Society of Heating, Refrigerating, and Air Conditioning Engineers, Inc., Atlanta, Georgia.

Ball, J. 1987. "A Micróprocessor Chiller Controller." Australian Refrigeration, Air Conditioning and Heating, April 1987, pp. 36-43.

Banta, V. E. 1974. "Continuous Cleaning Ups Chiller Performance." Power, June 1974, pp. 76-78.

Barber, J. 1983. "How to Improve Efficiency in Centrifugal Chillers." Energy, User News, March 7, 1983, Fairchild Business Newspaper Publishing, pp. 8-10.

Blake, R. T. 1977. "Correct Water Treatment Can Save Energy." Building Systems Design, April/May 1977, pp. 49-52.

Calm, J. M. 1992. "Alternative Refrigerants: Challenges, Opportunities." Heating/Piping/Air Conditioning, May 1992, Penton Publication, pp. 38-48.

Clark, E. M. 1991. "Retrofitting Existing Chillers with Alternative Refrigerants." ASHRAE Journal, April 1991, pp. 38-41.
Christie, R., and W. MiDougald. 1992. "Impact of Safety Requirements on Component Availability." In Proceedings from American Nuclear Society 1992 Meeting, June 7-12, 1992, Boston, Massachusetts.

Esslinger, S. 1988. "The True Cost of Refrigerant Leaks." ASHRAE Journal, November 1988, pp. 27-29.

Gorzelnik, E. F. 1977. "Load Controller Modulates Chillers." Electrical World, November 1, 1977, pp. 50-51.

Harmon, J. J. 1991. "Centrifugal Chillers and Glycol Ice Thermal Storage Units." ASHRAE Journal, December 1991, pp. 25-31

Leitner, G. 1980. "Controlling Chiller Tube Fouling." ASHRAE Journal, February 1980, pp. 40-43.

Levy, I. S., J. Wreathall, G. DeMoss, A. Wolford, E. P. Collins, and D. B. Jarrell. 1988. Prioritization of TIRGALEX - Recommended Components for Further Aging Research. NUREG/CR-5248 (PNL-6701), prepared for the U.S. Nuclear Regulatory Commission by Pacific Northwest Laboratory, Richland, Washington.

Niess, R. C. 1992. Selection of Large-Capacity Water Chillers in the 1990s. EPRI TR-100537s, prepared for the Electric Power Research Institute by Gilbert \& Associates, Gloucestor Point, Virginia.

Starner, K. E. 1976. "Effect of Fouling Factors on Heat Exchanger Design." ASHRAE Journal, May 1976, pp. 39-41.

Stebbins, W. L. 1991. "Implementing an Effective Utility Testing Process: A Keystone for Successful Energy Management." In Proceedings of IEEE Annual Textile, Fiber, and Film Industry Technical Conference, Greenville, South Carolina, pp. 1-11. 
References

Traver, D. G. 1976. "Saddle Damage of Cooler Tubes." ASHRAE Journal, March 1976, pp. 46-52.

U.S. Nuclear Regulatory Commission (USNRC). 1991. Nuclear Plant Aging Research (NPAR) Program Plan. NUREG-1144, Rev. 2, Washington, D.C.
Webb, R. L. 1986. "Gas in Refrigerant Condensers." ASHRAE Journal, May 1986, p. 52. 
Appendix A

LWR Plant Chiller Systems Description (FSAR Data) 
Appendix A

\section{Appendix A}

\section{LWR Plant Chiller Systems Description (FSAR Data)}

This appendix contains a summary of chiller information found by reviewing final safety analysis reports (FSARs) of U.S. NPPs. Information on plant chillers was not found in many of the FSARs. Some of the FSARs reviewed at PNL were not completely up-todate. However, it is believed that this information is sufficient to be a representative sample of typical NPP systems served by chillers in the United States. 
Appendix A

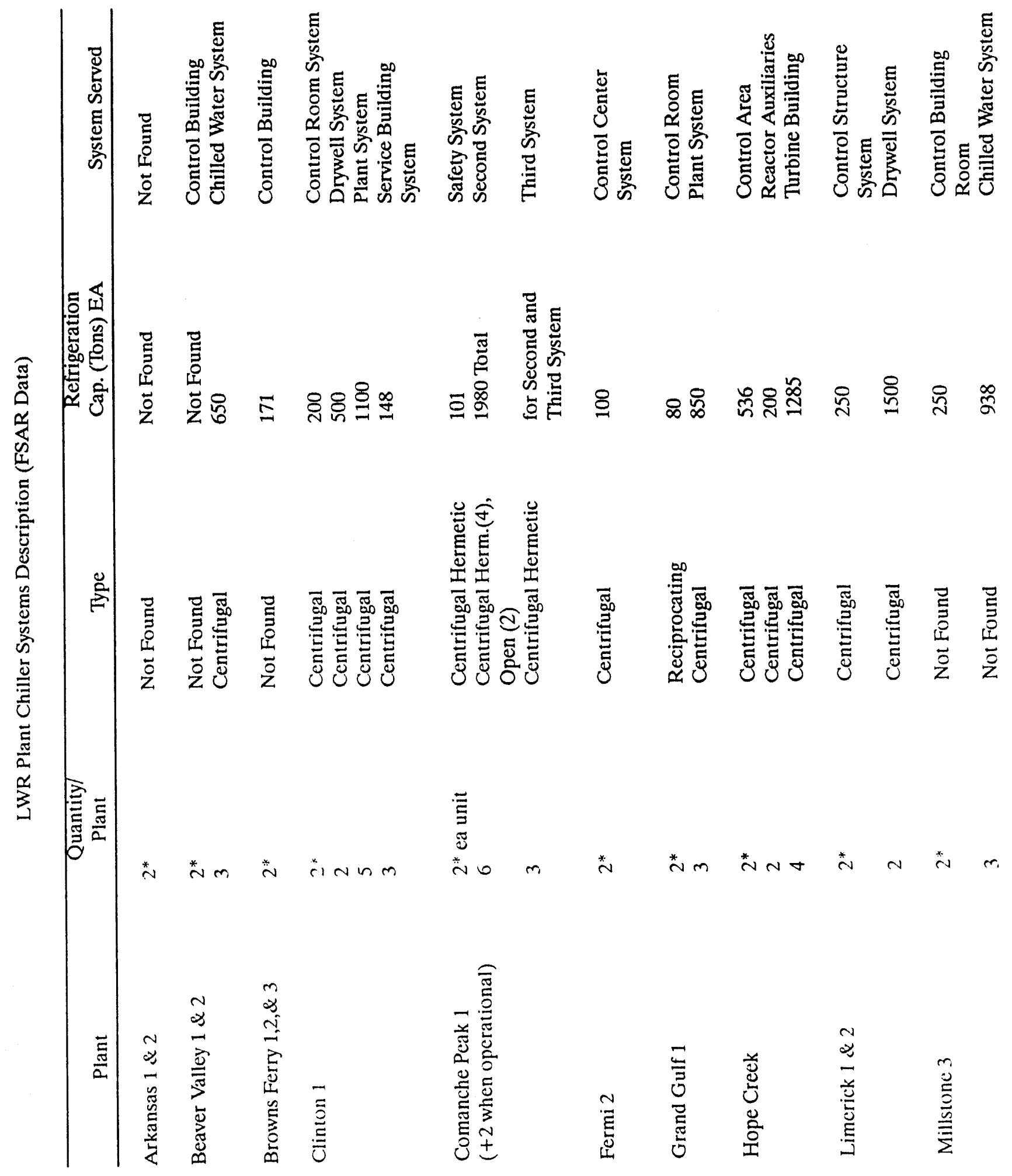


Appendix A

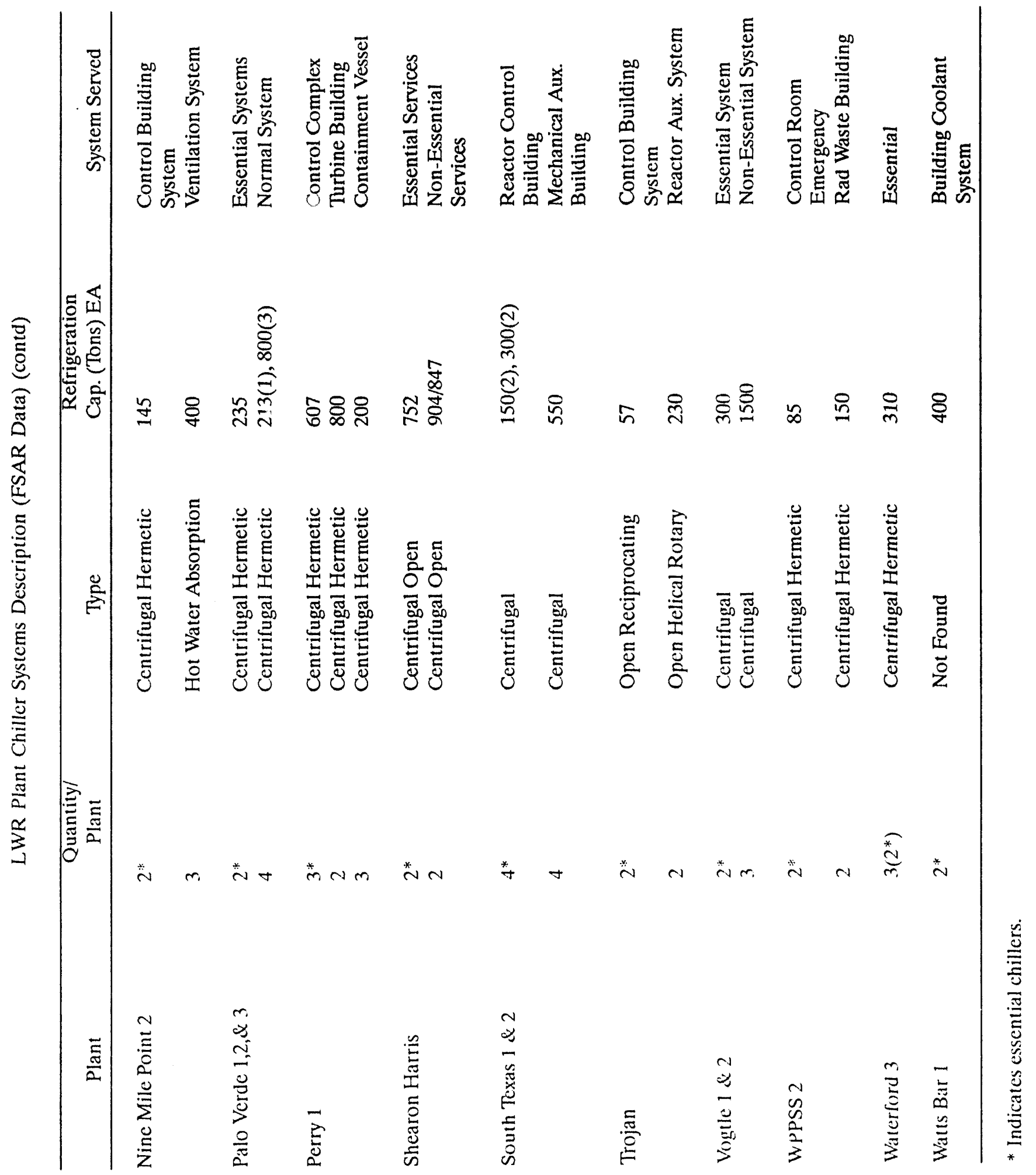


Appendix B

Hermetic Centrifugal Chiller Functional Description 


\section{Appendix B}

\section{Hermetic Centrifugal Chiller Functional Description}

This appendix describes how components in a hermetic centrifugal chiller function. It illustrates the refrigeration, motor cooling, and lubrication cycles that occur in an operating chiller and how the mechanical components interact. The description is from pages 17 to 19 of the Carrier Corporation's Operations and Maintenance Instruction manual for their model 19FA chiller (Form 19FA-1SO - courtesy of the Carrier Corporation). 
Appendix B

\section{GENERAL DATA}

Machine Nameplate is located on the cooler support foot at the suction end of the machine. Always give machine model, serial number.and name of owner in corresponding with Carrier.

Compressor Nameplate is mounted on the compressor support foot on the suction end of the compressor adjacent to the oil pump.

System Components include cooler, condenser, economizer, motor-compressoz and machine control center. A storage tank for the full refrigerant charge forms the support for compressor and control center. Most machines are also supplied with a machine-mounted pumpout unit.

COOLER - A heat exchanger vessel in which flashing refrigerant picks up heat from, and therefore chills, the water (or brine) flowing thru its tubes.
CONDLNSLR $-\Lambda$ licat exchanger vessel in which heat is removed from compressed refrigerant and is carried out of the system.

ECONOMIZER - A vessel at intermediate pressure between cooler and condenser which returns "Nash gas" to the compressor for greater cycle efficiency. MOTOR-COMPRESSOR maintains the necessary pressure differences in the system and moves the heat-carrying refrigerant from cooler to condenser.

CONTROL CENTER controls macline start and stop, regulates machine capacity as required, contains machine safety devices, indicates cooler, condenser and oil pump pressures and records machine operating hours.

STORAGE TANK supports machine components and provides a ready storage for the refrigerant charge during machine service periods and at extended shutdown.

PUMPOUT UNIT is used for refrigerant transfer, machine evacuation and machine pressurizing. 


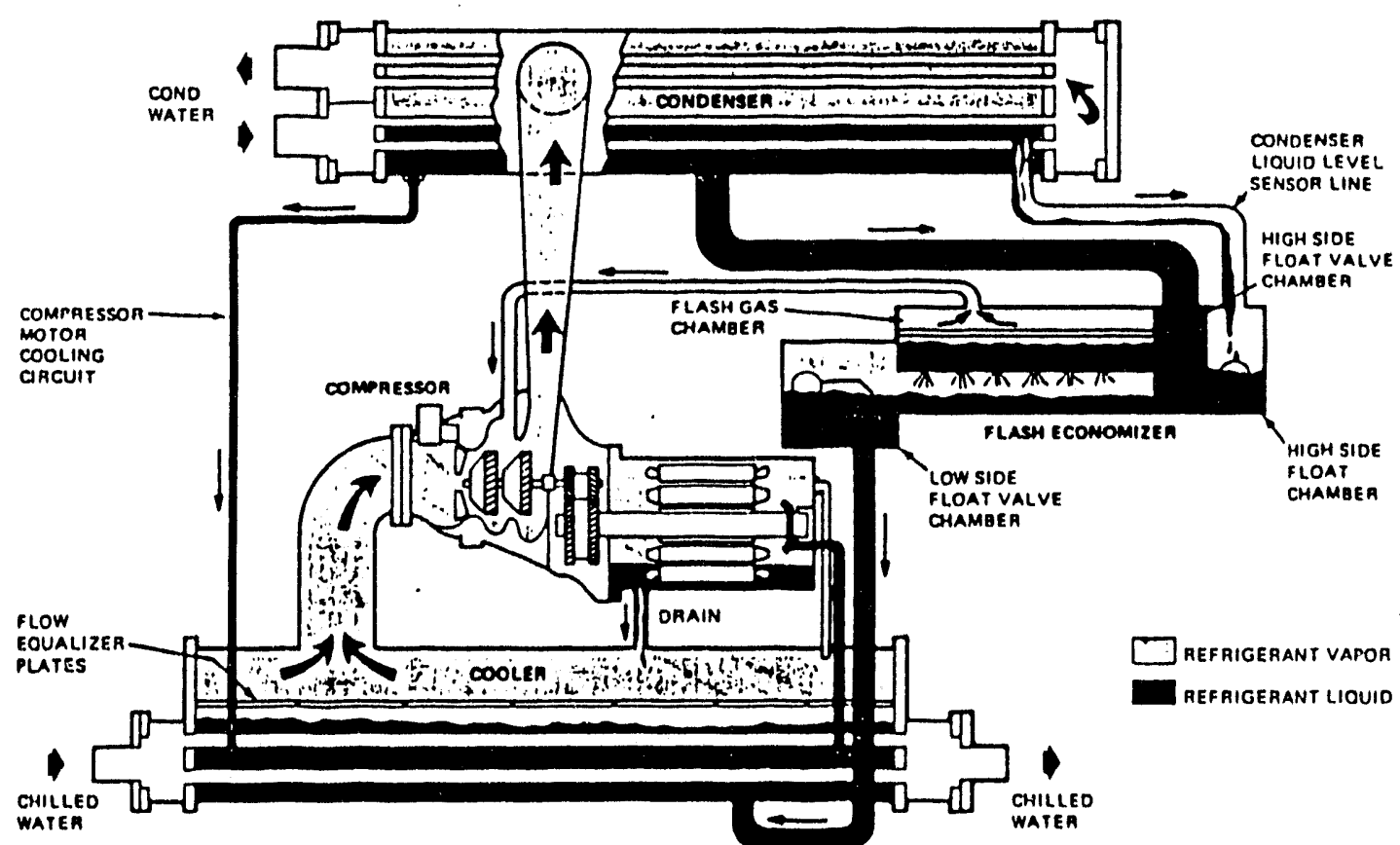

Fig. 12 - 19FA Refrigeration Cycle

19FA REFRIGERATION CYCLE

Will the exception of the thermal economizer, which is used on water chilling duty only, the basic refrigeration cycle described below is applicable to either water or brine chilling.

The machine compressor continuously Jraws large quantities of refrigerant vapor from the cooler, at a rate set by the amount of guide vane opening. This compressor suction reduces the pressurc witlin the cooler and ciluses the remaining refrigerant to boil vigorously at low temperature (typically 30 to $35 \mathrm{~F}$ ).

The energy required for boiling is obtained as lieat from the water (or brine) flowing thru the cooler tubes. With heat removed, the chilled water (brine) can then be used for air conditioning or for process liquid cooling.

After removing heat from the water, the refrig erant vapor passes thru the compressor first stage, is compressed and moves into the compressor second stage. Here it is mixed with flasheconomizer gas and is further compressed.

Compression raises the refrigerant temperature above that of the water flowing thru the condenser tubes. When the warm (typically 100 to $105 \mathrm{~F}$ ) refrigerant is discharged into the condenser, the relatively cool condensing water removes some of the lieat and the vapor condenses into a liquid. In water chilling machines, further removal of heat occurs in the thermal economizer at the bottom of the condenser. Here the liquefied refrigerant is subcooled by contact with the coolest (entering water) condenser tubes.

The liquid refrigerant drains into the Mash economizer where a valve system maintains pres. sure intermediate between the condenser and the cooler pressure. At this lower pressure, part of the liquid refrigerant flashes to gas, thus cooling the remaining liquid. The "Ilash gas" is returned directly to the compressor second stage. Here it is mixed will gas illeilly compressed by llic first stage impeller. Since the economizer gas his to pass thru only half the compression cycle to reach condenser pressure, there is a savings in power, lience the tcrm "cconomizer."

The cooled liquid refrigerant in the economizer is inetered thru the low-side nont clamber to the cooler. Because cooler pressure is lower than the economizer pressure, some of the liquid nashes and cools the remainder to cooler temperature. The cycle is now complete.

\section{FA MOTOR COOLING CYCLE}

Refrigerant liquid from a sump at the bottom of the condenser (Fig. 12) is subcooled by passage thru a line immersed in the refrigerant within the cooler. The lictuid then enters the compressor motor end where it sprays on and cools the compressor rotor and stator. It then collects in the base of the motor casing and drains back into the cooler. Refrigerant gas is vented from the compressor motor casing and returns to the upper 
Appendix B

portion of the cooler thru a check valve. Differential pressure between condenser and cooler maintains the refrigerant flow.

\section{FA LUBRICATION CYCLE}

General - The compressor oil pump and oil reservoir are located in the compressor base. Oil is pumped thru an oll cooler and a filter to remove heat and any foreign particles. Part of the oil now is directed to the compressor motor-end bearings and seal. The remaining now lubricates the compressor transmission, thrust and journal bearings and seal. Oil is then returned to the reservoir to complete the cycle (Fig. 13).

Lubrication Details - Oil is charged into reservoir (1) thru a liand valve (2) which also functions as an oil drain. If there is refrigerant in machine, a pump is required for charging. Sight glasses (5) on reservoir wall permit observation of oil level.

The motor-driven oil pump (6) discharges oil to an oil cooler (7) at a rate and pressure controlled by an oil regulator (8). The differential pressure (supply versus return) is registered on a gage at the machine control center.

Water flow thru the oil cooler is manually adjusted by a plug cock (9) to maintain the oil at an operating temperature, at the reservoir, of approximately $145 \mathrm{~F}$. During machine sliutdown, the oil temperature is also maintained at 140 to $150 \mathrm{~F}$ by an immersion heater $(10)$ so that absorption of refrigerant by the oil is minimized. OL FILTER 1 TEMPERATURE SHAFT OSPLACEMENT S SIZE COMPR - 2 REOD BRG (16) CONECTIONS (17) DEMST

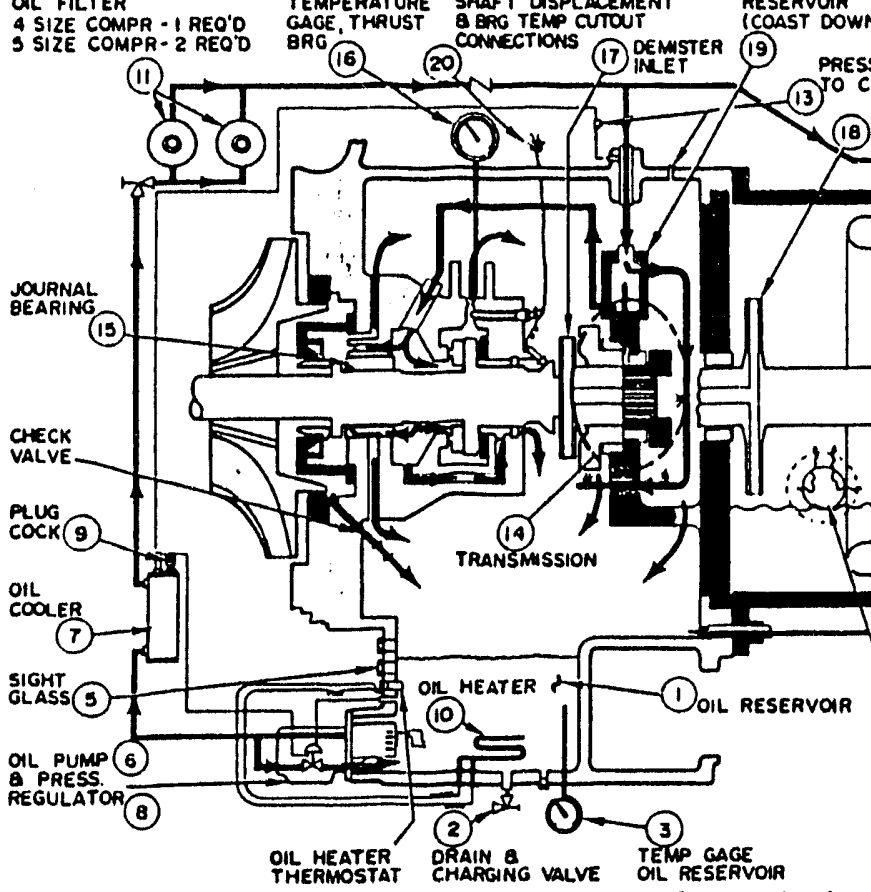

Fig. 13 - 19FA Lubrication Cycle
After it leaves the oil cooler, the oil is filtered (II) and a portion flows to the motor-end bearing (12) and seal. The remainder lubricates the compressor transmission (14) and the thrust and journal bearings (15). Thrust bearing temperature is indicated on a gage (16) mounted on the bearing inspection cover. Oil from eilcli circuit returns by bravily to llic reservuir.

A demister (17) and (18), by centrifugal action, draws refrigerant gas from the transmission area to the motor shell. The resulting pressure difference prevents oil in the transmission cavity from leaking into the motor shell.

Several safety devices monitor the lubrication system:

In the event of power failure, a sinall oil reservoir (19) supplies sufficient oil reserve to ensure continued lubrication until all compressor parts have come to a complete stop.

Solid state sensors (20) monitor motor-winding and bearing temperatures and shut off machine if temperature rises above a selected point.

Low-oil cutout (Fig. 14) shuts down machine or prevents start if oil pressure is not adequate.

A program timer in the machine control center ensures proper lubrication at start-up and at coastdown by energizing the oil pump for approximately 30 seconds before the compressor starts, and keeping the pump running for almost one minute after the compressor motor is de-energized. RESERVOIR MOTOR.END FROM (COAST DOWN)

PRESSURE CONNECTIONS CONTROL PANEL 
Appendix C

LWR Plant LER Review Summary 


\section{Appendix C}

\section{LWR Plant LER Review Summary}

This appendix contains a summary of LERs that were compiled using the Sequence Coding and Search Systems (SCSS), NUDOCS/AD database, and NRC staff sources. Some of these items are redundant with the NPE database. 
Chiller LER Review Summary

\begin{tabular}{|c|c|c|c|c|}
\hline LER & Plant & $\begin{array}{l}\text { Event } \\
\text { Date }\end{array}$ & Description & Cause \\
\hline $81-040$ & Arkansas 2 & $11-06-81$ & Low freon charge. & Leaking valve fitting. \\
\hline 83.006 & Arkansas 2 & $02-02-83$ & High condenser pressure. & $\begin{array}{l}\text { Power supply for the pressure indicating controller } \\
\text { was defective. }\end{array}$ \\
\hline $90-008$ & Byron 1 & $06-27-90$ & Chiller malfunction. & Evaporator tube leak. \\
\hline 86.003 & Catawba 1 & $01-16-86$ & Chiller failed to start. & $\begin{array}{l}\text { Chilled water compressor motor temperature } \\
\text { sensing module had failed. }\end{array}$ \\
\hline $86-005$ & Catawba 1 & $01-17-86$ & $\begin{array}{l}\text { Chiller tripped on low chilled water flow and } \\
\text { later on high motor bearing temperature. }\end{array}$ & $\begin{array}{l}\text { Misapplied pump seals and unreliable expansion } \\
\text { tank alarm. }\end{array}$ \\
\hline $90-030$ & Catawba 1 & $10-23-90$ & $\begin{array}{l}\text { Control room ventilation system chillers } \\
\text { inoperative. }\end{array}$ & $\begin{array}{l}\text { Failed hydrometer and out-of-calibration oil } \\
\text { pressure switch. }\end{array}$ \\
\hline $91-005$ & Catawba 1 & $02-12-91$ & $\begin{array}{l}\text { Low refrigerant temperature cut out switch set } \\
\text { point reached on Train A. Train B also tripped. }\end{array}$ & $\begin{array}{l}\text { Train } A \text {, refrigerant leak in compressor power } \\
\text { terminal box. Train } B \text {, condenser water auto } \\
\text { control valve failed to open. }\end{array}$ \\
\hline $89-041$ & Clinton 1 & $11-22-89$ & Low refrigerant pressure. & $\begin{array}{l}\text { Refrigerant leakage, no location } \\
\text { reported. }\end{array}$ \\
\hline 91.018 & Comanche 1 & $05-28-91$ & Safety chiller inoperable. & A faulty oil sump lever switch. \\
\hline $87-012$ & Hatch 2 & $09.16 \cdot 87$ & Equipment degradation & $\begin{array}{l}\text { Water chiller fouled by calcium } \\
\text { deposits. }\end{array}$ \\
\hline $86-029$ & Hope Creek 1 & $06-11-86$ & $\begin{array}{l}\text { Control area chiller tripped on low refrigerant } \\
\text { pressure. }\end{array}$ & $\begin{array}{l}\text { Ball float valve that controls refrigerant flow } \\
\text { malfunction. }\end{array}$ \\
\hline $88-015$ & Hope Creek 1 & $05-26-88$ & $\begin{array}{l}\text { Excess oil in one chiller and the other chiller } \\
\text { tripped. }\end{array}$ & $\begin{array}{l}\text { Lack of understanding of seasonal oil migration in } \\
\text { first chiller and defective high side float ball in } \\
\text { economizer of second chiller. }\end{array}$ \\
\hline 89.007 & Hope Creek 1 & $04-06-89$ & $\begin{array}{l}\text { Both } \mathrm{A} \text { and } \mathrm{B} \text { control room emergency } \\
\text { filtration units became inoperable. }\end{array}$ & $\begin{array}{l}\text { Seal failure in one chiller and failed damper in the } \\
\text { other chiller. }\end{array}$ \\
\hline 83.056 & McGuire 1 & $07-14-83$ & Low refrigerant temperature trip. & $\begin{array}{l}\text { Loose llange on suction side of } \\
\text { compressor. }\end{array}$ \\
\hline $87-001$ & McGuire 1 & $01-07-87$ & Loss of refrigerant. & A leaking threaded titting on oil cooler. \\
\hline 87.023 & McGuire 1 & $10-01-87$ & $\begin{array}{l}\text { Loss of essential control power in Train } A \text { and } \\
\text { control room air handling unit suction damper } \\
\text { not open causing Train B to be inoperable. }\end{array}$ & $\begin{array}{l}\text { Blown fuse in Train A and failure of an actuator } \\
\text { micro switch for Train B. }\end{array}$ \\
\hline $86-015$ & McGuire 2 & $08-09-86$ & Train A tripped. & $\begin{array}{l}\text { Blown fuse and chiller start mechanical timer not } \\
\text { operating. }\end{array}$ \\
\hline 81.025 & Norih Anna 1 & $04-28-81$ & Improperly operating steam chiller. & Lack of adequate cooling water. \\
\hline $83-032$ & North Anna 1 & $05-21-83$ & Chiller malfunctioned. & No cause given. \\
\hline
\end{tabular}


Chiller LER Review Summary (cont.)

\begin{tabular}{|c|c|c|c|c|}
\hline LER & Plant & $\begin{array}{l}\text { Event } \\
\text { Date }\end{array}$ & Description & - Cause \\
\hline 83-056 & North Anna 2 & $07-11-83$ & Chiller tripped on low compressor oil pressure. & No cause given. \\
\hline $85-063$ & Palo Verde 1 & $09-12-85$ & Loss of refrigerant. & No cause given. \\
\hline $81-003$ & Oconee 2 & $03-02-81$ & $\begin{array}{l}\text { High temperature on reactor building chiller } \\
\text { unit. }\end{array}$ & $\begin{array}{l}\text { Bearing high temperature caused by grease } \\
\text { starvation. }\end{array}$ \\
\hline 88-019 & Perry 1 & $05-15-88$ & Chillers inoperable. & $\begin{array}{l}\text { Mechanical failure of a compressor guide vane } \\
\text { linkage connector and an intermittent fault in the } \\
\text { motor starter circuit of the supply fan. }\end{array}$ \\
\hline $88-040$ & Perry 1 & $10-07-88$ & Electrical fault in chiller control power. & $\begin{array}{l}\text { Degradation of wire insulation results in grounding } \\
\text { of control power supply. }\end{array}$ \\
\hline 91-008 & Perry 1 & 03-05-91 & Low refrigerant temperature. & $\begin{array}{l}\text { Malfunctioning solenoid valve on the thermal purge } \\
\text { unit. }\end{array}$ \\
\hline $90-002$ & Riverbend 1 & $02-02-90$ & Chiller shutdown. & Indeterminate. \\
\hline $82-059$ & San Onofre 2 & $04-07-82$ & Found during maintenance. & Faulty flow control switch. \\
\hline $82-039$ & San Onofre 2 & $07-16-82$ & $\begin{array}{l}\text { Emergency chiller refrigerant compressor failed } \\
\text { to start. }\end{array}$ & Defective impeller displacement switch. \\
\hline $81-040$ & San Onofre 2 & $07-19-82$ & High bearing temperature. & Faulty high temperature bearing alarm module. \\
\hline $82-173$ & San Onofre 2 & $12-28-82$ & Chiller failed to start. & Loose wire on the low lube oil pressure switch. \\
\hline 83-012 & San Onofre 2 & $01-08-83$ & Chiller failed to start. & Faulty program timer. \\
\hline 83-043 & San Onofre 3 & $07-08-83$ & Chiller inoperable. & $\begin{array}{l}\text { Either a malfunction of chiller control circuitry or } \\
\text { mechanical malfunction in the power supply } \\
\text { breaker. }\end{array}$ \\
\hline 90-001 & San Onofre 3 & $01-30-90$ & $\begin{array}{l}\text { High motor/bearing temperature trip } \\
\text { indication. }\end{array}$ & Intermittent failure of a trip relay. \\
\hline $87-007$ & Shearon Harris 1 & $02-10-87$ & Chiller tripped and was restarted several times. & Low lube oil. \\
\hline $90-017$ & Shearon Harris 1 & $06-20-90$ & Chiller could not be started. & Mispositioned root isolation valve on the chiller. \\
\hline 88-039 & South Texas 1 & $06-16-88$ & Failure of chiller lube pump oil seal. & Failure of pump shaft bearing. \\
\hline 89.023 & South Texas 1 & $12-16-89$ & $\begin{array}{l}\text { Essential chiller could not be } \\
\text { secured. }\end{array}$ & $\begin{array}{l}\text { Contact oxidation and low contact pressure on an } \\
\text { auxiliary relay. }\end{array}$ \\
\hline 83-019 & Summer 1 & $03-17-83$ & Chiller failure. & Problem associated with starting circuitry of chiller. \\
\hline $86-024$ & Surry 1 & $08-13-86$ & $\begin{array}{l}\text { Loss of one control room and relay room A.C. } \\
\text { chiller. }\end{array}$ & $\begin{array}{l}\text { Clogging of chillers due to unfiltered river water } \\
\text { flowing through tubes. }\end{array}$ \\
\hline
\end{tabular}




\section{Appendix C}

\section{Chiller LER Review Summary (cont.)}

\begin{tabular}{|c|c|c|c|c|}
\hline LER & Plant & $\begin{array}{l}\text { Event } \\
\text { Date }\end{array}$ & Description & Cause \\
\hline $86-027$ & Surry 1 & $10-09-86$ & $\begin{array}{l}\text { Two of three control room A.C. chillers } \\
\text { inoperable. }\end{array}$ & $\begin{array}{l}\text { One out for maintenance, the other inoperable } \\
\text { because of failed relay. }\end{array}$ \\
\hline 87.003 & Surry 1 & $02-13-87$ & $\begin{array}{l}\text { Chiller inoperable because of lack of service } \\
\text { water and another because compressor relief } \\
\text { valve lifted, discharging refrigerant. }\end{array}$ & $\begin{array}{l}\text { Clogged suction strainer and excessive throttling of } \\
\text { compressor service water outlet valve. }\end{array}$ \\
\hline $87-005$ & Surry 1 & $02-21-87$ & $\begin{array}{l}\text { The chillers tripped due to insufficient service } \\
\text { water flow. }\end{array}$ & Marine growth inside of rotating strainer. \\
\hline $87-006$ & Surry 1 & $03-10-87$ & $\begin{array}{l}\text { Service water pump for } \mathrm{B} \text { control/ relay room } \\
\text { chiller tripped. }\end{array}$ & $\begin{array}{l}\text { Suspect thermal overload device at the motor } \\
\text { control center activated, tripping the pump. }\end{array}$ \\
\hline $88-007$ & Surry 1 & $02-24-88$ & Insufficient service water flow. & Bad pressure control valve. \\
\hline 88-039 & Surry 1 & $10-11-88$ & $\begin{array}{l}\text { Control/relay room chiller tripped on high } \\
\text { condenser discharge pressure. }\end{array}$ & $\begin{array}{l}\text { A small refrigerant leak in combination with } \\
\text { insufficient service water flow. }\end{array}$ \\
\hline $89-023$ & Surry 1 & $06-13-89$ & $\begin{array}{l}\text { Main control/emergency switch gear chiller } \\
\text { inoperable due to degraded performance. }\end{array}$ & Improper valve line-up. \\
\hline $91-018$ & Surry 1 & $04-25-91$ & $\begin{array}{l}\text { Control/emergency switch gear room chillers } \\
\text { inoperable. }\end{array}$ & $\begin{array}{l}\text { Failed oil pressure/overload reset } \\
\text { relay. }\end{array}$ \\
\hline $88-011$ & Surry 2 & $04-23.88$ & $\begin{array}{l}\text { Control/relay room chiller removed from } \\
\text { service to perform minor maintenance. }\end{array}$ & Refrigerant filter/dryer was becoming clogged. \\
\hline 87.022 & Susquehanna 1 & $06-19-87$ & Chiller experiencing spurious trips. & $\begin{array}{l}\text { Problems with cycle timer and low refrigerant trip } \\
\text { switch. }\end{array}$ \\
\hline $84-014$ & Susquehanna 2 & $07-23-84$ & Problems in the B Reactor Building. & No cause given. \\
\hline $87-049$ & Vogtle 1 & $07-22-87$ & Chiller failure. & Temperature switch failure on chiller. \\
\hline $89-004$ & Waterford 3 & 03-03-89 & $\begin{array}{l}\text { Low pressure valve ball float developed crack } \\
\text { allowing float to fill with freon, sink, and close } \\
\text { valve. }\end{array}$ & Intergranular stress corrosion cracking. \\
\hline 90.008 & Waterford 3 & $07-30-90$ & Compressor motor high temperature. & No cause given. \\
\hline
\end{tabular}


Appendix D

NPE Database on Chillers 


\section{Appendix D}

\section{NPE Database on Chillers}

This appendix contains a summary of the NPE database that applies to chillers in NPPs. The information is from Oak Ridge National Laboratory. 
Appendix D

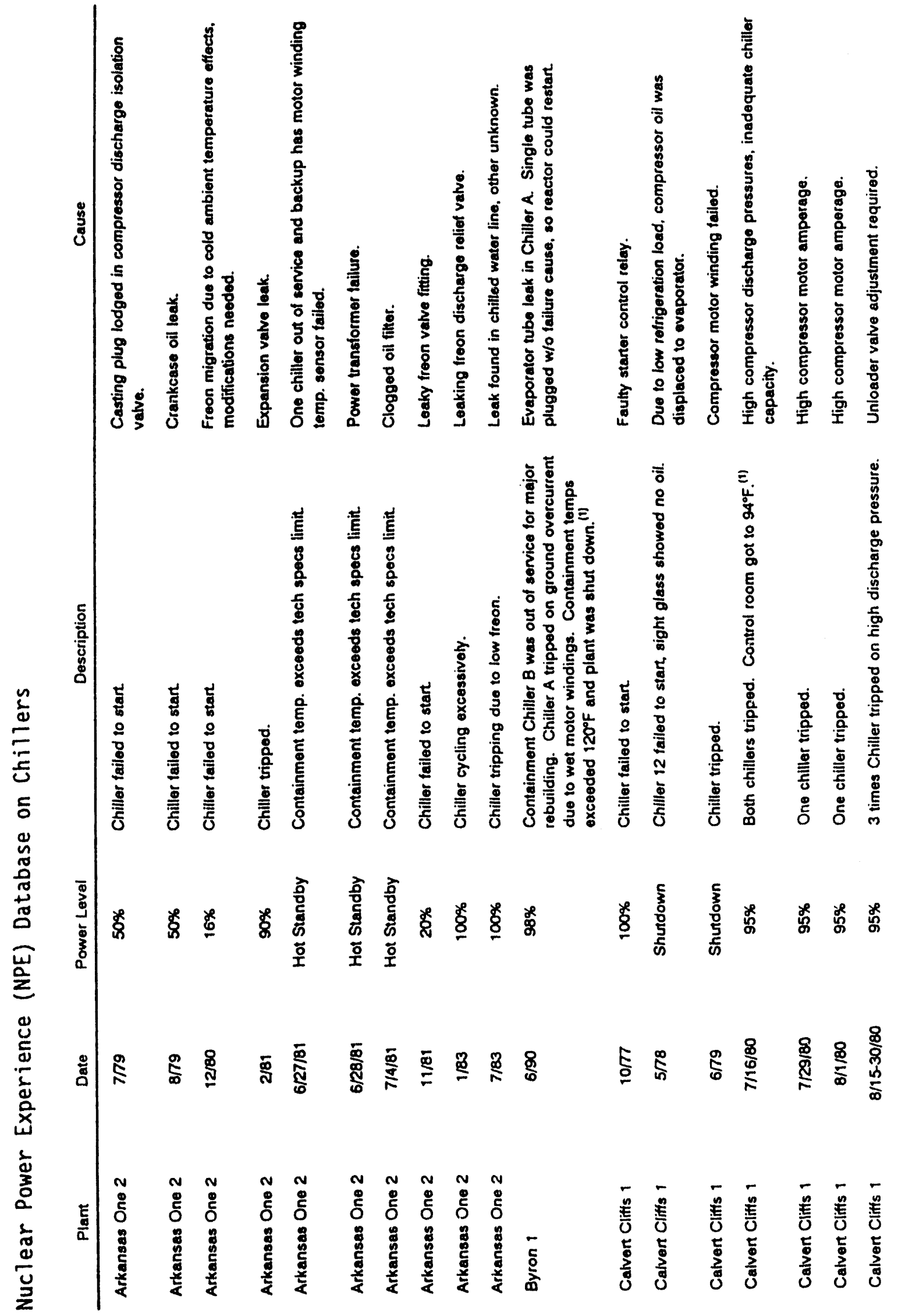


Appendix D

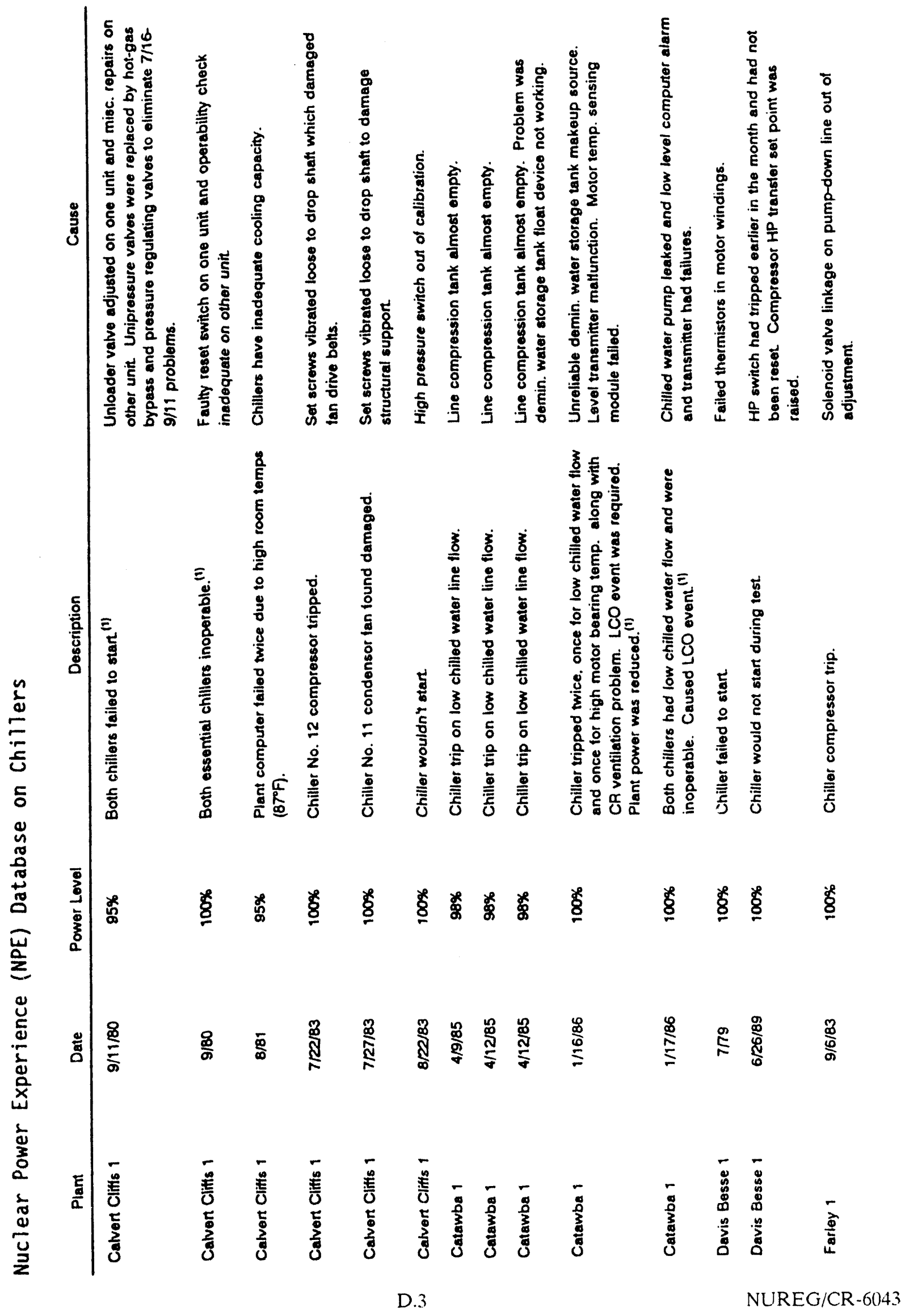


Appendix D

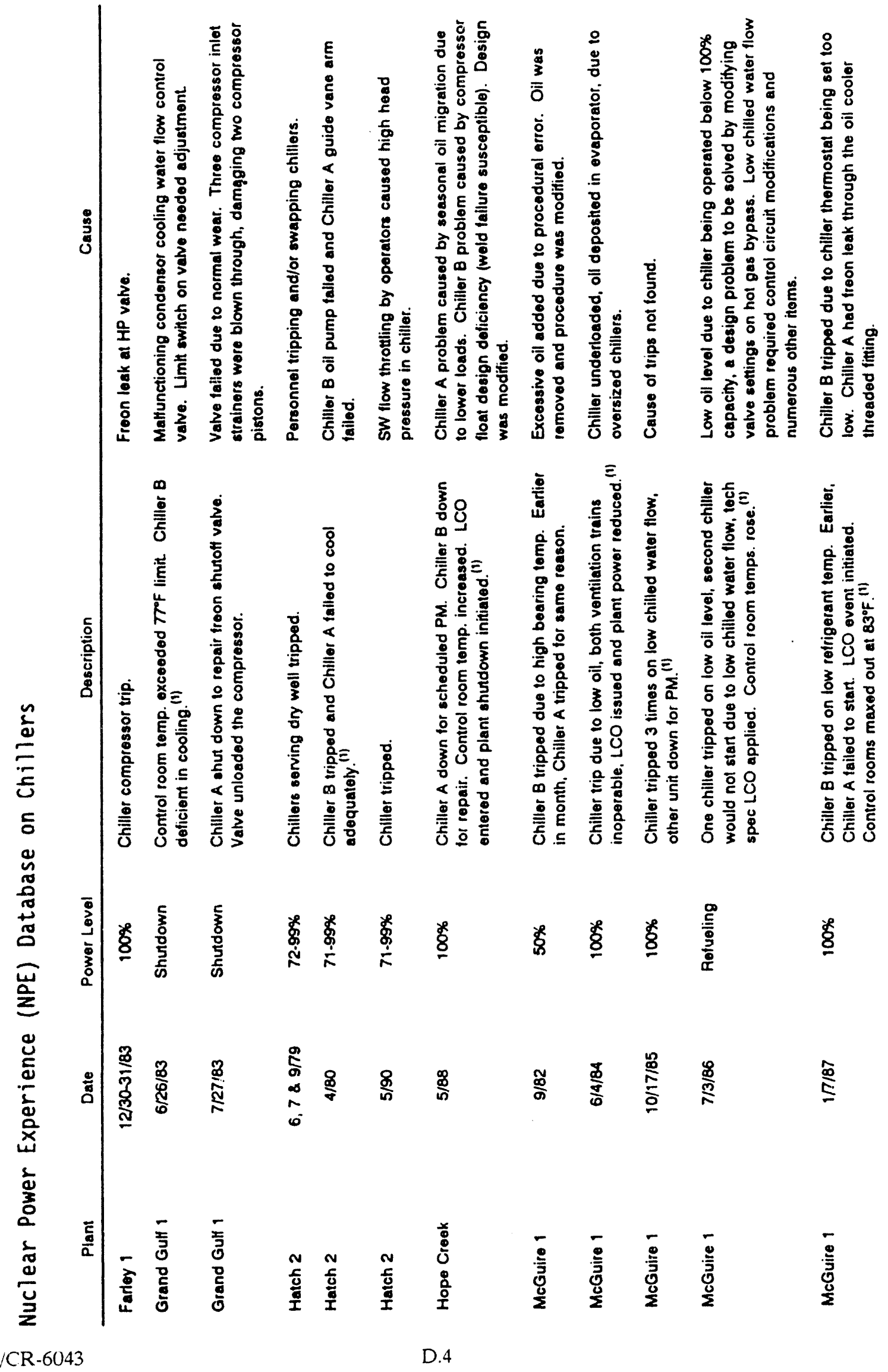


Appendix D

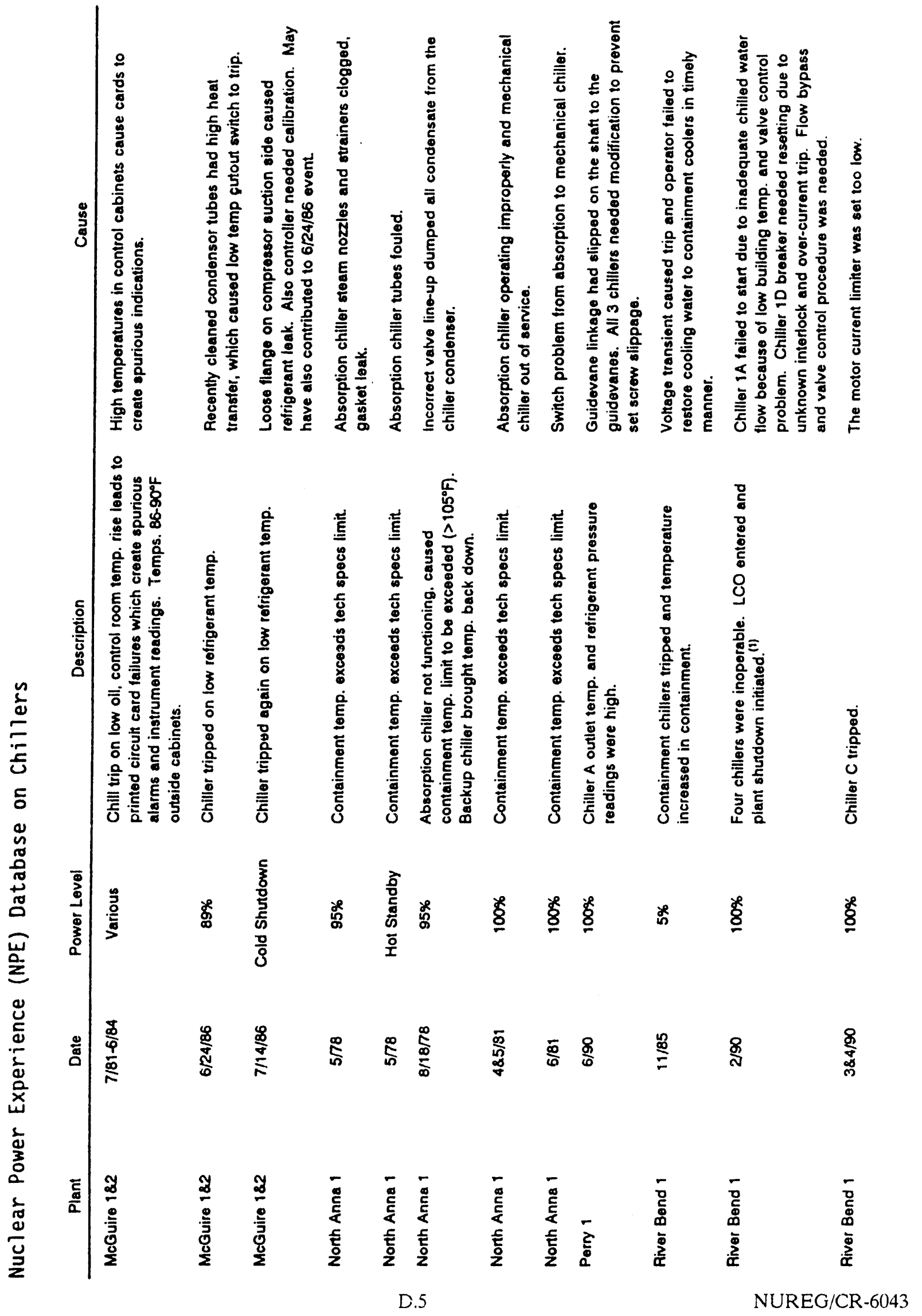


Appendix D

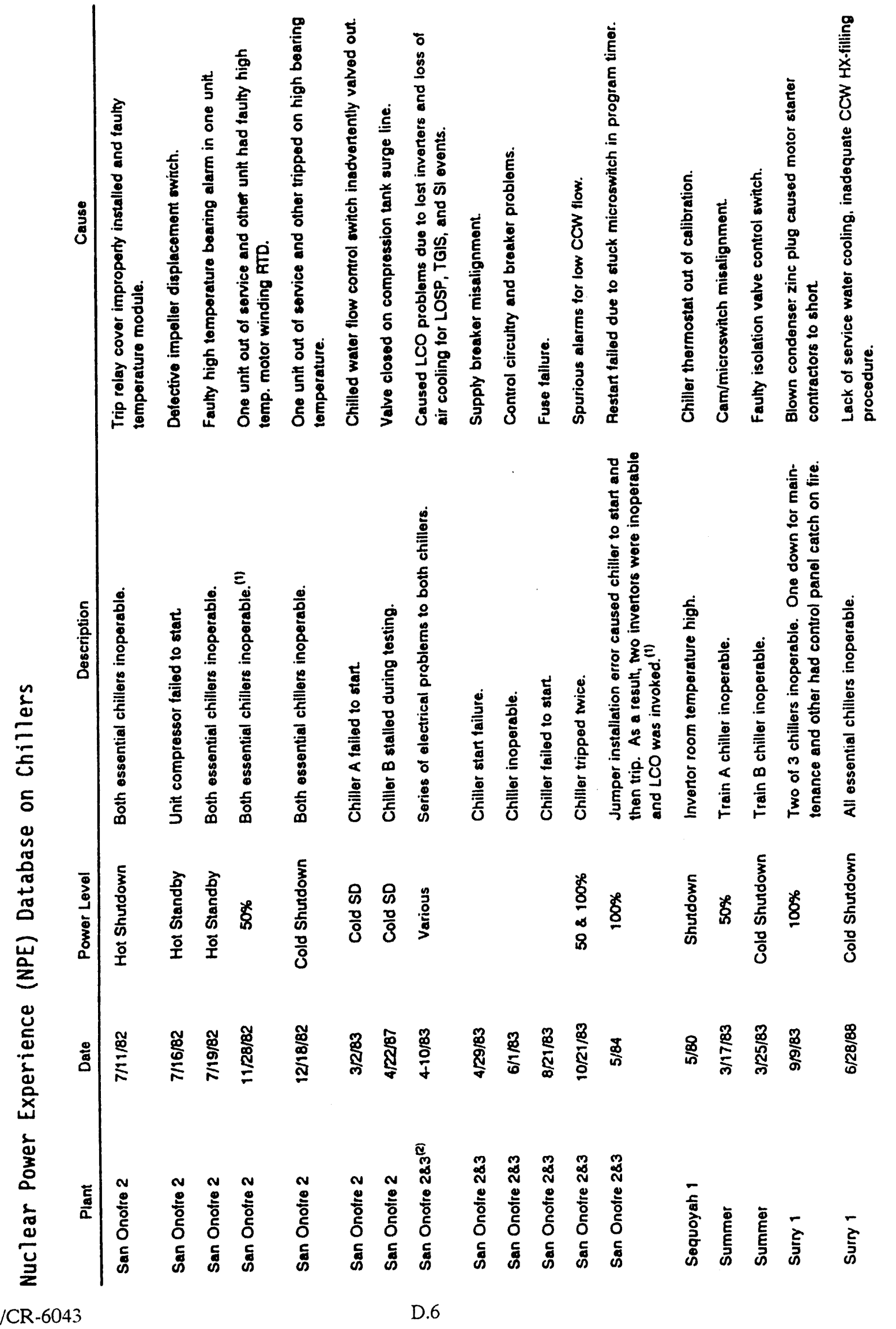


Appendix D

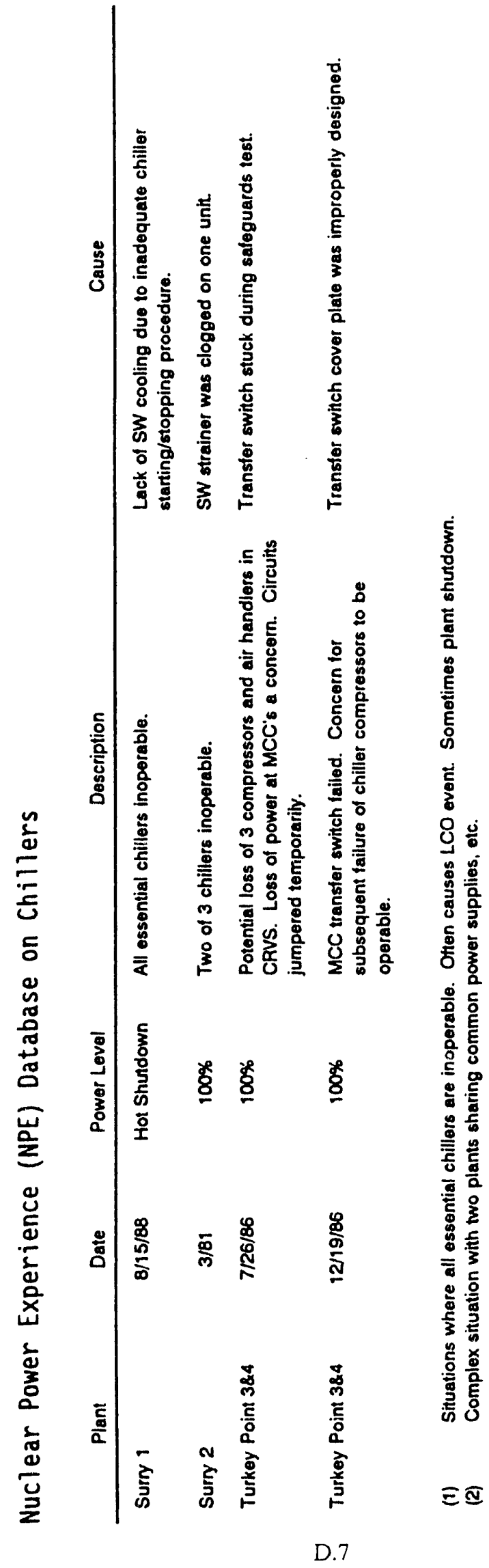


Appendix E

IPRDS Database Maintenance Report Summary for Nuclear Power Plant A 


\section{Appendix E}

\section{IPRDS Database Maintenance Report Summary for Nuclear Power Plant A}

This appendix contains a summary of chiller maintenance record data from a single NPP (Plant A). The information is from the IPRDS database at the Oak Ridge National Laboratory. The plant and chiller identification are confidential. 
Appendix E

Chiller Maintenance Records for Plant A, Chiller 1A

\begin{tabular}{|c|c|}
\hline Date & Description of Problem \\
\hline $10 / 18 / 82$ & Gasket blown. \\
\hline $10 / 18 / 82$ & Need to install a press gauge on the high press top of FS. \\
\hline $10 / 20 / 82$ & Anti-recycle timer has loose internals; contacts sometimes makeup. \\
\hline $03 / 03 / 83$ & Chiller high discharge pressure safety switch shutting down chiller. \\
\hline 03/03/83 & Condenser oil cooler tubes are getting plugged up, chiller can't make $100 \%$. \\
\hline $08 / 12 / 83$ & $\begin{array}{l}\text { Oil temperature sensing element should be located on oil line down stream of } \\
\text { oil pump. }\end{array}$ \\
\hline $08 / 28 / 83$ & Chiller condenser tubes plugged. \\
\hline $11 / 30 / 83$ & Cannot read delta on lube oil filter. Replace oil filter. \\
\hline $03 / 27 / 84$ & Chillers been tripping lately, with safety switches light on and 2TR relay. \\
\hline $03 / 30 / 84$ & Cannot get chiller loaded, oil pump breaker keeps tripping off. \\
\hline $05 / 11 / 84$ & Control building chiller tripped on oil pressure failure. \\
\hline $05 / 15 / 84$ & Suspect that the heat exchangers are becoming fouled again. \\
\hline $05 / 29 / 84$ & Chiller when in 'auto' tripped on low oil pressure. Slide VLV went T. \\
\hline $05 / 29 / 84$ & Chiller has oil leak on discharge pipe from oil pump. \\
\hline $06 / 14 / 84$ & Won't start. Not enough oil pressure hot gas B/P doesn't open. \\
\hline 07/22/84 & Chiller tripped on low oil press. The alarm would not reset. \\
\hline $08 / C .1 / 84$ & Lube oil filter $\mathrm{dP}$ is $22 \#$. Limit is $8-12$. \\
\hline $10,31 / 84$ & The " $A$ " ciniller trips with no associated alarms for indication of trip. \\
\hline $12 / 06 / 84$ & Several oil leaks including mechanical seal and oil drain plug. \\
\hline $02 / 23 / 85$ & Chilled water temperature too high. \\
\hline $03 / 16 / 85$ & While removing fire barrier from tray section $1 \mathrm{~L}-3 \mathrm{~A}$ cable $1 \mathrm{~B}-305 \mathrm{~A}$ nicked. \\
\hline $03 / 16 / 85$ & $\begin{array}{l}\text { Cable } 1 \mathrm{~B}-305 \mathrm{~A} \text { given temperature fix on MAR } 061346 \text { due to being nicked and } \\
\text { then shorting c ut. }\end{array}$ \\
\hline $03 / 26 / 85$ & Leaking oil, appears to be leaking at compressor seal near coupling. \\
\hline $06 / 17 / 85$ & Condenser on this chiller needs to be cleaned. \\
\hline $06 / 24 / 85$ & "A" chiller safety switch will not allow starting of $1 \mathrm{~V}-\mathrm{CH}-1 \mathrm{~A}$. \\
\hline $06 / 24 / 85$ & Hot gas B/P solenoid does not open. \\
\hline $06 / 24 / 85$ & $1 \mathrm{C026/ \textrm {B } 5}$ alarm; "A" chiller trouble in solenoid. There is no apparent problem. \\
\hline
\end{tabular}


Chiller Maintenance Records for Plant A, Chiller 1A

\begin{tabular}{cc}
\hline Date & Description of Problem \\
\hline $06 / 24 / 85$ & "A" chiller will not start due to safety switch activation.
\end{tabular}

$07 / 06 / 85$

$07 / 21 / 85$

On a startup sequence the oil pump comes on but will not clear/reset low.

$07 / 21 / 85$

" $\mathrm{A}$ " chiller shows characteristics of being very low on freon. Low suction pressure.

$08 / 08 / 85$

Oil plus discharge pressure gauge missing.

"A" chiller trips off on low temperature (oil sump) even when oil temperature shows $\mathrm{OK}$.

08/08/85 "A" chiller slide valve operation is sporadic.

01/06/86 Plug and seal top panel openings of chiller starter cabinet.

04/23/86 Oil pumps do not develop a discharge pressure. Chiller tripped on low oil pressure.

04/26/86 Oil leak of 1 drop/10 seconds from the southern most compressor load/unload solenoid.

$04 / 28 / 86100 \%$ current limit setting is 180 amps while motor nameplate is $230 \mathrm{~A}$.

$05 / 19 / 86$ It tripped on low oil sump temperature when sump temperature was $125^{\circ} \mathrm{F}$ and switch was set at 90 . Switch and/or gauge needs checked.

$06 / 01 / 86$

Chiller fails to start due to low oil pressure; low oil level.

$08 / 03 / 86$

Liquid line sight glass $1 / 2$ full. As per 1 P200 it should be full and clear.

$08 / 14 / 86$

$10 / 20 / 86$

Anti-recycle timer not set at 15 minutes per vendor manual.

Temperature load controller not holding chilled water temperature steady.

Temperature keeps dropping for a given setting.

11/11/86 Condenser head gasket is leaking (east end).

11/13/86 Relays and relay block terminal boards need to be replaced due to sloppiness in pin connection board. Switching relays and blocks: 1SR, 2SR, 3SR, and 4SR.

11/22/86 Oil leak on connection on the southern most unloader assembly solenoid valve. The leak is on upper connection between the solenoid operator and the valve body.

11/22/86 Oil leak on load solenoid valve.

12/08/86 Small freon leak on stem of load solenoid valve. This leak persisted after installing solenoid valve repair kit.

12/14/86 Oil and refrig leaking from suction flange of compressor and manual isolation unloading valve at the compressor near suction flange (leak is very small). 
Appendix E

Chiller Maintenance Records for Plant A, Chiller 1A

\begin{tabular}{|c|c|}
\hline Date & Description of Problem \\
\hline 04/03/87 & Does not dump hot gas at low load $(<20 \%)$. \\
\hline $04 / 26 / 87$ & $\begin{array}{l}\text { The "low } 0.7 \text { temperature" alarm light socket broke and shorted out. The chiller } \\
\text { will run without it, but we have no "low temperative" indication. }\end{array}$ \\
\hline $04 / 28 / 87$ & $\begin{array}{l}\text { The " } \mathrm{A} \text { " chiller has tripped three times today. No alarm conditions were } \\
\text { indicated by the time the second ASST got up there. Readjust oil pickup valves, } \\
\text { adjust TCU for the water. }\end{array}$ \\
\hline $05 / 01 / 87$ & A chiller waterbox gasket is blown out. \\
\hline $05 / 16 / 87$ & $\begin{array}{l}\text { Has an excessive oil leak as evidenced by lowering oil pressures and increasing } \\
\text { leak-off bottle level. This bottle level is increasing. }\end{array}$ \\
\hline $06 / 22 / 87$ & $\begin{array}{l}\text { Chiller is getting low on oil. Oil addition required unit to be shut down about } \\
\text { one hour. }\end{array}$ \\
\hline $07 / 20 / 87$ & Chiller condenser needs cleaning. \\
\hline $07 / 21 / 87$ & Check oil cooler tubes for cleanliness. \\
\hline $08 / 11 / 87$ & Mechanical seal of compressor still leaking. \\
\hline $08 / 18 / 87$ & Chiller tripping on oil press failure. \\
\hline 09/09/87 & Insufficient cooling in condenser. Believe tubes need to be cleaned. \\
\hline
\end{tabular}


Chiller Maintenance Records for Plant A, Chiller 1B

\section{Date}

$02 / 26 / 81$

$05 / 04 / 81$

05/19/82

$07 / 20 / 82$

$07 / 24 / 82$

$08 / 03 / 82$

$10 / 18 / 82$

$10 / 18 / 82$

$10 / 19 / 82$

$02 / 27 / 83$

$03 / 10 / 83$

$03 / 15 / 83$

$07 / 13 / 83$

$07 / 17 / 83$

08/30/83

$11 / 08 / 83$

$11 / 09 / 83$

$04 / 03 / 84$

$04 / 16 / 84$

$05 / 17 / 84$

$06 / 14 / 84$

07/09/84

$12 / 17 / 84$

$04 / 30 / 85$

$05 / 07 / 85$

$05 / 19 / 85$

$05 / 20 / 85$

$05 / 27 / 85$

\section{Description of Problem}

Chiller was not operating correctly.

Low oil pressure.

Chiller has low oil pressure after 2 days of running.

Gasket rupture on well WTR/FSW piping between condensate and cond outlet.

Gasket leak on chiller condenser, west side of condenser between end bel.

Control building chiller will not control load in auto. It always drifts.

\section{Gasket ruptured.}

Need to install a press gauge on the high press top of FS.

Copper line from sniffers to compressor suction line has crack and is leaking.

Condenser and oil cooler tubes are getting plugged.

TLC load signal causing load solenoid to chatter.

Chiller circuit power on local panel keeps tripping; chiller must be $C$.

Cannot read delta on lube oil filter.

Oil sump has low oil level; no level is visible with chiller on.

Chiller condenser tubes plugged.

Will not start.

Timing for anti-cycle does not work.

Timing for anti-cycle does not work.

Motor termination box for $200 \mathrm{HP}$ chiller motor has a hole burned in it.

Chiller tripped.

Control building chiller cycles continuously between loading and unloading.

Leaks oil from oil regulator that control slide valve.

Vertical run on oil pickup line has a crack in it.

Condenser refrigerant service valve leaks by seal.

Install temperature DP indicators across two-flow switches.

Three-way well water inlet valve to chiller condenser stuck closed.

Gaskets on both ends of chiller condenser are bad. Gaskets blown.

Oil leaks on unload solenoid throttle and load indicator housing. 


\begin{tabular}{|c|c|}
\hline Date & Description of Problem \\
\hline $05 / 29 / 85$ & Anti-recycle timer times out in 7 minutes. \\
\hline $06 / 01 / 85$ & $\begin{array}{l}\text { While performing PMAR on chiller, found contacts carboned over and badly } \\
\text { arched; needs replacement. }\end{array}$ \\
\hline $06 / 03 / 85$ & I. oad solenoid chatters at near temperature set point. \\
\hline $06 / 23 / 85$ & "B" chiller unloaded and stopped for STP. When restarted, would not load. \\
\hline $06 / 25 / 85$ & $\begin{array}{l}\text { " } \mathrm{B} \text { " chiller loading solenoid valve is chattering due to chiller loading and } \\
\text { unloading. }\end{array}$ \\
\hline $06 / 25 / 85$ & Circuit power button trips off. No safety switch trips on chiller. \\
\hline $09 / 24 / 85$ & Chiller will not load beyond $50 \%$ (loading solenoid is energized). \\
\hline $01 / 06 / 86$ & Plug and seal top panel openings of chiller control panel. \\
\hline $08 / 04 / 86$ & Anti-recycle timer times out in 4 minutes. \\
\hline $08 / 27 / 86$ & $\begin{array}{l}\text { The east end of chiller has a lagged pipe that connects the chiller, and the } \\
\text { compressor has an oil leak. Oil is leaking from under the lagging. }\end{array}$ \\
\hline 09/01/86 & Uppermost oil pickup line has a cracked flare fitting. \\
\hline $09 / 08 / 86$ & Oil pressure is low reading $33 \#$ 's instead of the normal $60 \#$. \\
\hline $09 / 26 / 86$ & $\begin{array}{l}\text { Load control unit was found to be rapidly blinking the load and unload lights on } \\
\text { and off causing loading solenoid valves to chatter continuously. }\end{array}$ \\
\hline $10 / 05 / 86$ & $\begin{array}{l}\text { Chiller cycles (loads) on and off. This MAR can be referenced to what was } \\
\text { worked on } 10 / 1 / 86 \text {, and problem still existed after sign off. }\end{array}$ \\
\hline $11 / 13 / 86$ & $\begin{array}{l}\text { Relays and relay block terminal boards need to be replaced due to sloppiness in } \\
\text { pin connection board. Switching relays and blocks } 1 \mathrm{SR}, 2 \mathrm{SR}, 3 \mathrm{SR} \text {, and } 4 \mathrm{SR} \text {. }\end{array}$ \\
\hline $02 / 13 / 87$ & Install new ejector valve and oil jet pump. \\
\hline $02 / 21 / 87$ & $\begin{array}{l}\text { Chiller tripped twice and was running with low suction press ( } 45 \#) \text { high oil } \\
\text { temperature. See attached readings, chiller will not run now. Trips on low } \\
\text { suction. Leak needs repair. }\end{array}$ \\
\hline $06 / 23 / 87$ & "B" chiller needs to have freon added to it. \\
\hline $08 / 24 / 87$ & $\begin{array}{l}\text { Temperature load control current limiter does not allow motor to go to full load } \\
\text { amps, thereby reducing full load capacity of chiller. Resistor needs to be } \\
\text { adjusted. }\end{array}$ \\
\hline
\end{tabular}




\section{Appendix F}

Chiller Work Request Summary for Nuclear Power Plant B 
Appendix $\mathrm{F}$

\section{Appendix F}

\section{Chiller Work Request Summary for Nuclear Power Plant B}

This appendix contains a summary of the Nuclear Power Plant B chiller maintenance, work-request database. The information was provided by a cooperating utility from their maintenance database. These two chillers are non-safety, and they are relatively new. 
Work Request Summary for Plant B, Chiller 1A

\begin{tabular}{|c|c|}
\hline llate & Work Request Description \\
\hline $01 / 08 / 88$ & $\begin{array}{l}\text { Verified S/D oil level, ran unit and monitored oil level for } 4 \text { hours. Oil less than } \\
1 / 2 \text { sight glass, no draining required. }\end{array}$ \\
\hline $01 / 08 / 88$ & Voided level normal per vendor operating procedures. \\
\hline 03/30/88 & Removed test gauges from chiller, capped test gauges and sensing lines. \\
\hline $04 / 27 / 88$ & Drained evaporator and purged with $\mathrm{N} 2$. \\
\hline $12 / 04 / 90$ & Completed flushing unit. \\
\hline $12 / 05 / 90$ & $\begin{array}{l}\text { Removed chiller float assembly, placed on storage racks. Removed condenser } \\
\text { and evaporator water heads, cleaned inner surfaces. Fabed flush fixtures, covers, } \\
\text { blind flanges, etc. for flushing cond/evap shell. }\end{array}$ \\
\hline $12 / 27 / 90$ & $\begin{array}{l}\text { Cut pipe on elbow socket, tightened nipple into float chamber nozzle, rewelded } \\
\text { socket. }\end{array}$ \\
\hline $01 / 17 / 91$ & $\begin{array}{l}\text { Fabricated magnetic liquid level indicator, piping hanger and installed. } \\
\text { Performed hydro test on level indicator. Repainted new hanger, installed } \\
\text { insulation on level indicator piping. }\end{array}$ \\
\hline $02 / 01 / 91$ & $\begin{array}{l}\text { Repaired plug welds as required in Section XI plan, appeared to be solid and } \\
\text { sound when finished. }\end{array}$ \\
\hline $01 / 21 / 91$ & Installed two $12 \mathrm{pt}$. screws. \\
\hline $02 / 27 / 91$ & $\begin{array}{l}\text { All electrical components on the chiller skid and in the control panel cleaned, } \\
\text { inspected, and tested. Various terminal UGS and electrical components were } \\
\text { replaced per MWR instructions. Startup of the chiller was per specifications. }\end{array}$ \\
\hline $06 / 10 / 91$ & Fabricated cover and gasket. \\
\hline $09 / 26 / 91$ & Replaced cover. \\
\hline $12 / 03 / 91$ & $\begin{array}{l}\text { Applied adequate heat and sufficient leverage to free shaft from bull gear. } \\
\text { Cleaned threads and shaft surface. }\end{array}$ \\
\hline $11 / 22 / 91$ & $\begin{array}{l}\text { Thirteen access holes were cut, plates were stamped and bagged, and tubes from } \\
\text { condenser and evaporator were removed. Cleaned purge unit. Cleaned inside } \\
\text { shell, wire brushed and sand blasted. Removed debris from shell. }\end{array}$ \\
\hline $01 / 29 / 92$ & $\begin{array}{l}\text { Cut service water supply piping to condenser, then cut off chilled water supply } \\
\text { piping to evaporator, reinstalled and hydrotested SW and } C C H \text { piping IAW } \\
\text { Section XI plan. }\end{array}$ \\
\hline $02 / 07 / 92$ & $\begin{array}{l}\text { Obtained spare jet pump solenoid from warehouse, removed solenoid and } \\
\text { installed it on this chiller, installed new terminal board and teplaced flex } \\
\text { conduit. }\end{array}$ \\
\hline 03/04/92 & Performed calibration as required. \\
\hline
\end{tabular}


Work Request Summary for Plant B, Chiller 1A

Date

Work Request Description

04/02/92 Painted chiller.

03/04/92 Prepped, reinstalled and welded access cut-out plates back onto shell IAW MWR and Section XI plan. Performed pneumatic testing on shell per test requirements.

03/04/92 Installed new evaporator tubes per MWR and Section XI plan number 2-0667 instructions, installed new mist eliminator and reinstalled expanded metal, installed and welded plugs in damaged tube sheet holes per change notice \#1 of Section XI plan. Added oil. 
Appendix F

Work Request Summary for Plant B, Chiller 1B

\begin{tabular}{|c|c|}
\hline Date & Work Request Description \\
\hline $01 / 05 / 87$ & $\begin{array}{l}\text { Void; no work required. Unit has held its charge since } 11 / 09 / 86 \text { without any loss } \\
\text { of pressure. }\end{array}$ \\
\hline $01 / 22 / 87$ & $\begin{array}{l}\text { Removed freon charge from } A / B \text { units, removed float chamber cover. Removed } \\
\text { wire tie down from float assembly, evacuated, purged with N2. Evacuated } \\
\text { second time, checked for leaks. Charged with } 650 \# \text { freon } 11 \text {. Started and ran } \\
\text { both units. Set hotgas bypass linkage. Torqued bolts to } 80 \# \text {. }\end{array}$ \\
\hline $04 / 02 / 87$ & $\begin{array}{l}\text { Removed and replaced oil pump from vendor, changed pump discharge tube } \\
\text { fitting. Run pump, checked rotation. Checked for leaks, found none. } \\
\text { Rebuilding of pump will be done. }\end{array}$ \\
\hline $01 / 11 / 88$ & $\begin{array}{l}\text { Started unit, monitored oil level for } 4 \text { hours, drew } 1 / 2 \text { gallon of oil to keep level } \\
<1 / 2 \text { upper sight glass. }\end{array}$ \\
\hline $04 / 25 / 88$ & Lack of run capability caused by a bad valve lineup. \\
\hline 07/06/88 & Replaced oil filter. \\
\hline 04/27/88 & Simulated all alarm sensor actuations, all operate fine. \\
\hline 06/29/88 & Void; no work required. \\
\hline 07/07/88 & Void; no work required. \\
\hline $08 / 17 / 88$ & Added about $21 / 2$ gallons of oil. \\
\hline $05 / 25 / 90$ & Added approximately $625 \mathrm{lb}$ freon R-11. \\
\hline 09/19/91 & Installed liquid level indicator on expansion piping at chiller. \\
\hline $11 / 14 / 91$ & Replaced refrigerant filter, leak checked, repaired leaks, serviced with R-11. \\
\hline $12 / 13 / 91$ & $\begin{array}{l}\text { Removed jet pump solenoid valve and rotated } 180^{\circ} \text { and reinstalled. Charged } \\
\text { system with oil and R-11, test ran machine. }\end{array}$ \\
\hline $12 / 16 / 91$ & $\begin{array}{l}\text { Changed oil filter and replaced with new oil. Solenoid valve coil needed } \\
\text { replacement, also removed bottom of jet pump for inspection and reassembly, } \\
\text { continued trouble-shooting steps. }\end{array}$ \\
\hline $01 / 16 / 92$ & $\begin{array}{l}\text { Installed test equipment for degraded voltage test. Performed preventive } \\
\text { maintenance. Disconnected test equipment for degraded voltage test. }\end{array}$ \\
\hline
\end{tabular}




\section{Appendix G}

ANS Paper Comparing Safety and Non-Safety Chillers 
Appendix G

\section{Appendix G}

\section{ANS Paper Comparing Safety and Non-Safety Chillers}

This appendix contains a transactions summary of a paper that compares safety-and non-safety-related chiller failure experience at the River Bend NPP. The paper was presented at the American Nuclear Society
(ANS) 1992 Annual Meeting in Boston, Massachusetts, June 7-12, 1992. This summary is from ANS Transactions, Volume 65, June 1992, Pages 303-305 (courtesy of the American Nuclear Society). 
4. Impact of Safety Requirements on Component Availability, Bob Christie (RAPA), Wendell McDougald (Gulf States Util, St. Francisville)

The purpose of this work was to show the impact of safety requirements on the availability of similar components. It is generally believed that "safety-related" equipment is more reliable than non-safety-related equipment. This is not always the case. This work documents the negative impact that safety requirements can have on component availability.

As part of the System Reliability Program at the River Bend Nuclear Station, component availabilities were calculated and trended for the control building chillers (safety related) and for the turbine building chillers (non-safety related). There are four control building chillers (A and C in Division I; B and D in Division II) with only one chiller running at a time. There are three turbine building chillers $(\mathrm{A}, \mathrm{B}, \mathrm{C})$ with two running at a time.

The chillers are very similar in design. All the chillers have been cooled by the same normal service water and powered by essentially the same electric power sources. The major differences in the chillers are as follows:

1. Control Building Chillers

Manufacturer: Carrier Model MFA 443

Size: $\quad 189 \mathrm{t}$

Loading: Mostly throttled

2. Turbine Building chillers

Mantifacturer: Trane Model NOX-T52-WV2

Size: $\quad 1250 \mathrm{t}$

Loading: Generally fully loaded.

The availabilities of the non-safety-related turbine building chillers have been generally above the availabilities of the safety-related control building chillers.
Tables I and II show the run hours, fail hours, availability, number of failures, mean-time-to-failure, and mean-time-to-repair of the respective chillers. The key difference is the mean-time-to-failure of the average turbine building chiller versus the mean-time-to-failure of the average control building chiller. The safetyrelated control building chillers fail approximately three times as often.

The safety-related control building chillers fail approximately three times as often as the non-safety-related turbine building chillers because of the stringent control requirements imposed on the control building chillers. The control building chillers must meet the single-failure criterion and must respond automatically to a wide variety of changing parameters following any perturbation in the control building chilled water system. This added complexity in the control building chillers has resulted in a significantly lower availability and a significantly higher maintenance and operation burden on plant personnel.

The control building chillers are included in the technical specifications for the plant because of their safety classification. Because of the lower availabilities of the control building chillers, the conditions that place the system in a limiting condition for operation (LCO) are frequently entered. Operations and maintenance personnel have been able to avoid plant derating due to exceeding the LCO (time) in the period covered in Tables I and II. However, the plant was derated twice in 1987 because of problems with the control building chillers.

While the final numbers have not yet been compiled for calendar year 1991, the same pattern is continuing. The non-safety-related turbine building chillers have achieved an availability of $>99 \%$ while the availability of the safety-related control building chillers dipped bclow 80\% in 1991. 
Reliability and Risk Assessment

Table I Turbine Building Chillers

\begin{tabular}{|c|c|c|c|c|c|}
\hline & & 1988 & 1989 & 1990 & TOTAL \\
\hline \multirow[t]{6}{*}{ HVN-CHL1A } & Run Hours & 6379 & 4480 & 3750 & 14609 \\
\hline & Fail Hours & 20 & 0 & 0 & 20 \\
\hline & Availability & 99.7 & 100 & 100 & 99.9 \\
\hline & Failures & 3 & 0 & 0 & 3 \\
\hline & MTTF & 2126 & $\cdots$ & $\cdots$ & 4870 \\
\hline & MTTR & 6.7 & $\cdots$ & -..- & 6.7 \\
\hline \multirow[t]{6}{*}{ HVN-CHL1B } & Run Hours & 4627 & 4363 & 5403 & 14893 \\
\hline & Fail Hours & 187 & 30 & 387 & 604 \\
\hline & Availability & 96.1 & 99.4 & 93.3 & 96.1 \\
\hline & Failures & 4 & 2 & 4 & 10 \\
\hline & MTTF & 1157 & 2432 & 1350 & 1490 \\
\hline & MTTR & 46.8 & 15 & 97 & 60 \\
\hline \multirow[t]{6}{*}{ HVN-CHL1C } & Run Hours & 6387 & 3365 & 4693 & 14445 \\
\hline & Fail Hours & 665 & 29 & 76 & 770 \\
\hline & Availability & 90.6 & 99.1 & 98.4 & 94.9 \\
\hline & Failures & 4 & 2 & 2 & 8 \\
\hline & MTTF & 1597 & 1680 & 2350 & 1810 \\
\hline & MTTR & 166 & 14.5 & 38 & 96 \\
\hline \multirow[t]{6}{*}{ ALL } & Run Hours & 17393 & 12708 & 13846 & 43947 \\
\hline & Fail Hours & 872 & 59 & 463 & 1394 \\
\hline & Availability & 95.2 & 99.5 & 96.8 & 96.9 \\
\hline & Failures & 11 & 4 & 6 & 21 \\
\hline & MTTF & 1581 & 3177 & 2308 & 2090 \\
\hline & MTTR & 79.3 & 14.8 & 77.2 & 66 \\
\hline
\end{tabular}


Appendix G

Reliability and Risk Assessment

Table II Control Building Chillers (Paper 4)

\begin{tabular}{|c|c|c|c|c|c|}
\hline & & 1988 & 1989 & 1990 & ALL \\
\hline \multirow{6}{*}{$\begin{array}{l}\mathrm{HVK}{ }^{*} \mathrm{CHL} 1 \\
\mathrm{~A}\end{array}$} & Run Hours & 3654 & 1650 & 2356 & 7660 \\
\hline & Fail Hours & 96 & 2 & 2 & 100 \\
\hline & Availability & 97.4 & 99.9 & 99.9 & 98.7 \\
\hline & Failures & 6 & 2 & 2 & 20 \\
\hline & MTTF & 609 & 825 & 1150 & 766 \\
\hline & MTTR & 16 & 1 & 1 & 10 \\
\hline \multirow{6}{*}{$\begin{array}{l}\mathrm{HVK}^{*} \mathrm{CHL} 1 \\
\mathrm{~B}\end{array}$} & Run Hours & 2102 & 2723 & 1588 & 6413 \\
\hline & Fail Hours & 46 & 2 & 820 & 868 \\
\hline & Availability & 97.9 & 99.9 & 66.0 & 88.1 \\
\hline & Failures & 3 & 6 & 2 & 10 \\
\hline & MTTF & 350 & 1360 & 794 & 641 \\
\hline & MTTR & 7.7 & 1 & 410 & 86.8 \\
\hline \multirow{6}{*}{$\begin{array}{l}\mathrm{HVK}{ }^{*} \mathrm{CHL} 1 \\
\mathrm{C}\end{array}$} & Run Hours & 1292 & 1516 & 1101 & 3909 \\
\hline & Fail Hours & 82 & 5 & 5 & 92 \\
\hline & Availability & 94.0 & 99.7 & 99.6 & 97.7 \\
\hline & Failures & 4 & 2 & 1 & 7 \\
\hline & MTTF & 323 & 758 & 1101 & 558 \\
\hline & MTTR & 20.5 & 2.5 & 5 & 13.1 \\
\hline \multirow{6}{*}{$\begin{array}{l}\mathrm{HVK} * \mathrm{CHL1} \\
\mathrm{D}\end{array}$} & Run Hours & 1739 & 615 & 2130 & 4484 \\
\hline & Fail Hours & 8 & 775 & 254 & 1037 \\
\hline & Availability & 99.5 & 44.2 & 89.4 & 81.2 \\
\hline & Failures & 3 & 2 & 3 & 8 \\
\hline & MTTF & 580 & 310 & 710 & 561 \\
\hline & MTTR & 2.7 & 390 & 85 & 130 \\
\hline \multirow[t]{6}{*}{ ALL } & Run Hours & 8787 & 6504 & 7175 & 22466 \\
\hline & Fail Hours & 232 & 784 & 1081 & 2097 \\
\hline & Availability & 97.4 & 89.2 & 86.9 & 91.5 \\
\hline & Failures & 19 & 8 & 8 & 35 \\
\hline & MTTF & 460 & 813 & 897 & 642 \\
\hline & MTTR & 12.2 & 98 & 135 & 60 \\
\hline
\end{tabular}




\section{Distribution}

No. of

Copies

\section{OFFSITE}

J. Bekhazi

Washington Public Power Supply System 3000 George Washington Way

P.O. Box 968

Richland, WA 99352

20

J. J. Burns

U.S. Nuclear Regulatory Commission Office of Nuclear Regulatory Research MS: NLS217B

Washington, DC 20555

T. W. Camp

Landis \& Gyr Powers, Inc.

2410 S.E. 11th Avenue

Portland, OR 97214

D. A. Casada

Oak Ridge National Laboratory

P.O. Box 2009

Oak Ridge, TN 37831-8038

J. Corey

Electric Power Research Institute

P.O. Box 10412

Palo Alto, CA 94304

T. J. Kepner

Landis \& Gyr Powers, Inc.

2410 S.E. 11th Avenue

Portland, OR 97214

L. E. Kokajko

U.S. Nuclear Regulatory Commission

MS: $13 E 16$

Washington, DC 20555

W. T. Lefave

U.S. Nuclear Regulatory Commission

MS: $8 \mathrm{D} 1$

Washington, DC 20555
No. of

Copies

\section{T. Leung}

U.S. Nuclear Regulatory Commission

MS: NLS314

Washington, DC 20555

H. L. Magleby

EG\&G Idaho, Inc.

P.O. Box 1625

Idaho Falls, ID 83415-2406

C. Michelson

U.S. Nuclear Regulatory Commission

MS: P-315

Washington, DC 20555

J. E. Rhoads

Washington Public Power Supply System 3000 George Washington Way

P.O. Box 968

Richland, WA 99352

J. H. Taylor

Brookhaven National Laboratory

Building 130

Upton, NY 11973

M. Vagins

U.S. Nuclear Regulatory Commission Office of Nuclear Regulatory Research MS: NLS217B

Washington, DC 20555

J. P. Vora

U.S. Nuclear Regulatory Commission Office of Nuclear Regulatory Research MS: NLS217B

Washington, DC 20555 
No. of

Copies

ONSITE

Westinghouse Hanford Company

B. G. Berglin, N2-01

50 Pacific Northwest Laboratory

R. P. Allen, P8-10 (10)

D. E. Blahnik, P8-10 (24)

M. E. Cunningham, P8-34
No. of

Copies

P. M. Daling, K6-40

J. L. Ethridge, P8-34

D. D. Hatley, P7-08

A. B. Johnson, Jr., P8-10

R. F. Klein, P8-33

I. S. Levy, P8-10

S. K. Loverne, P8-34

R. L. Moffitt, K6-46

H. D. Steele, K2-55

Publishing Coordination

Technical Report Files (5) 
